\title{
VEGFR-1 function and dysfunction in monocytes
}

Citation for published version (APA):

Tchaikovski, V. E. (2009). VEGFR-1 function and dysfunction in monocytes. [Doctoral Thesis, Maastricht University]. Datawyse / Universitaire Pers Maastricht. https://doi.org/10.26481/dis.20091216vt

Document status and date:

Published: 01/01/2009

DOI:

10.26481/dis.20091216vt

Document Version:

Publisher's PDF, also known as Version of record

\section{Please check the document version of this publication:}

- A submitted manuscript is the version of the article upon submission and before peer-review. There can be important differences between the submitted version and the official published version of record.

People interested in the research are advised to contact the author for the final version of the publication, or visit the DOI to the publisher's website.

- The final author version and the galley proof are versions of the publication after peer review.

- The final published version features the final layout of the paper including the volume, issue and page numbers.

Link to publication

\footnotetext{
General rights rights.

- You may freely distribute the URL identifying the publication in the public portal. please follow below link for the End User Agreement:

www.umlib.nl/taverne-license

Take down policy

If you believe that this document breaches copyright please contact us at:

repository@maastrichtuniversity.nl

providing details and we will investigate your claim.
}

Copyright and moral rights for the publications made accessible in the public portal are retained by the authors and/or other copyright owners and it is a condition of accessing publications that users recognise and abide by the legal requirements associated with these

- Users may download and print one copy of any publication from the public portal for the purpose of private study or research.

- You may not further distribute the material or use it for any profit-making activity or commercial gain

If the publication is distributed under the terms of Article $25 \mathrm{fa}$ of the Dutch Copyright Act, indicated by the "Taverne" license above, 
VEGFR-1 Function and Dysfunction in Monocytes 
VEGFR-1 Function and Dysfunction in Monocytes

ISBN 9789052788944

Layout and cover by Svetlana N. Tchaikovski

Printed by Datawyse BV । Universitaire Pers Maastricht

(C) V.E. Tchaikovski, Maastricht 2009 


\section{VEGFR-1 Function and Dysfunction in Monocytes}

\section{PROEFSCHRIFT}

ter verkrijging van de graad van doctor aan de Universiteit Maastricht op gezag van de Rector Magnificus, Prof. mr. G.P.M.F. Mols, volgens het besluit van het College van Decanen, in het openbaar te verdedigen op woensdag 16 december 2009 om 14:00 uur

door

Vadim Egorovich Tchaikovski

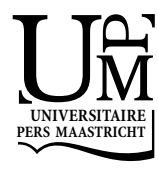




\section{Promotor}

Prof. dr. J. Waltenberger

\section{Beoordelingscommissie}

Prof. dr. M.J. Post (voorzitter)

Dr. E. Lutgens

Prof. dr. J.G.R. de Mey

Prof. dr. M. Simons (Yale University School of Medicine, USA)

Prof. dr. C.D.A. Stehouwer

Financial support by Stichting Hartsvrienden RESCAR for the publication of this thesis is gratefully acknowledged. 
To my parents and Svetlana Моим родителям и Светлане посвящается 



\section{Contents}

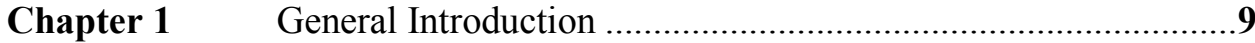

Chapter 2 The molecular basis of VEGFR-1 signal transduction pathways in primary human monocytes..................................21

Chapter 3 Diabetes mellitus activates signal transduction pathways resulting in VEGF resistance of human monocytes ..................43

Chapter 4 Monocyte dysfunction as a previously unrecognized pathophysiological mechanism in ApoE-/- mice contributing to impaired arteriogenesis .........................................................67

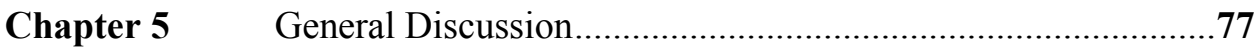



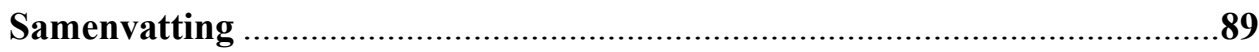

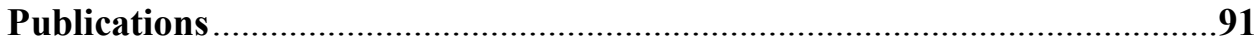

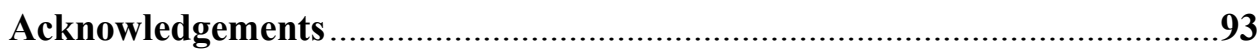

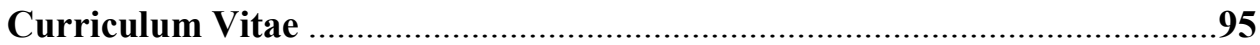





\section{Chapter 1}

\section{General Introduction}

Based on:

Tchaikovski V, Waltenberger J. Angiogenesis and Arteriogenesis in Diabetes Mellitus: Signal Transduction Defects as The Molecular Basis of Vascular Cell Dysfunction. In: Deindl E, Kupatt C, eds. Therapeutic Neovascularization: Quo Vadis? Munich: Springer; 2007:33-74. 


\section{Arteriogenesis}

Arteriogenesis is a process encompassing the growth of pre-formed collateral blood vessels (arterioles) to form functional arteries. ${ }^{1}$ It occurs in response to either severe limitation or cessation of regional blood supply secondary to an advanced atherosclerotic disease, such as coronary artery disease (CAD) or peripheral artery disease (PAD). Arteriogenesis is driven by the redirection of blood flow resulting in enhanced shear stress that serves as an initial trigger for the collateral artery growth. ${ }^{1}$

Endothelial cells (EC) are an important cell type in arteriogenesis as their activation by shear stress is one of the crucial initial steps. The activated EC secret vascular endothelial growth factor (VEGF), which induces synthesis of monocyte chemoattractant protein -1 (MCP-1) in the endothelium and in the vascular smooth muscle cells (VSMC) of the media. ${ }^{1}$ VEGF and MCP-1 facilitate the attachment of monocytes and T-cells to the endothelium, their attraction into the adventitial space and subsequent activation of these cells. Migrated mononuclear cells produce proteases and growth factors that digest the extracellular matrix (ECM) to allow the motility and provide space for other proliferating or migrating cells.

In addition, periendothelial cells are essential for arteriogenesis to complete and for the developing vessels to mature. Periendothelial cells, namely VSMC, fibroblasts and pericytes stabilize immature vessels by inhibiting EC proliferation and migration, and by stimulating production of ECM. ${ }^{2}$ Large part of new tissue production in the growing vessel is carried out by the VSMC of the media, which transform their phenotype from a contractile into a synthetic and proliferative one. During arteriogenesis the arteriolar media enlarges by the growth of the VSMC layer, which results in vessels with full vasomotor properties, so that they can functionally adapt to changes in the tissue perfusion.

Arteriogenesis is strictly regulated by signals from the blood and from the surrounding ECM environment. ${ }^{2}$ It is a complex event that is highly dependent on diverse soluble factors. These factors act on the resident cells with arteriogenic potential, i.e. EC, VSMC, fibroblasts, resident macrophages as well as circulating cells such as monocytes, lymphocytes and circulating progenitor cells (CPC). VEGF, MCP-1, angiopoetin (Ang), fibroblast growth factor (FGF) and transforming growth factor- $\beta$ (TGF- $\beta$ ) are the most critical factors for arteriogenesis. ${ }^{1}$ These factors act upon "arteriogenic" cells thereby reprogramming the basic physiological processes and turning the cells into an "arteriogenic" phenotype. ${ }^{2}$ The specific cellular aspects of arteriogenesis are proliferation, differentiation, apoptosis and survival, adhesion and migration. ${ }^{1}$ 


\section{Monocytes and VEGF/VEGFR system in arteriogenesis}

\subsection{Monocytes}

By employing scanning and transmission electron microscopy in the study of collateral vessels at various stages of their maturation it was noticed that monocytes attach to the activated "rocky" endothelial surface at early stages of the development and subsequently enter the sub-endothelial space. ${ }^{3,4}$ The adventitial space becomes subsequently invaded by bone marrow derived cells, mostly T-lymphocytes, which render the process of arteriogenesis with an inflammatory scenario. ${ }^{5}$

Several studies investigated the role of monocytes in arteriogenesis by modulating the circulating monocyte count. A reduction of blood monocyte count or their elimination with nanoencapsulated bisphosphonates strongly inhibited arteriogenesis. ${ }^{6,7}$ In opposite, monocyte rebound from cytotoxic treatment or over-transfusion with monocytes facilitated arteriogenesis following femoral ligation, ${ }^{6,8}$ whereas animals genetically lacking these cells (osteopetrotic mice and rats) were almost unable to develop collateral vessels. ${ }^{9}$

The contribution of monocytes was further strengthened by the findings that the monocyte stimulant lipopolysaccharide (LPS) markedly stimulates $\operatorname{arteriogenesis}^{10}$ and leads to the overexpression of tumor necrosis factor- $\alpha$ $(\mathrm{TNF}-\alpha){ }^{6,11}$

\subsection{VEGF family members and VEGFR-1 in arteriogenesis}

The process of the monocyte attraction into the periadventitial space of growing collateral vessels is mediated by a set of arteriogenic factors, with VEGF-A produced by EC and MCP-1 produced by EC and smooth muscle cells being the most crucial ones.

The family of VEGF and its receptors is intimately involved in the process of arteriogenesis ${ }^{7,12}$ acting upon two important cell types, i.e. EC and monocytes ${ }^{7}, 12,13$ VEGF-A binds to two different receptor tyrosine kinases on EC, namely VEGFR-1 (Flt-1) and VEGFR-2 (KDR/Flk-1). ${ }^{14,15}$ VEGFR-2 is the major mediator of EC activation in response to VEGF and it mediates a large spectrum of the EC functions. ${ }^{14,15}$ Monocytes can also be activated by members of the VEGF family. VEGFR-1 is the only VEGFR present on the surface of monocytes and it mediates a chemotactic response to VEGF-A and tissue factor induction. ${ }^{16}$ Placenta growth factor (PlGF-1), another member of the VEGF family that was shown to promote the cytokine and chemokine gene expression in monocytes and chemotaxis in the monocytic cell line THP- $1 .{ }^{17}$ Both PlGF and VEGF-A were shown to promote arteriogenesis, ${ }^{7,}{ }^{12}$ seemingly being 
equally potent. Accumulation of activated monocytes/macrophages around collateral vessels in PlGF-treated animals was observed. ${ }^{7}$ Furthermore, in monocyte-depleted animals, the ability of PIGF to enhance the collateral growth in the rabbit model and to rescue impaired arteriogenesis in PIGF gene-deficient mice is abrogated. ${ }^{7}$ Together, these data indicate that the arteriogenic activity observed with the VEGFR-1-ligands PIGF and VEGF-A is monocytedependent.

To summarize, plethora of evidence suggests that monocytes produce growth factors acting in an autocrine and paracrine manner as well as proteolytic enzymes modifying the composition of ECM. These findings highlighted the importance of monocyte contribution into the process of arteriogenesis.

\section{Diabetes mellitus and vascular pathology}

Diabetes mellitus (DM) is associated with an increased incidence of morbidity and mortality from atherosclerotic disease including CAD and PAD. ${ }^{18,19}$ The adverse influence of DM on the development and prognosis of CAD is well established. The risk of myocardial infarction (MI) increases with hyperglycemia. ${ }^{20,21}$ Furthermore, increased mortality following MI or stroke correlates with hyperglycemia, whereas increased levels of glycosylated HbAlc are associated with higher incidence of another fatal MI or stroke. ${ }^{22}$ Importantly, no clear threshold can be provided for the risk of developing macrovascular complications in DM. ${ }^{23}$ The same study, has clearly shown that the incidence of cardiac and peripheral macrovascular complications of DM tremendously increases with increasing concentrations of $\mathrm{HbAlc}$. On the contrary, intensive glycemic control results in a significant improvement of the frequency of cardiac and peripheral macrovascular complications of DM. ${ }^{23}$

The higher severity of CAD and PAD in diabetic patients has been linked to impaired ability to develop adequate collateral circulation, i.e. impaired arteriogenesis. ${ }^{33,34}$ The studies on collateral circulation in DM are summarized in Table 1. In a retrospective study ${ }^{24}$ diabetic individuals were found to have reduced coronary collateral formation compared to non-diabetics (see Table 1). This has been confirmed in another study with a smaller cohort of patients. ${ }^{26}$ In contrast, Melidonis et al ${ }^{25}$ reported that male diabetic patients younger than 55 years old develop more extensive collaterals. The different outcomes of these studies may relate to the subjective nature of the quantification of the collateral formation. Patient selection, especially with regard to the extent of CAD in diabetics and non-diabetics, appears to be the major source of variance, as the 
mere number of affected coronary vessels (e.g. 3-vessel disease) does not fully reflect the intensity of the vascular changes, which are more diffuse and therefore more severe in DM than in non-DM individuals. Therefore, when quantifying collaterals in DM and non-DM patients, one may compare patient groups with different severity of the disease despite the formal equality. In another study by Melidonis et al, diabetic patients had a greater frequency of total occlusions of the proximal right coronary artery and the left anterior descending artery. ${ }^{35}$ Thus, diabetics may have a reduced capacity for collateral formation given a similar degree of ischemic myocardial area. However, diabetic individuals generally tend to have more extensive obstructive $\mathrm{CAD},{ }^{24}$, 35, 36 which should serve as a stimulus for collateral formation. In fact, a deleterious effect of DM upon collateral-dependent tissue perfusion of myocardium was shown to be independent of the number of the affected vessels. ${ }^{26}$

Table 1. Clinical studies on collateral formation

\begin{tabular}{|lcll|}
\hline \multicolumn{1}{|c}{$\begin{array}{c}\text { Author, } \\
\text { year (ref) }\end{array}$} & $\begin{array}{c}\text { Nr. DM } \\
\text { patients }\end{array}$ & $\begin{array}{l}\text { Method of assessment of } \\
\text { coronary collaterals }\end{array}$ & Specific findings in DM patients \\
\hline $\begin{array}{l}\text { Abaci } \text { et al, } \\
1999^{24}\end{array}$ & 205 & $\begin{array}{l}\text { Angiography, collateral } \\
\text { score (Rentrop) }\end{array}$ & $\begin{array}{l}\text { Reduced collateralization (lower } \\
\text { collateral score) }\end{array}$ \\
\hline $\begin{array}{l}\text { Melidonis } \text { et } \\
\text { al, 1999 }\end{array}$ & 463 & $\begin{array}{l}\text { Angiography, collateral } \\
\text { score (Rentrop) }\end{array}$ & $\begin{array}{l}\text { More extensive (age- and sex- } \\
\text { dependent) collaterals present }\end{array}$ \\
\hline $\begin{array}{l}\text { Rzechuch } \text { et } \\
\text { al, 2003 }\end{array}$ & 70 & $\begin{array}{l}\text { Angiography, collateral } \\
\text { score (Rentrop) }\end{array}$ & Lower collateral score \\
\hline $\begin{array}{l}\text { Nahser } \text { et al, } \\
1995^{27}\end{array}$ & 24 & $\begin{array}{l}\text { Intracoronary Doppler and } \\
\text { pressure recordings }\end{array}$ & $\begin{array}{l}\text { Diminished maximal pharmacologic } \\
\text { flow reserve; reduced collateral } \\
\text { blood flow during exercise }\end{array}$ \\
\hline $\begin{array}{l}\text { Nisanci et } \\
\text { al, 2002 }\end{array}$ & 20 & $\begin{array}{l}\text { Intracoronary pressure } \\
\text { recordings }\end{array}$ & $\begin{array}{l}\text { Decreased pressure-derived flow } \\
\text { index (indicating reduced collateral } \\
\text { function) }\end{array}$ \\
\hline $\begin{array}{l}\text { Werner } \text { et al, } \\
2003^{29}\end{array}$ & 72 & $\begin{array}{l}\text { Intracoronary Doppler and } \\
\text { pressure recordings in TCO }\end{array}$ & $\begin{array}{l}\text { Increased resistance of the collateral } \\
\text { circulation early (less than 3 } \\
\text { months) after coronary occlusion }\end{array}$ \\
\hline $\begin{array}{l}\text { Kyriakides } \\
\text { et al, 2003 }\end{array}$ & 18 & $\begin{array}{l}\text { Intracoronary Doppler and } \\
\text { pressure recordings }\end{array}$ & $\begin{array}{l}\text { No difference in functional } \\
\text { parameters (collateral recruitment) }\end{array}$ \\
\hline $\begin{array}{l}\text { Sezer } \text { et al, } \\
2004^{31}\end{array}$ & 21 & $\begin{array}{l}\text { Intracoronary pressure } \\
\text { recordings }\end{array}$ & $\begin{array}{l}\text { Decreased pressure-derived flow } \\
\text { index indicating reduced collateral } \\
\text { function }\end{array}$ \\
\hline $\begin{array}{l}\text { Zbinden } \text { et } \\
\text { al, 2005 }\end{array}$ & 100 & $\begin{array}{l}\text { Intracoronary Doppler and } \\
\text { pressure recordings }\end{array}$ & $\begin{array}{l}\text { No difference in functional } \\
\text { parameters }\end{array}$ \\
\hline
\end{tabular}


The collateral score (Rentrop classification) was similarly reduced in diabetic individuals with single-, two- and three-vessel disease as compared to nondiabetic counterparts. In contrast, others ${ }^{37-39}$ reported no difference in collateralization between diabetic and non-diabetic CAD-patients.

The somewhat conflicting reports on the presence of the coronary collaterals in DM were based on the angiographic assessment of collaterals. ${ }^{40}$ However, it has later been shown that the angiographic assessment of the collaterals does not correlate well with the quantitative parameters of the collateral function. ${ }^{41}$ In this context, one study is of a particular interest as collateralization was quantitatively assessed in patients with chronic total coronary occlusions (TCOs). ${ }^{29}$ The recruitable collateral function was significantly reduced (i.e. the collateral resistance was significantly higher) in diabetic patients compared to non-diabetic patients, when the occlusions of $<3$ months duration were studied. For older collaterals, i.e. associated with TCOs longer than 3 months, no differences in collateral resistance were seen between the diabetic and non-diabetic vascular beds. ${ }^{29}$ These data are compatible with the conclusion that the growth and maturation of the collateral arteries, i.e. arteriogenesis, is slowed down under the diabetic conditions, resulting in the development of immature collaterals within the first three months after the occlusion of a coronary artery. This difference between diabetic and nondiabetic patients may imply a delayed development of functional collateral circulation due to an impaired cellular response ${ }^{34,42}$ in the process of the collateral growth in diabetic patients.

Several studies quantitatively assessed collateral recruitment upon balloon-based coronary occlusion in diabetic individuals with CAD bearing different degrees of coronary stenosis. These studies $27,28,31$ supported the findings observed in TCOs. ${ }^{29}$ In contrast, others could not find differences in collateral recruitment in the stenotic coronary regions. ${ }^{30,32}$

All in all, using different assessment modalities, the evidence has been generated that DM leads to an impaired innate capacity to develop new collateral vessels.

\section{Circulating cells with arteriogenic potential as effectors and biosensors of pathological changes in DM}

Most of the current explanations for the impaired new blood vessel growth in DM focused on alterations in the function of mature ECs. ${ }^{43}$ Hyperglycemia and DM are associated with EC dysfunction ${ }^{44}$ and reduced neovascularization in 
response to tissue ischemia, ${ }^{45}$ a process that is essential for wound healing and prevention of cardiovascular ischemia. ${ }^{24}$

A growing body of evidence indicates that the vessel growth in adults does not exclusively depend on the resident vascular cells, but also involves bone marrow-derived circulating cells. ${ }^{6,46}$ An important physiologic function of the circulating "arteriogenic" cells, such as monocytes and progenitor cells, is their ability to migrate towards gradients of growth factors or cytokines, also defined as chemotaxis. There is accumulating evidence that these circulating cells are also affected under diabetic conditions. This is reflected in an aberrant ability of these cells to home to the sites of the vessel growth, to proliferate and to acquire an active "arteriogenic" phenotype.

The functional response of monocytes is impaired in diabetic individuals as demonstrated by ex vivo analysis. ${ }^{34,47}$ Monocytes from diabetic individuals cannot migrate towards VEGF-A, a relevant arteriogenic stimulus, ${ }^{7,}{ }^{12}$ while they still can migrate towards tripeptide formyl-Met-Leu-Phe (fMLP). ${ }^{34}$ The impaired function of monocytes could be due to signal transduction defects defect as the kinase function of the relevant cell surface receptor, i.e. VEGF receptor-1 (VEGFR-1) was fully intact.

Likewise, CD34+ cells from diabetic patients do not migrate in response to VEGF or stromal cell-derived factor-1 (SDF-1), and exhibit cytoskeletal rigidity probably due to the aberrant $\mathrm{NO}$ signaling. ${ }^{48}$ Transendothelial migration of monocytes from type 1 diabetes patients is decreased towards the proinflammatory chemokines CCL2 and CCL $3 .{ }^{49}$ In contrast, the migration of type 1 diabetes monocytes towards lymphoid tissue-related CCL19 is enhanced, which may be due to an increased expression of the corresponding receptor. ${ }^{49}$

Circulating cells from diabetic individuals are in an activated state, ${ }^{50}$ which is mimicked by the exposure of circulating cells to hyperglycemia in vitro. ${ }^{51}$ In vitro generated EPC under the hyperglycemic conditions reveal a notable increase in the expression of several transcription factors, but show an impaired TNF- $\alpha$ triggered adhesion to EC. ${ }^{51}$ Impaired cellular physiology is explained by the activation of the p38 signaling pathway under the conditions of hyperglycemia in vitro. ${ }^{51}$ A specific blockade of this signaling pathway reverts the hyperglycemia-related impairment of the EPC proliferation in vitro. ${ }^{51}$

Furthermore, the migratory capacity of monocytes is impaired in DM. ${ }^{47,49}$ At the same time, upregulation of the surface adhesion molecules can be observed, which results in an increased monocyte adhesion. ${ }^{50}$ Hyperglycemia and DM cause activation of several signaling pathways ${ }^{52-54}$ leading to the augmented transcriptional activity and expression of the markers of activation and adhesion molecules. ${ }^{50,51}$ On the other hand, such cellular "preactivation" is 
most likely to deprive the cells of their ability to respond properly to migratory stimuli.

The functional defects observed in the circulating monocytes appear to mirror the status of the vascular cells involved in arteriogenesis. As monocytes allow the detection of the pathology-related cellular and vascular defects, they can be used to detect negative influences on the vasculature. The analysis of the effect of DM on the resident "arteriogenic" cells, namely EC and perivascular cells (SMC and fibroblasts) is rather limited due to the lack of possibilities to isolate them and to study them ex vivo. So far, only fibroblasts could be isolated from patients and studied in the relation to DM and wound healing, ${ }^{55}$ the latter being strictly dependent on angiogenesis.

Recent evidence suggests that DM and its basic pathophysiological mechanisms affect the function of circulating cells with the arteriogenic potential. This results in impaired synthetic, proliferative and migratory properties of the cells. All this implies that the cellular defects in the circulating cells relate to an impairment of arteriogenesis. It also demonstrates that the circulating cells may function as "biosensors", translating metabolic aberrations into an altered function.

\section{Aim of the Thesis}

The goal of this thesis was to investigate the mechanisms of VEGFR-1mediated migration of primary human monocytes. Furthermore, we aimed to study the mechanisms of adverse influence of cardiovascular risk factors on the VEGFR-1-dependent monocyte migration. In chapter 1 a systemic review of the literature on the role of monocytes and VEGFR-1 in arteriogenesis is provided and the detrimental effect of DM on arteriogenesis is overviewed.

In chapter 2 we describe the intracellular signaling pathways mediating the biological functions triggered by VEGFR-1 in primary monocytes. We also show the contribution of distinct pathways to the VEGFR-1-dependent migratory response of monocytes.

In chapter 3 we establish the existence of VEGFR-1 resistance in monocytes in the presence of DM. This VEGFR-1 resistance results from the increased baseline activation of the VEGFR-1-related signaling pathways. We highlight the contribution of several DM-linked biochemical alterations to the increased baseline activation of monocytes.

In chapter 4 we established monocyte isolation from mice and ex vivo monocyte chemotaxis assay. We verified the detrimental effect of an isolated 
cardiovascular risk factor (hyperlipidemia) on the VEGFR-1-mediated monocyte chemotaxis in a mouse model using ApoE-/- mice.

Chapter 5 discusses the most important finding of this thesis.

\section{References}

1. Schaper W. Collateral circulation: past and present. Basic Res Cardiol. 2009;104:5-21.

2. Carmeliet P. Mechanisms of angiogenesis and arteriogenesis. Nat Med. 2000;6:389-395.

3. Schaper $\mathrm{J}$, et al. The endothelial surface of growing coronary collateral arteries. Intimal margination and diapedesis of monocytes. A combined SEM and TEM study. Virchows Arch A Pathol Anat Histol. 1976;370:193-205.

4. Schaper J, et al. Ultrastructure of ischemia-induced changes in the precapillary anastomotic network of the heart. Am J Cardiol. 1972;29:851-859.

5. Borgers $\mathrm{M}$, et al. Acute vascular lesions in developing coronary collaterals. Virchows Arch A Pathol Pathol Anat. 1970;351:1-11.

6. Heil M, et al. Blood monocyte concentration is critical for enhancement of collateral artery growth. Am J Physiol Heart Circ Physiol. 2002;283:H2411-2419.

7. Pipp F, et al. VEGFR-1-selective VEGF homologue PlGF is arteriogenic: evidence for a monocyte-mediated mechanism. Circ Res. 2003;92:378-385.

8. Herold J, et al. Transplantation of monocytes: a novel strategy for in vivo augmentation of collateral vessel growth. Hum Gene Ther. 2004;15:1-12.

9. Bergmann $\mathrm{CE}$, et al. Arteriogenesis depends on circulating monocytes and macrophage accumulation and is severely depressed in op/op mice. J Leukoc Biol. 2006;80:59-65.

10. Arras $\mathrm{M}$, et al. Monocyte activation in angiogenesis and collateral growth in the rabbit hindlimb. J Clin Invest. 1998;101:40-50.

11. Arras M, et al. Tumor necrosis factor-alpha in macrophages of heart, liver, kidney, and in the pituitary gland. Cell Tissue Res. 1996;285:39-49.

12. Babiak A, et al. Coordinated activation of VEGFR-1 and VEGFR-2 is a potent arteriogenic stimulus leading to enhancement of regional perfusion. Cardiovasc Res. 2004;61:789-795.

13. Ferrara N, et al. The biology of VEGF and its receptors. Nat Med. 2003;9:669-676.

14. Olsson AK, et al. VEGF receptor signalling - in control of vascular function. Nat Rev Mol Cell Biol. 2006;7:359-371.

15. Waltenberger J, et al. Different signal transduction properties of KDR and Flt1, two receptors for vascular endothelial growth factor. J Biol Chem. 1994;269:26988-26995.

16. Clauss $\mathrm{M}$, et al. The vascular endothelial growth factor receptor Flt-1 mediates biological activities. Implications for a functional role of placenta growth factor in monocyte activation and chemotaxis. J Biol Chem. 1996;271:17629-17634.

17. Selvaraj SK, et al. Mechanism of monocyte activation and expression of proinflammatory cytochemokines by placenta growth factor. Blood. 2003;102:1515-1524.

18. Donnan PT, et al. Prognosis following first acute myocardial infarction in Type 2 diabetes: a comparative population study. Diabet Med. 2002;19:448-455.

19. Haffner SM, et al. Mortality from coronary heart disease in subjects with type 2 diabetes and in nondiabetic subjects with and without prior myocardial infarction. $N$ Engl $J$ Med. 1998;339:229-234.

20. Balkau B, et al. High blood glucose concentration is a risk factor for mortality in middle-aged nondiabetic men. 20-year follow-up in the Whitehall Study, the Paris Prospective Study, and the Helsinki Policemen Study. Diabetes Care. 1998;21:360-367.

21. Fuller $\mathrm{JH}$, et al. Mortality from coronary heart disease and stroke in relation to degree of glycaemia: the Whitehall study. Br Med J (Clin Res Ed). 1983;287:867-870.

22. Stevens RJ, et al. Risk factors for myocardial infarction case fatality and stroke case fatality in type 2 diabetes: UKPDS 66. Diabetes Care. 2004;27:201-207. 
23. Stratton IM, et al. Association of glycaemia with macrovascular and microvascular complications of type 2 diabetes (UKPDS 35): prospective observational study. Bmj. 2000;321:405-412.

24. Abaci A, et al. Effect of diabetes mellitus on formation of coronary collateral vessels. Circulation. 1999;99:2239-2242.

25. Melidonis A, et al. Comparison of coronary collateral circulation in diabetic and nondiabetic patients suffering from coronary artery disease. Clin Cardiol. 1999;22:465-471.

26. Rzeczuch $\mathrm{K}$, et al. Coronary collateral circulation is less developed when ischaemic heart disease coexists with diabetes. Kardiol Pol. 2003;58:85-92.

27. Nahser PJ, Jr., et al. Maximal coronary flow reserve and metabolic coronary vasodilation in patients with diabetes mellitus. Circulation. 1995;91:635-640.

28. Nisanci Y, et al. Relationship between pressure-derived collateral blood flow and diabetes mellitus in patients with stable angina pectoris: a study based on coronary pressure measurement. J Invasive Cardiol. 2002;14:118-122.

29. Werner GS, et al. Impaired acute collateral recruitment as a possible mechanism for increased cardiac adverse events in patients with diabetes mellitus. Eur Heart J. 2003;24:1134-1142.

30. Kyriakides ZS, et al. Type II diabetes does not prevent the recruitment of collateral vessels and the normal reduction of myocardial ischaemia on repeated balloon inflations during angioplasty. Heart. 2002;87:61-66.

31. Sezer M, et al. [Reduced coronary collateral vessel recruitment capacity in diabetes mellitus: an evidence for defective ischaemic tolerance]. Anadolu Kardiyol Derg. 2004;4:54-58.

32. Zbinden R, et al. Influence of diabetes mellitus on coronary collateral flow: an answer to an old controversy. Heart. 2005;91:1289-1293.

33. Schaper W, et al. Collateral circulation and diabetes. Circulation. 1999;99:2224-2226.

34. Waltenberger J. Impaired collateral vessel development in diabetes: potential cellular mechanisms and therapeutic implications. Cardiovasc Res. 2001;49:554-560.

35. Melidonis A, et al. Angiographic study of coronary artery disease in diabetic patients in comparison with nondiabetic patients. Angiology. 1999;50:997-1006.

36. Barzilay JI, et al. Coronary artery disease and coronary artery bypass grafting in diabetic patients aged $>$ or $=65$ years (report from the Coronary Artery Surgery Study [CASS] Registry). Am J Cardiol. 1994;74:334-339.

37. Cohen M, et al. Determinants of collateral filling observed during sudden controlled coronary artery occlusion in human subjects. J Am Coll Cardiol. 1989;13:297-303.

38. Fujita M, et al. Determinants of collateral development in patients with acute myocardial infarction. Clin Cardiol. 1999;22:595-599.

39. Mason MJ, et al. Influence of clinical and angiographic factors on development of collateral channels. Coron Artery Dis. 2000;11:573-578.

40. Rentrop KP, et al. Changes in collateral channel filling immediately after controlled coronary artery occlusion by an angioplasty balloon in human subjects. J Am Coll Cardiol. 1985;5:587592.

41. Piek JJ, et al. Comparison of collateral vascular responses in the donor and recipient coronary artery during transient coronary occlusion assessed by intracoronary blood flow velocity analysis in patients. J Am Coll Cardiol. 1997;29:1528-1535.

42. Chou E, et al. Decreased cardiac expression of vascular endothelial growth factor and its receptors in insulin-resistant and diabetic States: a possible explanation for impaired collateral formation in cardiac tissue. Circulation. 2002;105:373-379.

43. Hink $\mathrm{U}$, et al. Mechanisms underlying endothelial dysfunction in diabetes mellitus. Circ Res. 2001;88:E14-22.

44. Sheetz MJ, et al. Molecular understanding of hyperglycemia's adverse effects for diabetic complications. Jama. 2002;288:2579-2588.

45. Tamarat $\mathrm{R}$, et al. Impairment in ischemia-induced neovascularization in diabetes: bone marrow mononuclear cell dysfunction and therapeutic potential of placenta growth factor treatment. Am J Pathol. 2004;164:457-466. 
46. Asahara T, et al. Isolation of putative progenitor endothelial cells for angiogenesis. Science. 1997;275:964-967.

47. Waltenberger J, et al. Vascular endothelial growth factor-A-induced chemotaxis of monocytes is attenuated in patients with diabetes mellitus: A potential predictor for the individual capacity to develop collaterals. Circulation. 2000;102:185-190.

48. Segal MS, et al. Nitric oxide cytoskeletal-induced alterations reverse the endothelial progenitor cell migratory defect associated with diabetes. Diabetes. 2006;55:102-109.

49. Bouma G, et al. An increased MRP8/14 expression and adhesion, but a decreased migration towards proinflammatory chemokines of type 1 diabetes monocytes. Clin Exp Immunol. 2005;141:509-517.

50. Cipolletta C, et al. Activation of peripheral blood CD14+ monocytes occurs in diabetes. Diabetes. 2005;54:2779-2786.

51. Seeger FH, et al. p38 mitogen-activated protein kinase downregulates endothelial progenitor cells. Circulation. 2005;111:1184-1191.

52. Ceolotto $\mathrm{G}$, et al. Protein kinase $\mathrm{C}$ activity is acutely regulated by plasma glucose concentration in human monocytes in vivo. Diabetes. 1999;48:1316-1322.

53. Ceolotto G, et al. Hyperglycemia acutely increases monocyte extracellular signal-regulated kinase activity in vivo in humans. $J$ Clin Endocrinol Metab. 2001;86:1301-1305.

54. Ding Y, et al. Phosphorylation of pleckstrin increases proinflammatory cytokine secretion by mononuclear phagocytes in diabetes mellitus. J Immunol. 2007;179:647-654.

55. Loots MA, et al. Cultured fibroblasts from chronic diabetic wounds on the lower extremity (non-insulin-dependent diabetes mellitus) show disturbed proliferation. Arch Dermatol Res. 1999;291:93-99. 



\section{Chapter 2}

\section{The molecular basis of VEGFR-1 signal transduction pathways in primary human monocytes}

Vadim Tchaikovski, Guido Fellbrich, and Johannes Waltenberger

Arteriscler Thromb Vasc Biol 2008; 28(2): 322-8 


\begin{abstract}
Objective Arteriogenesis, the growth of pre-existing arterioles into functional arteries, is dependent on the proper function of monocytes. Likewise, wound healing is monocyte-dependent. The activation of vascular endothelial growth factor receptor-1 (VEGFR-1) in monocytes induces a chemotactic response, triggers the expression of tissue factor, and gene expression of cytokines and chemokines. Little is known about intracellular signaling pathways mediating the biological functions triggered by VEGFR-1 in primary monocytes.
\end{abstract}

Methods and Results Monocytes were isolated from peripheral venous blood of young healthy individuals using indirect magnetic labelling. Stimulation of monocytes with either vascular endothelial growth factor-A (VEGF-A) or placenta growth factor (P1GF-1) triggered VEGFR-1 autophosphorylation and phosphorylation of distinct downstream proteins: phosphatidylinositol-3 kinase (PI-3K), Akt, p38 and extracellular signal-regulated kinase-1/2 (ERK1/2). PI$3 \mathrm{~K}$ appears to be a central regulator in VEGFR-1 signaling in monocytes as the activation of Akt, p38 and ERK1/2 are PI-3-K-dependent. In addition, Akt activation functions downstream of p38 kinase. VEGFR-1-mediated chemotaxis of monocytes is dependent on the activation of PI-3K, p38 kinase, Akt and ERK1/2, when assessed in a modified Boyden chamber.

Conclusions Both P1GF-1 and VEGF-A can activate VEGFR-1-dependent signaling pathways in primary human monocytes, leading to the activation of several intracellular signaling pathways. These pathways are critically involved in primary monocyte chemotaxis. 


\section{Introduction}

Angiogenesis and arteriogenesis are two distinct processes that are stimulated in the ischemic heart and related to ischemia in other tissues. Both processes can enhance regional blood flow and improve impaired muscle/organ function. Angiogenesis occurs by either sprouting or intussusceptive growth of capillaries, whereas arteriogenesis represents the growth of collateral arteries from preexisting ones. ${ }^{1}$ Monocytes ${ }^{2-4}$ and tissue resident precursor cells ${ }^{5}$ contribute to arteriogenesis by their recruitment to the growing vessel. Moreover, there is evidence that angiogenesis is monocyte-dependent, which was shown for angiogenesis in wound healing. ${ }^{6}$

The family of vascular endothelial growth factor (VEGF) and its receptors is crucially involved in the process of angiogenesis and arteriogenesis ${ }^{4}$ acting upon two important cell types, i.e. endothelial cells and monocytes. ${ }^{4,7}$ VEGF-A binds to two different receptor tyrosine kinases on vascular endothelial cells, namely VEGFR-1 (Flt-1) and VEGFR-2 (KDR/Flk-1). ${ }^{8}{ }^{9}$ VEGFR-2 is the major mediator of endothelial activation in response to VEGF and it mediates a large spectrum of endothelial functions. ${ }^{8,9}$ Monocytes can also be activated by members of the VEGF family. VEGFR-1 is the only VEGFR present on the surface of monocytes and it mediates a chemotactic response to VEGF-A and tissue factor induction. ${ }^{10}$ Placenta growth factor (PlGF-1), another member of the VEGF family, was shown to promote cytokine and chemokine gene expression in monocytes and chemotaxis in the monocytic cell line THP-1. ${ }^{11}$ Critically, the presence of VEGFR-3 on atherosclerotic plaque macrophages has been recently argued in conflicting reports. ${ }^{12,}{ }^{13}$ However, macrophages, although most likely monocyte-derived, represent a cell population phenotypically different from monocytes and are activated under respective conditions.

Several pathological conditions were shown to negatively affect the process of arteriogenesis. Diabetes mellitus specifically impairs endothelial function ${ }^{14}$ and arteriogenesis, as the development and function of coronary collateral vessels is significantly reduced in patients with diabetes mellitus. ${ }^{15}$ The reduced collateral growth in diabetic individuals corresponds with a significantly altered ex vivo chemotactic response of monocytes to VEGF-A. ${ }^{16}$ At the same time, the kinase function of VEGFR-1 is intact in monocytes derived from diabetic individuals implying a signal transduction defect downstream from the receptor to be responsible for the impaired monocytic response. ${ }^{16}$ A similar impairment of VEGF-induced monocyte function has recently been shown for hypercholesterolemia ${ }^{17}$ and smoking. ${ }^{18}$ Circulating 
monocytes may therefore be used as biosensors to study the influence of different pathological conditions on cellular function.

Considering the importance of VEGFR-1-stimulated monocytes in vascular biology, ${ }^{3,4}$ we have characterized intracellular signal transduction pathways mediating VEGF-A- and PlGF-1-induced monocyte chemotaxis following activation of VEGFR-1. In the present study we show that both PIGF1 and VEGF-A can activate VEGFR-1 in primary human monocytes. Stimulation of monocytes with PlGF-1 or VEGF-A leads to the activation of several intracellular signaling molecules including phosphatidylinositol-3 kinase (PI-3K), Akt, extracellular signal-regulated kinase-1/2 (ERK1/2) and p38 mitogen-activated protein kinases (MAPK). In addition, we show that PlGF-1and VEGF-A-induced activation of PI-3K, Akt, ERK1/2 and p38 is crucially involved in mediating the signal for monocyte chemotaxis.

\section{Methods}

\section{Reagents}

Recombinant human VEGF-A VI65 $_{1}$ PlGF-1 and PlGF-2 were obtained from RELIATech GmbH (Braunschweig; Germany) and formylMetLeuPhe (fMLP) was from Sigma-Aldrich (Saint Louis, Missouri; USA). Kinase inhibitors LY294002 (2-(4-morpholinyl)-8-phenyl-4H-1-benzopyran-4-one), SB203580 (4-(4-fluorophenyl)-2-(4-methylsulinylphenyl)-5-(4-pyridyl)1H-imidazole), PD98059 (2'-amino-3'-methoxyflavone), AktVIII inhibitor (1,3-Dihydro-1-(1((4-(6-phenyl-1H-imidazo[4,5-g]quinoxalin-7-yl)phenyl)methyl)-4-piperidinyl)2H-benzimidazol-2-one) and Wortmannin (KY12420) were purchased from Calbiochem (San Diego, California; USA). Antibodies recognizing phosphorylated Akt (Ser473), ERK1/2 (Thr202/Tyr204), p38 (Thr180/Tyr182) and Akt were from New England BioLabs/Cell Signaling (Beverly, MA; USA) and a anti-p38 kinase antibody was from BD Biosciences Pharmingen (Franklin Lakes, NJ, USA). Anti-VEGFR-1 (clone Flt-19) monoclonal antibody was obtained from Sigma-Aldrich (Saint Louis, Missouri; USA). The antibody against the p85 subunit of PI-3 kinase was from Upstate Biotechnology (Lake Placid, NY; USA). Secondary horseradish peroxidase-conjugated goat antimouse and goat anti-rabbit antibodies were from DAKO (Glostrup, Denmark) and Amersham (Braunschweig, Germany), correspondingly. The antiphosphotyrosine antibody PY99 was purchased from Santa Cruz Biotechnology Inc. (Santa Cruz, California, USA). Lysine-free RPMI 1640 and DMEM medium were purchased from Invitrogen (Karlsruhe; Germany). Fetal calf serum (FCS) was from Biochrom AG (Berlin; Germany). Western blot stripping 
buffer was from Pierce (Rochford, IL; USA). Protein assay was from Bio-Rad Laboratories GmbH (Munchen; Germany). FITC-labeled CD14 antibodies were from PharMingen. CellTiter 96 Aqueous One Solution Cell Proliferation Assay was from Promega.

\section{Isolation of monocytes from peripheral venous blood}

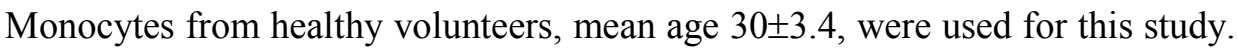
Blood samples were collected with informed consent and permission of local ethical committee. Donors with concurrent inflammatory or malignant disease and those with a history of smoking were excluded from these investigations.

Monocytes were isolated from $100 \mathrm{~mL}$ of heparinized freshly drawn venous blood using a monocyte isolation kit from Miltenyi Biotec (Bergisch Gladbach, Germany) by indirect magnetic labeling to separate unlabeled monocytes from human peripheral blood mononuclear cells (PBMC) according to manufacturer's protocol. In brief, density centrifugation was performed using Ficoll separation solution with a density of $1.077 \mathrm{~g} / \mathrm{mL}$ (Biochrom) to isolate PBMCs. Subsequently, indirect magnetic labeling of T cells, NK cells, B cells, dendritic cells and basophils from PBMC population with an antibody cocktail of hapten-conjugated CD3, CD7, CD19, CD45RA, CD56 and anti-IgE was performed. Afterwards, these hapten-labeled cells were coupled to anti-hapten antibodies carring MicroBeads followed by separation in the magnetic field on MACS columns (Miltenyi Biotec). Purity of monocyte isolation was generally around $95 \%$.

\section{Assessment of the purity of monocyte isolation}

Freshly isolated monocytes were fixed with $1 \%$ paraformaldehyde in PBS. Blocking was performed with $0.5 \%$ bovine serum albumin (BSA) solution in PBS. Monocytes were incubated with either CD14 FITC-labeled antibodies or isotype control FITC-labeled antibodies.

\section{Immunoprecipitation and in-vitro kinase assay}

Assays were performed as previously published. ${ }^{9}$

\section{Western blot analysis of VEGFR-1 phosphorylation}

Monocytes were isolated from buffy-coat using two-step gradient centrifugation procedure as described. ${ }^{16}$ Isolated monocytes $\left(20 \times 10^{6}\right.$ cells/assay $)$ were incubated in lysine-free RPMI 1640 medium containing 2\% FCS for 10 minutes at $37^{\circ} \mathrm{C}$ in $2 \mathrm{~mL}$ tubes (Eppendorf, Hamburg; Germany) and subsequently incubated with $100 \mu \mathrm{mol} / \mathrm{L} \mathrm{Na}_{3} \mathrm{VO}_{4}$ for additional 5 minutes. Afterwards, cells 
were stimulated with PlGF-1 for 5 minutes at the indicated concentrations. Stimulated monocytes were centrifuged $\left(2200 \mathrm{~g}, 4^{\circ} \mathrm{C}\right)$, washed with $500 \mu \mathrm{l}$ icecold PBS, pH 7.4, containing $100 \mu \mathrm{mol} / \mathrm{L} \mathrm{Na}_{3} \mathrm{VO}_{4}$ and subsequently lysed in ice-cold lysis buffer $(20 \mathrm{mmol} / \mathrm{L}$ Tris- $\mathrm{HCl}, \mathrm{pH} 7.4 ; 150 \mathrm{mmol} / \mathrm{L} \mathrm{NaCl} ; 10$ $\mathrm{mmol} / \mathrm{L}$ EDTA, $10 \%$ glycerol, 1\% Trasylol (Bayer, Leverkusen; Germany), $1 \mathrm{mmol} / \mathrm{L}$ phenylmethylsulfonyl fluorid; $1 \%$ Triton ${ }^{\circledR} \mathrm{X}-100$. Lysates were centrifuged (15000 g, 10 minutes) and equal amounts of supernatants were used for immunoprecipitation at $4{ }^{\circ} \mathrm{C}$ overnight using an antibody recognising VEGFR-1 (ReliaTech). Precipitated proteins were then immobilized on Protein A-Sepharose CL-4B (Amersham) and subsequently separated by SDS-PAGE and blotted onto nitrocellulose membrane (Amersham). Immunodetection was performed using antibodies recognizing phosphorylated tyrosine residues (PY99). The images were captured by scanning utilizing an LAS documentation system (FujiFilm).

\section{Lipid-kinase assay - PI-3 kinase assay}

Lysates of ligand-stimulated monocytes were used for immunoprecipitation at $4^{\circ} \mathrm{C}$ overnight with a polyclonal antiserum raised against $\mathrm{p} 85$ subunit of PI-3 kinase (see Reagents). Lipid-kinase assay was performed as previously described. ${ }^{9}$

\section{Western blot analysis of Akt, p38 and ERK1/2}

Monocytes $\left(5 \times 10^{6}\right.$ cells/assay) were pretreated, where indicated, with pharmacologic inhibitors and subsequently incubated with $100 \mu \mathrm{mol} / \mathrm{L} \mathrm{Na}_{3} \mathrm{VO}_{4}$ for additional 5 minutes. Cells were stimulated with either VEGF-A or PlGF-1 before solubilization in ice-cold lysis buffer. Protein concentration was measured in the supernatant of lysates. Sample aliquots containing equal amounts of protein were boiled in $\beta$-mercaptoethanol-containing sample buffer and separated on $7.5-12 \%$ sodium dodecylsulphate polyacrylamide gel electrophoresis (SDS-PAGE) followed by a transfer onto nitrocellulose membranes (Amersham). Subsequently, membranes were blocked with 5\% semi-dry milk solution and incubated with specific primary antibodies. Antibodies recognizing phosphorylated forms of Akt, p38 and ERK1/2 were used at a dilution of 1:1000. Horseradish peroxidase-conjugated secondary antibodies were added and the specific proteins were detected using Supersignal chemiluminescence substrate (Pierce). The intensity of bands was quantified by scanning utilizing an LAS documentation system. To monitor protein loading, blots were stripped and reprobed using 1:1000 or 1:2500 dilutions of antibodies recognizing AKT or $\mathrm{p} 38$, correspondingly. 


\section{Monocyte chemotaxis}

Monocytes at a concentration of $5 \times 10^{5}$ cells $/ \mathrm{mL}$ were preincubated with the appropriate inhibitors or vehicle (dimethylmethylsulfoxide, DMSO) at the indicated concentrations for 1 hour (AktVIII inhibitor) or 30 minutes (all other inhibitors) at $37^{\circ} \mathrm{C}$ in DMEM. Subsequently, monocytes were placed to the upper wells, stimulated with growth factors added to the lower wells. Upper and lower wells were separated with polycarbonate membrane (pore size $5 \mu \mathrm{m}$ ) across which the chemotaxis occurred. The cells were allowed to migrate for 3 hours in a humidified incubator $\left(5 \% \mathrm{CO}_{2}\right)$ at $37^{\circ} \mathrm{C}$. Adherent cells on polycarbonate membrane were fixed for 10 minutes using absolute ethanol and stained with Giemsa dye before scraping off cells from the upper side of the membrane. Migrated cells were quantified by counting 15 high power fields (20x primary magnification) in 3 different wells.

\section{Assessment of monocyte viability in the presence of different kinase inhibitor}

Monocytes at a concentration of $5 \times 10^{5}$ cells $/ \mathrm{mL}$ were incubated with the appropriate inhibitors or vehicle (dimethylmethylsulfoxide, DMSO) at the indicated concentrations for 4 hours (time frame of chemotaxis assay for AktVIII inhibitor) or 3 hours 30 minutes (time frame of chemotaxis assay for all other inhibitors) at $37^{\circ} \mathrm{C}$ in DMEM. Subsequently, number of viable cells was determined with CellTiter 96 Aqueous One Solution Cell Proliferation Assay (Promega) according to manufacturer's instructions.

\section{RT-PCR analysis of VEGFR-2 expression}

Total RNA was isolated with RNeasy Mini Kit (Qiagen, Karlsrue, Germany). First strand cDNA synthesis was performed with Omniscript reverse transcriptase (Qiagen, Karlsrue, Germany). As a control cDNA was omitted from the reaction. The presence VEGFR-2 was detected using the primers and PCR conditions as reported. ${ }^{19} \beta$-actin was used as a housekeeping gene with the following primers (forward 5'-TCA TGT TTG AGA CCT TCA A-3', reverse 5'-GTC TTT GCG GAT GTC CAC G-3') and PCR conditions (annealing temperature $55^{\circ} \mathrm{C}, 30$ cycles).

\section{Statistical analysis}

In the chemotaxis experiments data are given as mean \pm SEM. The probability of difference between the samples without stimulus (chemokinesis) or with a stimulus (chemotaxis) was evaluated using Kruskal-Wallis test. Subsequently, 
Mann-Whitney test was performed to estimate the level of significance. Level of significance $\mathrm{p}<0.01$ was considered significant.

\section{Results}

\section{PIGF-1 and VEGF-A activate VEGFR-1 and induce phosphorylation of various intracellular proteins in monocytes}

Primary human monocytes present with low expression of VEGFR-1. ${ }^{10}$ The method of choice to analyze VEGFR-1 activation in these cells remains radioactive in-vitro kinase assay. ${ }^{16}$

A

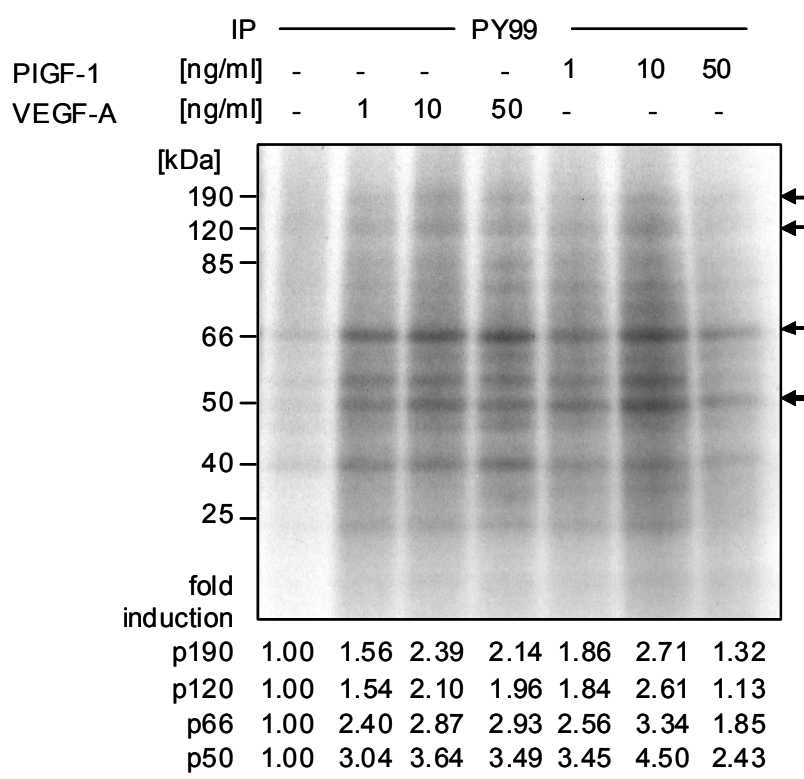

B



Figure 1. Effect of PlGF-1 and VEGF-A on tyrosine phosphorylation and VEGF receptor 1 autophosphorylation in monocytes. Following stimulation with either PlGF-1 or VEGF-A for 5 min, tyrosine-phosphorylated proteins (A) or VEGFR-1 (B) were immunoprecipitated followed by in vitro kinase reaction. The relative activation of 4 individual proteins (p190, p120, p66 and p50 - indicated with arrows, A) or VEGFR-1 (B) was quantified. 
Following stimulation of VEGFR-1 with either PlGF-1 or VEGF-A, tyrosine phosphorylation of a number of proteins could be observed (Fig. 1A). Four distinct proteins $(190,120,66,50 \mathrm{kDa})$ showed the strongest level of phosphorylation in a ligand-concentration-dependent fashion. The maximal phosphorylation was observed at $10 \mathrm{ng} / \mathrm{mL}$ for both VEGF-A and PlGF-1 with a 2- to 4-fold increase (Fig. 1A).

Stimulation of monocytes for 5 minutes with either PlGF-1 or VEGF-A $(10 \mathrm{ng} / \mathrm{mL})$ resulted in a considerable phosphorylation of VEGFR-1 (Fig. 1B). Further increase in the ligand concentrations to $50 \mathrm{ng} / \mathrm{mL}$ did not result in higher VEGFR-1 activity. Similar results were obtained, when VEGFR-1 was specifically immunoprecipitated and subsequently immunoblotted with an antiphosphotyrosine antibody (Figure I, Supplement). Critically, the latter assay, in contrast to in-vitro kinase assay, required 4 times higher number of monocytes, namely $20 \times 10^{6} / \mathrm{sample}$, which can be obtained from $60-80 \mathrm{ml}$ of blood.

The concentration $10 \mathrm{ng} / \mathrm{mL}$ was chosen for further experiments with both ligands. Critically, the concentrations of $1 \mathrm{ng} / \mathrm{mL}$ of both PIGF-1 and VEGF-A, used in chemotaxis assay (see bellow and Fig. 5) were able to stimulate tyrosine phosphorylation overall (Fig. 1A) as well as activation of a set of important signaling molecules (Figure V, Supplement).

\section{PIGF-1 and VEGF-A activate the PI-3K/Akt signaling pathway in monocytes}

PlGF-1 was shown to stimulate Akt phosphorylation in the monocytic cell line THP-1. ${ }^{11}$ This stimulation was dependent on the activation of PI-3 kinase. Stimulation of primary human monocytes with either PlGF-1 or VEGF-A for 5 minutes resulted in an increased activity of PI-3K as measured by the ability of PI-3K to phosphorylate the substrate PI at 3' position in a lipid-kinase assay (Fig. 2). Both VEGF-A and PlGF-1 (10 ng/mL) caused a 2.7- and 1.7-fold increase, respectively, in the formation of phosphatidylinositol phosphate (PIP) as compared to the non-stimulated control.

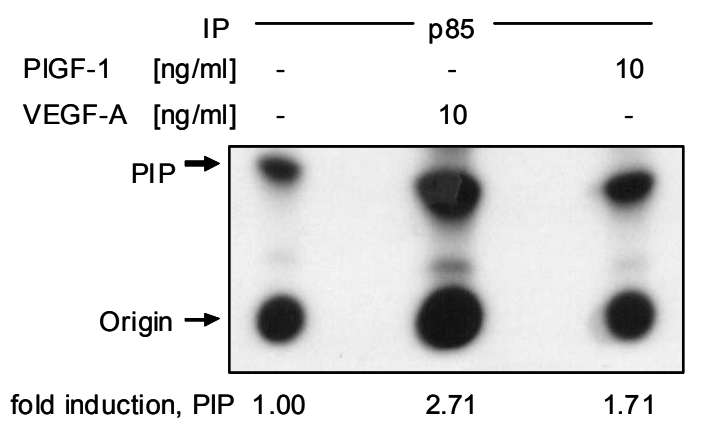

Figure 2. $P l G F-1$ and $V E G F-A$ induce PI-3 kinase activation. Lysates of ligandstimulated monocytes $(5 \mathrm{~min})$ were subjected to a lipid-kinase assay. Activity of PI-3 kinase was assessed using PI as an exogenous substrate. Data are presented as fold induction of PIP phosphorylation. The analysis is representative of 3 independent experiments. 
Both VEGF-A and PlGF-1 induced Akt (Ser473) phosphorylation by about 2.6and 5.2-fold, correspondingly (Fig. 3A). Pretreatment of monocytes with 10 $\mu \mathrm{mol} / \mathrm{L}$ of LY294002 (Fig. 3A) completely abolished Akt (Ser473) phosphorylation in response to either VEGF-A or PlGF-1. Similar results were observed following monocyte pretreatment with Wortmannin, another PI-3K inhibitor (Figure III, Supplement).

\section{P38 kinase regulates Akt (Ser473) phosphorylation}

In neutrophils, Akt was found in the signaling complexes together with members of the p38 MAPK signaling pathway. ${ }^{20}$ Akt phosphorylation on Ser473 residue was found to be dependent on $\mathrm{p} 38$ kinase activation in vascular smooth muscle cells. ${ }^{21}$ Stimulation of monocytes with either VEGF-A or PlGF1 leads to a 1.95- or 2.4-fold induction of Akt (Ser473) phosphorylation (Fig. 3B). Preincubation of monocytes with p38 kinase inhibitor SB203580 completely abrogated VEGF-A- and PlGF-1-stimulated Akt phosphorylation, indicating that either p38 itself or a downstream member of p38 signaling pathway inflict Akt phosphorylation.

A

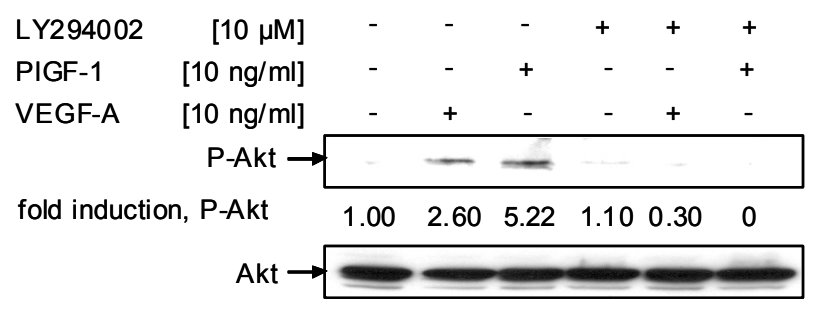

B

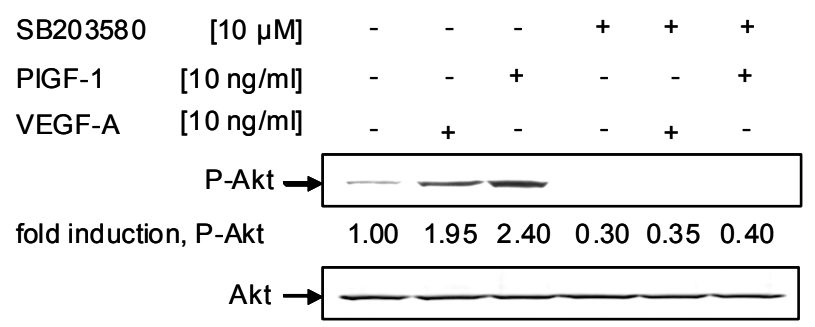

Figure 3. PlGF-1 and VEGF-A-induced phosphorylation of Akt (Ser473) is dependent on PI-3 kinase (A) and p38 kinase (B). Monocytes were preincubated with LY294002 (A) or SB203580 (B) for $30 \mathrm{~min}$ followed by ligand stimulation $(5 \mathrm{~min})$. After detection of Akt (Ser473) phosphorylation, the membranes were stripped and re-probed with anti-Akt antibodies. Each Western blot analysis is representative of 3 independent experiments. 


\section{PI-3K mediates VEGF-A-/PIGF-1-induced activation of two MAPKs, p38 and ERK1}

Recent studies have shown that migratory responses of monocytes to various chemoattractants were dependent on MAPK signaling pathways. ${ }^{22-24}$ Stimulation of monocytes with either VEGF-A or PlGF-1 $(10 \mathrm{ng} / \mathrm{mL})$ results in the phosphorylation of ERK1 (5.8-fold and 10-fold increase, respectively) and in a somewhat weaker phosphorylation of ERK2 (Fig. 4). Preincubation of monocytes with the PI-3K inhibitor LY294002 for 30 minutes prior to ligand stimulation completely abrogated ERK1 phosphorylation. The fairly detectable ligand-induced phosphorylation of ERK2 may be attributed to its tremendously higher baseline activation (Fig. 4).

Stimulation of monocytes with VEGF-A or PlGF-1 leads to phosphorylation of p38 kinase with a 4- and 10-fold increase in p38 kinase activity, respectively (Fig. 4). Pretreatment of monocytes with LY294002 suppressed p38 kinase phosphorylation to undetectable levels.

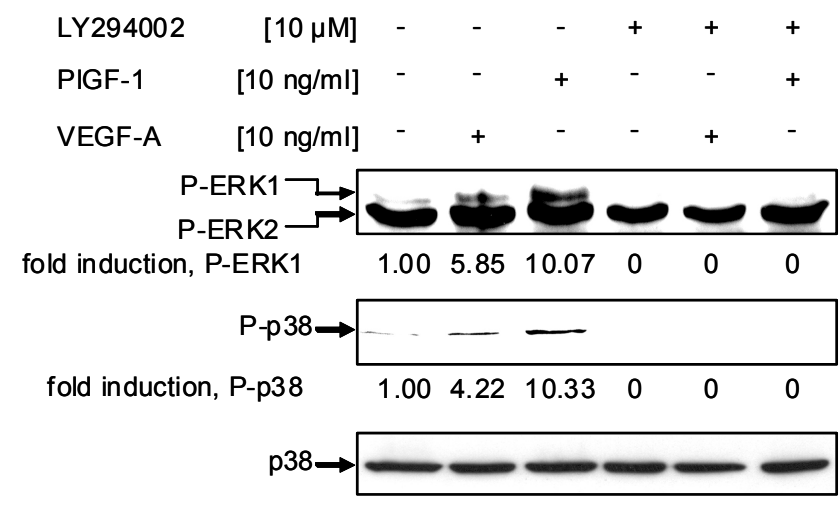

Figure 4. Role of PI-3K in VEGF-A- and PlGF-1-induced activation of $p 38$ and ERK1/2. Pretreatment of monocytes with LY294002 (30 $\mathrm{min})$ was followed by ligand stimulation (5min). After detection of the activated form of ERK1/2 (Thr202/Tyr204) membranes were re-probed using antibodies against an activated form of $\mathrm{p} 38$ (Thr180/Tyr182). As a control of equal protein loading blots were reprobed with anti-p38 antibodies. Data are representative of 3 independent experiments.

\section{Biological effects of VEGFR-1-dependent Akt activation in primary human monocytes are independent of ERK1/2 pathway activation}

VEGFR-1-mediated phosphorylation of ERK1/2 in THP-1 cells was shown to depend on Akt. We used a recently developed inhibitor of Akt (Ser473) phosphorylation, AktVIII inhibitor, ${ }^{25}$ to test this hypothesis in primary monocytes. AktVIII inhibitor effectively abolishes more than $90 \%$ of both baseline and VEGFR1-ligand-induced Akt (Ser473) phosphorylation in primary 
human monocytes at $1 \mu \mathrm{mol} / \mathrm{L}$ (Figure IVA, Supplement). Pretreatment of monocytes with $1 \mu \mathrm{mol} / \mathrm{L}$ of AktVIII inhibitor did not affect phosphorylation of neither ERK1/2 nor p38 (Figure IVB, Supplement). This indicates that VEGFR1-induced biological effects in primary monocytes are mediated by Akt independently of ERK1/2 pathway.

\section{P38, ERK1/2 MAPK and Akt/PKB signaling pathways are involved in VEGF-A-/PIGF-1-induced chemotaxis of human monocytes}

VEGF-A is an established chemoattractant for primary human monocytes. ${ }^{10} \mathrm{We}$ therefore investigated which intracellular signaling pathways are involved in the motogenic response of monocytes. Thus, monocyte chemotaxis was studied in the presence of various kinase inhibitors. Monocytes responded with a significant $(\mathrm{p}<0.01) 45 \pm 3.4 \%$ and $35 \pm 4.2 \%$ increase in chemotaxis when stimulated with either $1 \mathrm{ng} / \mathrm{mL}$ of VEGF-A or P1GF-1 (Fig. 5).

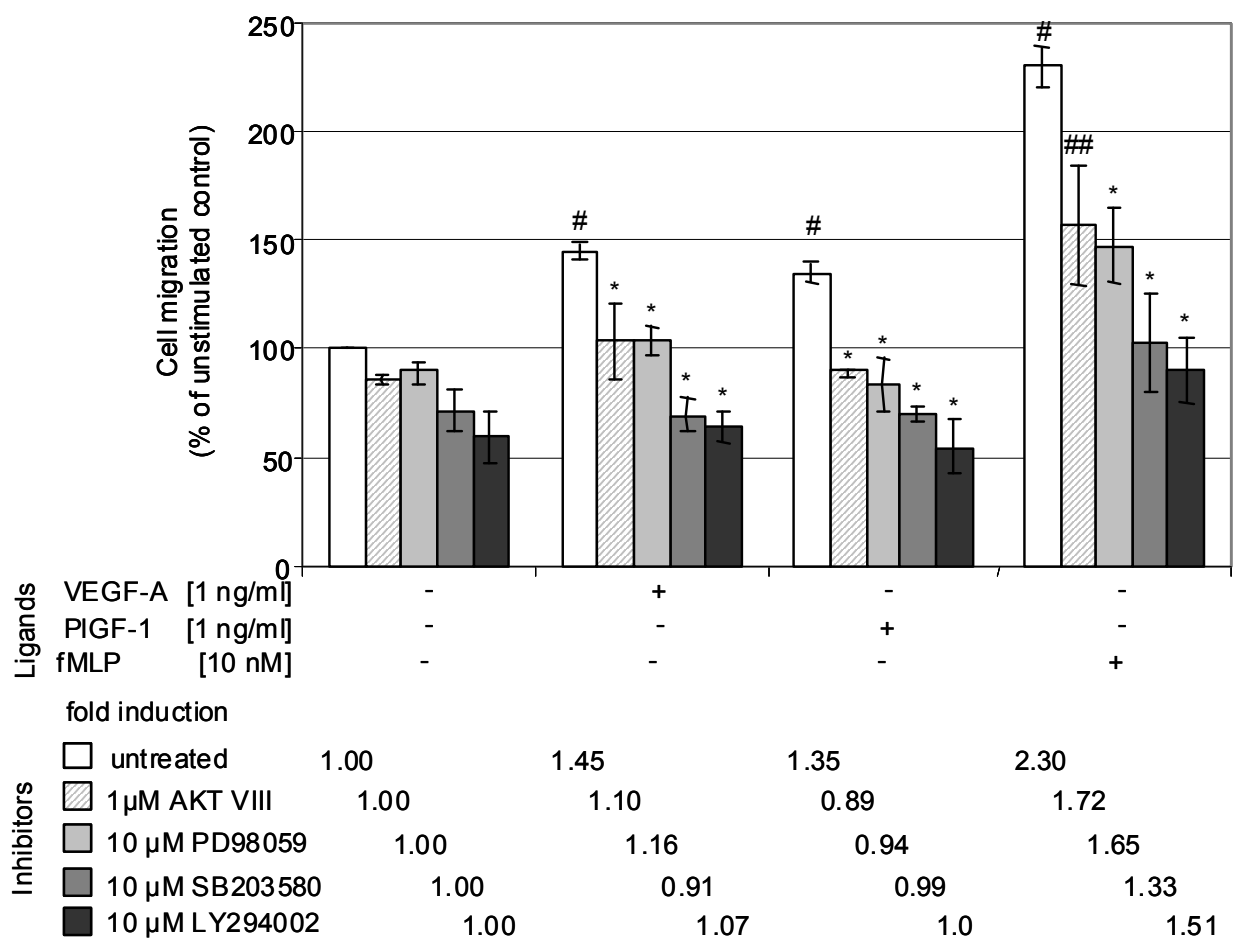

Figure 5. VEGF-A- and PlGF-1-induced monocyte chemotaxis requires activation of PI-3K, $A k t / P K B, p 38$ and ERK1/2 MAPKs. Monocytes were preincubated with different inhibitors. Ligand-induced chemotaxis was studied with modified Boyden chamber (pore size $5 \mathrm{~m}$ ). In each case, non-stimulated untreated or inhibitor-treated control is referred to as $100 \%$ migration. Results are given as mean \pm SEM of four independent experiments, each performed in triplicate. \# - $\mathrm{p}<0.001$ vs. unstimulated control (chemokinesis), ${ }^{*}-\mathrm{p}<0.01$, \#\# - $\mathrm{p}=0.017$ (all vs. ligandstimulated untreated control). 
Ligand concentration of $1 \mathrm{ng} / \mathrm{mL}$ was established to be optimal for chemotaxis. ${ }^{16}$ The lower concentration of PIGF-1 or VEGF-A required in chemotaxis assay, as compared to $10 \mathrm{ng} / \mathrm{mL}$ used in biochemical analysis of enzyme phosphorylation, may be attributed to the longer period of stimulation in chemotaxis assay sufficient to induce the biological response. A stronger chemotactic response was observed following stimulation with fMLP (130\% increase over the unstimulated baseline value, $\mathrm{p}<0.001)$. Further, we used established pharmacological inhibitors at effective concentrations shown to specifically inhibit their targets.

Monocyte migration towards VEGF-A or PlGF-1 was significantly $(\mathrm{p}<0.01)$ suppressed in the presence of the AktVIII inhibitor by $29 \pm 7.0 \%$ and $34 \pm 6.4 \%$, correspondingly (Fig. 5). In the presence of the ERK $1 / 2$ pathway inhibitor PD98059, VEGF-A- and PlGF-1-induced chemotaxis was significantly $(\mathrm{p}<0.01)$ decreased by $29 \pm 4.5 \%$ and $38 \pm 6.5 \%$, respectively. Pretreatment with the p38 kinase inhibitor SB203580 resulted in a strong suppression $(\mathrm{p}<0.01)$ of VEGF-A- and P1GF-1-induced monocyte chemotaxis by $52 \pm 7.3 \%$ and $48 \pm 1.9 \%$. Comparable inhibition of monocyte chemotaxis by $55 \pm 6.3 \%$ and $54 \pm 7.6 \%$ was observed using the PI-3K inhibitor LY294002 $(\mathrm{p}<0.01$, (Fig. 5).

When assessing fMLP-induced monocyte-migration $(10 \mathrm{nmol} / \mathrm{L})$, i.e. growth factor-independent stimulation of monocyte migration, various kinase inhibitors abrogated ligand-stimulated locomotion with a comparable pattern (Fig. 5). Notably, monocytes could still respond to fMLP stimulation with residual chemotaxis in the presence of the different inhibitors. This residual chemotactic response varied from $33 \%$ in the presence of $\mathrm{p} 38$ kinase inhibitor to $72 \%$ in the presence of Akt inhibitor. This may imply stimulus-dependent activation of different signaling pathways in the chemotactic response of primary monocytes.

\section{Discussion}

In this study, we were able to significantly extend our knowledge on the signal transduction properties of VEGFR-1 in primary human monocytes. Critically, this is the first paper describing the intracellular signaling pathways involved in the process of VEGFR-1-mediated monocyte migration. Several previous studies reported distinct biological responses of primary human monocytes or monocytic cells in response to VEGFR-1 ligands without showing VEGFR-1 activation. $^{10,11,26}$ Because of the involvement of monocyte migration in arteriogenesis and because of the previously described signal transduction 
defects in diabetes, ${ }^{16}$ hypercholesterolemia ${ }^{17}$ and smoking, ${ }^{18}$ these data are of crucial importance for our understanding of monocyte (dys)function as well as physiologic and defective arteriogenesis.

Monocytes express significant level of VEGFR-1 mRNA, but no VEGFR-2 mRNA (Figure II, Supplement). ${ }^{10}$ Activation of VEGFR-1 induces migration of human monocytes. ${ }^{10}$ Macrophages carrying a mutant VEGFR-1 lacking the tyrosine kinase domain (VEGFR-1 TK-/-) showed markedly decreased migration towards VEGF. ${ }^{27}$ Mice carrying VEGFR-1 TK-/- are characterized by slower growth of some tumors ${ }^{28}$ and reduced tumor metastasis. ${ }^{28}$ Impaired migration and activation of monocytes/macrophages in these mice is responsible for a delayed progression of rheumatoid arthritis. ${ }^{28}$ These observations indicate that the VEGFR-1 tyrosine kinase domain is required for physiological monocyte function, namely the induction of monocyte/macrophage migration.

In the present study, stimulation of human primary monocytes with either VEGF-A or PlGF-1 led to VEGFR-1 autophosphorylation in vitro. Ligandinduced autophosphorylation of tyrosine residues in the cytoplasmic region of VEGFR-1 is a key event coupling VEGFR-1 to intracellular signal transduction pathways. The intracellular signaling pathways activated after VEGFR-1 stimulation are poorly understood, mainly because of the comparably weak tyrosine kinase activity of VEGFR-1. ${ }^{28}$ VEGFR-1 was documented to undergo autophosphorylation at Tyr-1169, 1213, 1242, 1327, $1333 .^{28}$

Following VEGF stimulation, VEGFR-1 is autophosphorylated on Tyr$1213 .{ }^{29}$ PI-3K is a potential candidate mediating biological effects following Tyr-1213 autophosphorylation. ${ }^{28}$ PI-3K is a pivotal enzyme and a wellestablished mediator of locomotive function in monocytes and monocyte-like cells. ${ }^{11,30}$ We demonstrate that PI-3K plays a crucial role in VEGFR-1-mediated monocyte signaling as PI-3K activity increases upon stimulation with either VEGF-A or PIGF-1. Several distinct signalling molecules such as Akt, p38 and ERK1/2 are activated in a PI-3K-dependent fashion. Our data are in line with recent data generated in the monocytic cell line THP-1, where PlGF stimulated Akt phosphorylation in a PI-3 kinase-dependent fashion. ${ }^{11}$ It is important to note, however, that our novel data represent the first proof of VEGF signalling in primary human monocytes, where we can exclude any differentiation or dedifferentiation, which is always possible in stable or transformed cell lines such as THP-1.

In porcine aortic endothelial cells stably expressing human VEGFR-1 (PAEC/Flt-1), ${ }^{9}$ stimulation of VEGFR-1 did not result in ligand-induced activation of PI-3K. ${ }^{31}$ Likewise, activation of VEGFR-1 in PAEC/Flt-1 was 
unable to induce endothelial cell migration. ${ }^{9}$ Our novel data clearly demonstrate that this situation is different in primary human monocytes with a functional VEGFR-1-PI-3K axis.

The serine/threonine kinase Akt is one of the signal transduction mediators acting downstream of PI-3K. ${ }^{32}$ Akt activation plays a critical role in mediating cell proliferation, differentiation and survival. ${ }^{33}$ In our study, VEGFR-1 propagated the phosphorylation of Ser473 of Akt in monocytes, which was strictly PI-3K-dependent. Two inhibitors of PI-3K, Wortmannin and LY294002, abolished VEGF-A- and PlGF-1-stimulated Akt activation to almost undetectable levels. Activation of Akt (Ser473 phosphorylation) was recently shown in monocytic THP-1 cells in response to PIGF. ${ }^{11}$ Similarly, the motogenic response following VEGFR-2 stimulation in endothelial cells requires subsequent activation of PI-3K and $\mathrm{Akt}^{34}$

Previous reports suggested that phosphorylation of Ser473 was the result of autophosphorylation following PDK1-dependent Akt Thr308 phosphorylation or was due to sequential phosphorylation of Thr308 and then Ser473. ${ }^{35}$ It was recently described that p38 kinase is required for $\mathrm{PIP}_{3^{-}}$ stimulated activation of Akt Ser473 in human neutrophils. ${ }^{20}$ Our results provide initial evidence that $\mathrm{p} 38$ kinase $^{34}$ participates in the signal transduction pathway leading to Akt-Ser473 activation in monocytes.

According to our new data, stimulation of VEGFR-1 in monocytes activates the p38 kinase pathway, which in turn is required for the VEGFR-1mediated chemotactic response of monocytes. Activation of p38 revealed a rapid response ( 5 minutes) in contrast to a somewhat delayed activation profile in the monocytic cell line MonoMac6 following stimulation with MCP-1 or sFKN. ${ }^{36,37}$ Activation of $\mathrm{p} 38$ upon stimulation of primary human monocytes with plasmin peaked at 15 minutes and was involved in plasmin-induced chemotaxis. ${ }^{22}$ All this implies that the kinetics of monocyte/monocytic cell activation are stimulus- and cell-dependent.

Recently, activation of VEGFR-1 was implied in chemokine and cytokine gene expression and chemotaxis of the monocytic cell line THP-1. ${ }^{11}$ The chemotactic response to PlGF-1 was dependent on the activation of PI-3K, Akt and ERK1/2 kinases. In the same study, ligand-induced activation of ERK1/2 was abolished to different extent in the presence of a PI-3K inhibitor as well as following transfection of the dominant-negative form of PI-3K into THP-1 cells. Our findings support and extend these data. We were able to show that the chemotactic response of primary human monocytes mediated by VEGFR-1 requires activation of PI-3K/Akt and ERK1/2. In primary human monocytes, we observed significant activation of these molecules at concentrations of 10 
$\mathrm{ng} / \mathrm{mL}$ for both VEGF-A and PlGF-1. In our study, the chemotactic response of primary monocytes was optimal at concentrations between 1 and $10 \mathrm{ng} / \mathrm{mL}$ for both PIGF-1 and VEGF-A, which corresponds with previously published data on VEGF-A-induced chemotaxis of primary human monocytes, ${ }^{10,}{ }^{16}$ mouse macrophage ${ }^{27}$ and primary mouse monocytes (own unpublished data).

Our findings extend current knowledge on the signal transduction events mediated by VEGFR-1. Selvaraj et al. suggested that a cross-talk between PI$3 \mathrm{~K} / \mathrm{Akt}$ and ERK1/2 pathways may converge on MEK1/2, which is the kinase upstream from ERK1/2. ${ }^{38}$ Our results indicate that activation of ERK1/2 in response to VEGFR-1 ligands is dependent on PI-3K but does not require Akt activation in primary human monocytes (Figure IVB, Supplement).

The ligand-induced VEGFR-1-mediated monocyte chemotaxis was affected in the presence of distinct kinase inhibitors. Application of Akt inhibitor led to a $30 \%$ decrease in monocyte chemotaxis (Fig. 5). This supports similar findings in THP-1 monocytic cells, ${ }^{11}$ where expression of dominantnegative Akt inhibited PlGF-induced chemotaxis by about 50\%. Similar inhibition of VEGFR-1-mediated monocyte chemotaxis was observed when using an ERK1/2 pathway inhibitor.

A central role of PI3-K in VEGFR-1-mediated signaling in primary human monocytes was supported by its role in monocyte chemotaxis. Inhibition of PI3-K resulted in a 55\% decrease of ligand-induced migration. Directed cell motility is driven by chemoattractants that bind to G-protein coupled receptors (e.g. fMLP) ${ }^{30}$ or growth factors that signal through receptor tyrosine kinases (e.g. VEGF). In both cases, studies have shown that PI3-K is an important mediator of these chemotactic responses. Moreover, neutrophils or peritoneal macrophages deficient in $\mathrm{p} 110 \gamma$, a catalytic subunit of PI3-K, show a reduced chemotaxis towards fMLP. ${ }^{30,39}$

For the first time, we present data indicating that VEGFR-1 stimulation in primary monocytes induces a chemotactic response by activating distinct signaling pathways (Fig. 6). The exclusive use of pharmacological inhibitors to dissect VEGFR-1-dependent signaling pathways in primary monocytes may be considered as a limitation of the current study. However, the primary nature of monocytes did not allow us to use either siRNA or vectors carrying dominantnegative or constitutively-active forms of enzymes to silence or activate specific signaling events. The latter would require at least 24 hours of monocyte culturing and would lead to their differentiation into macrophages.

In summary, VEGFR-1-mediated ligand-induced signal transduction in monocytes involves activation of PI-3K/Akt and two MAP kinase pathways, p38 and ERK1/2. Ligand-induced monocyte migration is dependent on the 
activation of PI-3 kinase, p38 MAPK and - to a somewhat lesser extent - on ERK1/2 and Akt. PI-3 kinase plays a central role in monocyte signaling downstream of VEGFR-1, and activation of p38 and ERK1/2 pathways are strongly dependent on PI-3K activation. These data create a solid and valuable basis for the further elucidation of the recently described signal transduction defects responsible for impaired monocyte migration in diabetic, ${ }^{16}$ hypercholesterolemic ${ }^{17}$ and smoking ${ }^{18}$ individuals. The identification of the underlying molecular defects may change our understanding of the interindividual differences in arteriogenesis (poor and good collateralizers) and may be of help to develop novel strategies for stimulating therapeutic angiogenesis/arteriogenesis.

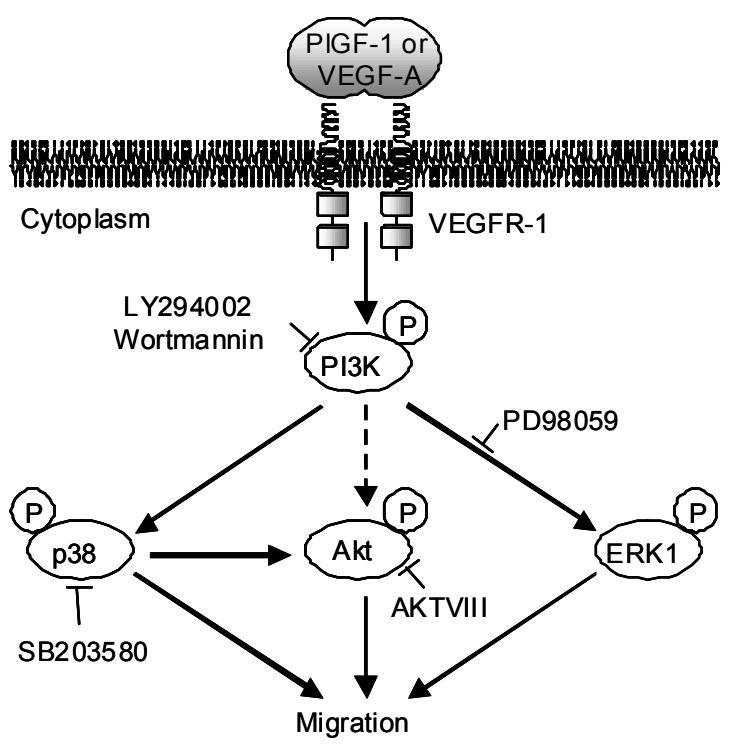

Figure 6. Working model of PlGF-1and VEGF-A-induced intracellular signal transduction cascades in monocytes leading to monocyte chemotaxis. VEGF-A and PlGF-1 induce autophosphorylation of VEGFR-1 in monocytes. Subsequently, the PI-3 kinase/Akt, the p38 and the ERK1/2 MAP kinase pathways are activated. This promotes monocyte chemotaxis. PI3-Kdependent activation of Akt is p38 dependent (solid arrows), though other molecules may also be involved (dashed arrow). Arrows indicate positive (stimulatory) effects. Inhibitors employed to specifically block respective signaling molecules (pathways) are also depicted.

\section{Acknowledgements}

Source of Funding - This work was supported in part by the European commission (VEGF-therapies QLK3-CT-2002-01955), the German Research Council DFG (Project Wa734/6-2 of Priority Research Project 1069 "Angiogenesis; Heisenberg.Scholarship Wa734/5-1 and DFG SFB452/B1) and the Cardiovascular Research Institute Maastricht (CARIM), all to J.W. Disclosure - no conflicts of interest. 


\section{Supplement Figures}

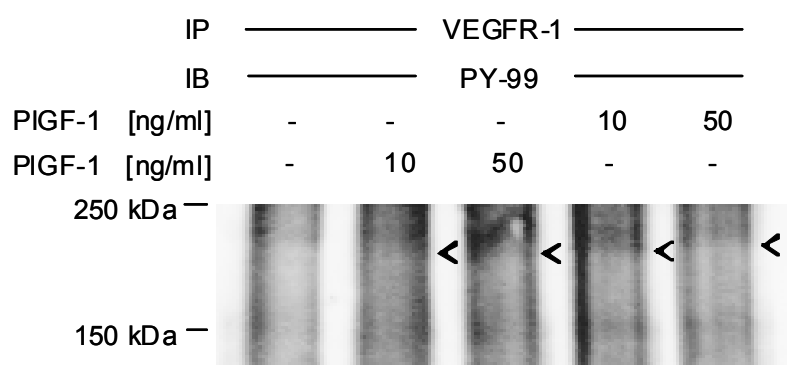

Figure I. VEGF receptor 1 phosphorylation induced by PlGF-1. Lysates from either PIGF-1stimulated $(10 \mathrm{ng} / \mathrm{mL}$ and $50 \mathrm{ng} / \mathrm{mL})$ monocytes were used to immunoprecipitate VEGFR-1. Immunoprecipitates immobilized on Protein A-Sepharose were used for Western blot analysis. Following protein separation on SDS-PAGE, immunodetection was used to analyze phosphotyrosine residues. Arrows indicate phosphorylated VEGFR-1.

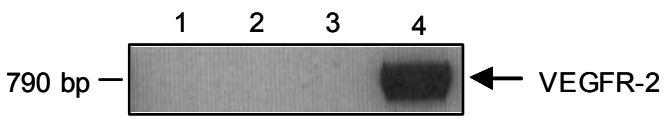

Figure II. VEGFR-2 expression in various cell types. VEGFR-2 (upper panel) and $\beta$-actin (lower panel) expression in primary human monocytes isolated using Monocyte Isolation Kit II (1), isolated using Hystopaque/Percoll gradient centrifugation protocol (2), THP-1 cells (3) and PAEC/KDR cells (4) using RT-PCR.

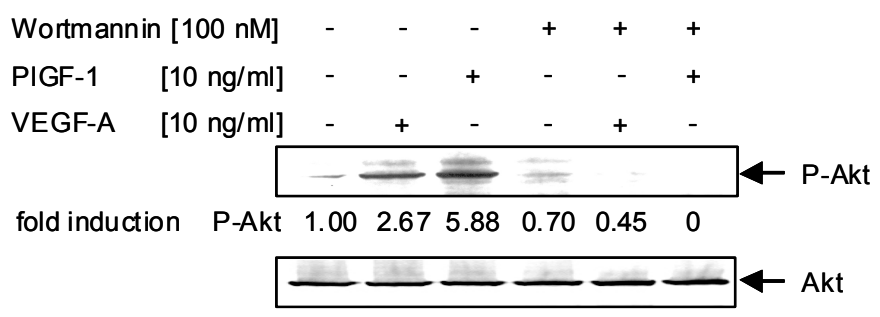

Figure III. PlGF-1 and VEGF-A-induced phosphorylation of Akt (Ser473) is dependent on PI-3 kinase. Western blot analysis of monocyte lysates probed with anti-Akt (Ser473) antibodies. Monocytes were preincubated with $100 \mathrm{nmol} / \mathrm{L}$ Wortmannin for 30 minutes followed by stimulation with indicated ligands for 5 minutes. After detection of Akt (Ser473) phosphorylation, the membranes were stripped and re-probed with anti-Akt antibodies. Each Western blot analysis shown is a representative example of 3 independent experiments. 
A

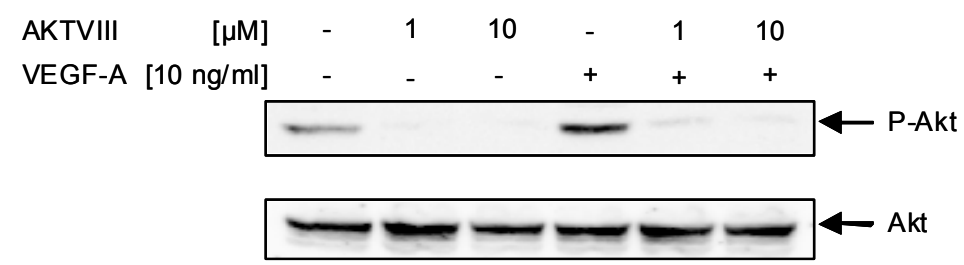

B

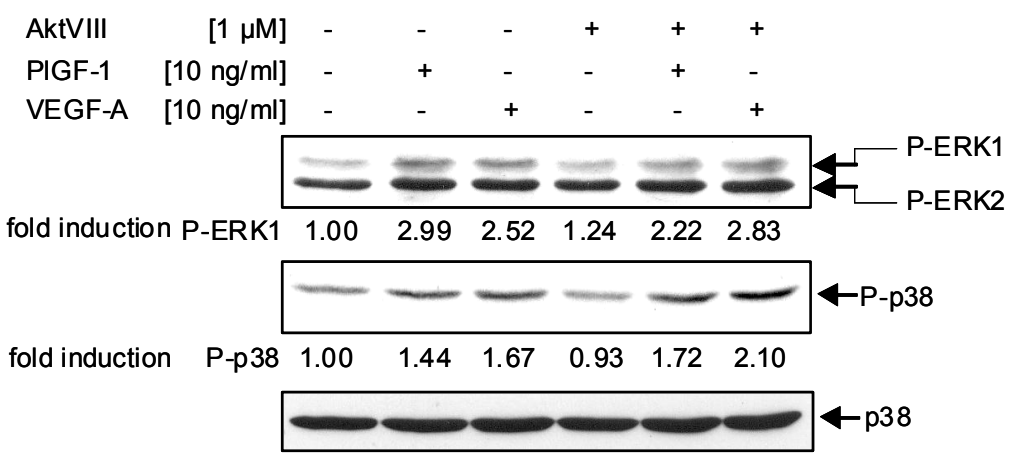

Figure IV. Effect of AktVIII inhibitor on phosphorylation of Akt (A) and p38 and ERK1/2 (B) in primary human monocytes. Monocytes were preincubated with AktVIII for 60 minutes followed by ligand stimulation for 5 minutes. A. Aliquots of the lysates were blotted with anti-P-Akt (Ser473) and anti-Akt antibodies. Each Western blot analysis is a representative example of 2 independent experiments. B. Following detection of the activated form of ERK1/2 (Thr202/Tyr204), membranes were re-probed using antibodies recognizing the activated form of p38 (Thr180/Tyr182). Blots were reprobed with anti-p38 antibodies to control for equal protein loading. Data are representative of 3 independent experiments. 
A

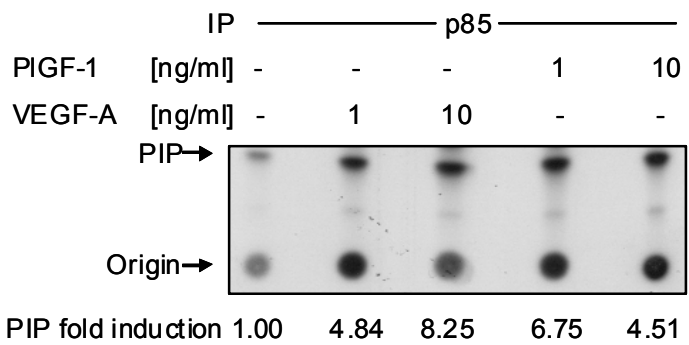

B

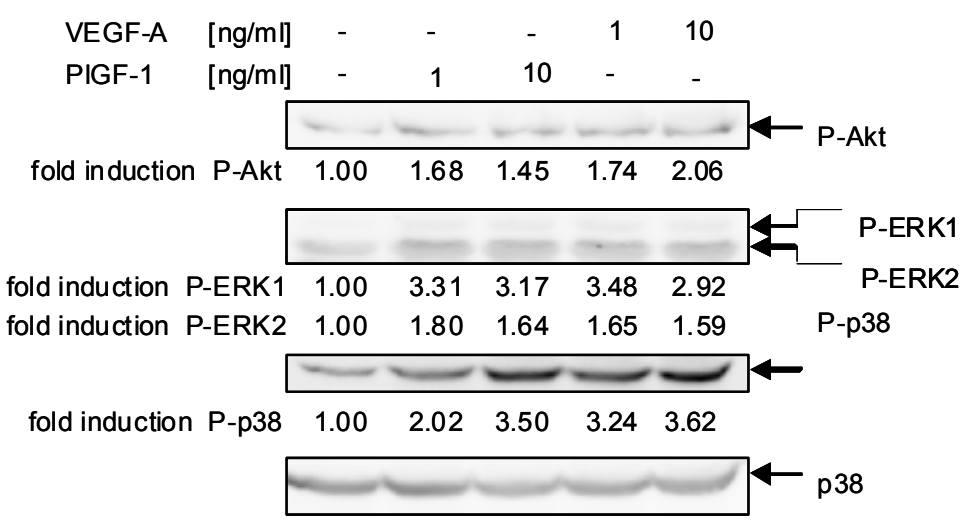

Figure V. Both $1 \mathrm{ng} / \mathrm{mL}$ and $10 \mathrm{ng} / \mathrm{mL}$ of PlGF-1 and VEGF-A induce activation of VEGFR-1dependent signaling pathways. A. Lysates of ligand-stimulated monocytes were subjected to a lipid-kinase assay. Activity of PI-3 kinase was assessed using PI as an exogenous substrate. Data are presented as fold-induction of phosphorylation of PIP. B. Lysates of ligand-stimulated monocytes were subjected to Western blot analysis with antibodies recognizing the activated forms of Akt or ERK1/2. Membranes were re-probed using antibodies against an activated form of p38. As a control of equal protein loading aliquots of the lysates were blotted with anti-p38 antibodies. Each Western blot analysis shown is a representative example of 2 independent experiments.

\section{References}

1. Carmeliet P. Mechanisms of angiogenesis and arteriogenesis. Nat Med. 2000;6:389-395.

2. Arras M, et al. Monocyte activation in angiogenesis and collateral growth in the rabbit hindlimb. J Clin Invest. 1998;101:40-50.

3. Pipp F, et al. VEGFR-1-selective VEGF homologue PlGF is arteriogenic: evidence for a monocyte-mediated mechanism. Circ Res. 2003;92:378-385.

4. Babiak A, et al. Coordinated activation of VEGFR-1 and VEGFR-2 is a potent arteriogenic stimulus leading to enhancement of regional perfusion. Cardiovasc Res. 2004;61:789-795.

5. Khmelewski E, et al. Tissue resident cells play a dominant role in arteriogenesis and concomitant macrophage accumulation. Circ Res. 2004;95:E56-64.

6. Crowther $\mathrm{M}$, et al. Microenvironmental influence on macrophage regulation of angiogenesis in wounds and malignant tumors. J Leukoc Biol. 2001;70:478-490. 
7. Ferrara N, et al. The biology of VEGF and its receptors. Nat Med. 2003;9:669-676.

8. Olsson AK, et al. VEGF receptor signalling - in control of vascular function. Nat Rev Mol Cell Biol. 2006;7:359-371.

9. Waltenberger J, et al. Different signal transduction properties of KDR and Flt1, two receptors for vascular endothelial growth factor. J Biol Chem. 1994;269:26988-26995.

10. Clauss M, et al. The vascular endothelial growth factor receptor Flt-1 mediates biological activities. Implications for a functional role of placenta growth factor in monocyte activation and chemotaxis. J Biol Chem. 1996;271:17629-17634.

11. Selvaraj SK, et al. Mechanism of monocyte activation and expression of proinflammatory cytochemokines by placenta growth factor. Blood. 2003;102:1515-1524.

12. Schmeisser A, et al. Apoptosis of human macrophages by Flt-4 signaling: implications for atherosclerotic plaque pathology. Cardiovasc Res. 2006;71:774-784.

13. Rutanen J, et al. Vascular endothelial growth factor-D expression in human atherosclerotic lesions. Cardiovasc Res. 2003;59:971-979.

14. Feener EP, et al. Vascular dysfunction in diabetes mellitus. Lancet. 1997;350 Suppl 1:SI9-13.

15. Werner GS, et al. Impaired acute collateral recruitment as a possible mechanism for increased cardiac adverse events in patients with diabetes mellitus. Eur Heart J. 2003;24:1134-1142.

16. Waltenberger J, et al. Vascular endothelial growth factor-A-induced chemotaxis of monocytes is attenuated in patients with diabetes mellitus: A potential predictor for the individual capacity to develop collaterals. Circulation. 2000;102:185-190.

17. Czepluch FS, et al. Hypercholesterolaemia impairs monocyte function in CAD patients. $J$ Intern Med. 2007;261:201-204.

18. Stadler $\mathrm{N}$, et al. Smoking-induced monocyte dysfunction is reversed by vitamin $\mathrm{C}$ supplementation in vivo. Arterioscler Thromb Vasc Biol. 2007;27:120-126.

19. Gill $\mathrm{M}$, et al. Vascular trauma induces rapid but transient mobilization of VEGFR2(+)AC133(+) endothelial precursor cells. Circ Res. 2001;88:167-174.

20. Rane MJ, et al. p38 Kinase-dependent MAPKAPK-2 activation functions as 3phosphoinositide-dependent kinase-2 for Akt in human neutrophils. $J$ Biol Chem. 2001;276:3517-3523.

21. Taniyama Y, et al. Role of p38 MAPK and MAPKAPK-2 in angiotensin II-induced Akt activation in vascular smooth muscle cells. Am J Physiol Cell Physiol. 2004;287:C494-499.

22. Burysek L, et al. The serine protease plasmin triggers expression of MCP-1 and CD40 in human primary monocytes via activation of p38 MAPK and janus kinase (JAK)/STAT signaling pathways. $J$ Biol Chem. 2002;277:33509-33517.

23. Ayala JM, et al. Serum-induced monocyte differentiation and monocyte chemotaxis are regulated by the p38 MAP kinase signal transduction pathway. J Leukoc Biol. 2000;67:869875.

24. Kintscher U, et al. Angiotensin II induces migration and Pyk2/paxillin phosphorylation of human monocytes. Hypertension. 2001;37:587-593.

25. Lindsley CW, et al. Allosteric Akt (PKB) inhibitors: discovery and SAR of isozyme selective inhibitors. Bioorg Med Chem Lett. 2005;15:761-764.

26. Barleon B, et al. Migration of human monocytes in response to vascular endothelial growth factor (VEGF) is mediated via the VEGF receptor flt-1. Blood. 1996;87:3336-3343.

27. Hiratsuka S, et al. Flt-1 lacking the tyrosine kinase domain is sufficient for normal development and angiogenesis in mice. Proc Natl Acad Sci U S A. 1998;95:9349-9354.

28. Shibuya M. Differential roles of vascular endothelial growth factor receptor-1 and receptor-2 in angiogenesis. J Biochem Mol Biol. 2006;39:469-478.

29. Murakami M, et al. Signaling of vascular endothelial growth factor receptor-1 tyrosine kinase promotes rheumatoid arthritis through activation of monocytes/macrophages. Blood. 2006;108:1849-1856.

30. Hirsch E, et al. Central role for G protein-coupled phosphoinositide 3-kinase gamma in inflammation. Science. 2000;287:1049-1053. 
31. Gille $\mathrm{H}$, et al. A repressor sequence in the juxtamembrane domain of Flt-1 (VEGFR-1) constitutively inhibits vascular endothelial growth factor-dependent phosphatidylinositol 3'kinase activation and endothelial cell migration. Embo J. 2000;19:4064-4073.

32. Burgering BM, et al. Protein kinase B (c-Akt) in phosphatidylinositol-3-OH kinase signal transduction. Nature. 1995;376:599-602.

33. Shiojima I, et al. Role of Akt signaling in vascular homeostasis and angiogenesis. Circ Res. 2002;90:1243-1250.

34. Jia $\mathrm{H}$, et al. Vascular endothelial growth factor (VEGF)-D and VEGF-A differentially regulate KDR-mediated signaling and biological function in vascular endothelial cells. $J$ Biol Chem. 2004;279:36148-36157.

35. Toker A, et al. Akt/protein kinase B is regulated by autophosphorylation at the hypothetical PDK-2 site. J Biol Chem. 2000;275:8271-8274.

36. Cambien B, et al. Signal transduction involved in MCP-1-mediated monocytic transendothelial migration. Blood. 2001;97:359-366.

37. Cambien B, et al. Signal transduction pathways involved in soluble fractalkine-induced monocytic cell adhesion. Blood. 2001;97:2031-2037.

38. Kyriakis JM, et al. Mammalian mitogen-activated protein kinase signal transduction pathways activated by stress and inflammation. Physiol Rev. 2001;81:807-869.

39. Sasaki T, et al. Function of PI3Kgamma in thymocyte development, T cell activation, and neutrophil migration. Science. 2000;287:1040-1046. 


\section{Chapter 3}

\section{Diabetes mellitus activates signal transduction pathways resulting in VEGF resistance of human monocytes}

Vadim Tchaikovski, M.D.; Serve Olieslagers, B. Sc.; Frank-D. Böhmer, Ph.D.; Johannes Waltenberger, M.D., Ph.D.

Circulation 2009; 120(2): 150-9 


\section{Abstract}

Background Monocytes are cellular components of wound repair, arteriogenesis and atherogenesis. The growth factors VEGF-A and PlGF recruit monocytes to sites of_arteriogenesis via stimulation of VEGF receptor-1 (VEGFR-1). The chemotactic response of monocytes to VEGF-A is attenuated in individuals with diabetes mellitus (DM). This VEGF resistance correlates with impaired collateral growth. The aim of this study is to elucidate the molecular basis of VEGF resistance and impaired monocyte response in DM.

Methods and Results Phosphorylation of Akt, p38 and ERK1/2 could be stimulated with either PlGF-1 or VEGF-A in Mo from non-DM, but not in Mo from DM individuals. In contrast, fMLP caused a comparable activation of these molecules in both DM and non-DM monocytes. Baseline phosphorylation of Akt, p38 and ERK1/2 was significantly elevated in monocytes from DM as compared to non-DM subjects. Of note, $\mathrm{H}_{2} \mathrm{O}_{2}$ activated Akt, p38 and ERK1/2 in non-DM monocytes ex vivo. Protein Tyrosine Phosphatases (PTPs) had stronger oxidative modifications in monocytes from DM than from non-DM individuals, which reflects functional PTP inhibition, similarly as seen after $\mathrm{H}_{2} \mathrm{O}_{2}$ challenge. Overall PTP and PTP1B activity were reduced in DM monocytes. DM monocytes revealed higher expression of RAGE. Stimulation with RAGE ligands resulted in activation of non-DM monocytes and inhibition of VEGFR1-mediated chemotaxis. The elevated baseline phosphorylation/activation of Akt, p38 and ERK1/2 in DM monocytes is likely causing the resistance to further stimulation with specific stimuli, such as VEGF-A, revealing a molecular explanation of the DM-related signal transduction defect.

Conclusions We propose that elevated RAGE expression and increased oxidative stress in diabetic Mo lead to activation of VEGFR-1-related signaling pathways and to desensitization of VEGFR-1 responses. These data establish VEGF resistance as a novel molecular concept for DM-related cellular dysfunction. 


\section{Introduction}

Growth factors are potent and crucial mediators of vascular growth processes including angiogenesis and arteriogenesis. ${ }^{1,2}$ Both processes can enhance regional blood flow and restore impaired tissue function. Monocytes contribute to arteriogenesis by recruitment to the growing vessel wall. ${ }^{3-5}$ Moreover, angiogenesis is monocyte-dependent in the context of wound healing. ${ }^{6}$

The family of vascular endothelial growth factor (VEGF) and its receptors (VEGFR) are mediators of angiogenesis and arteriogenesis, both in embryonic development and adult life. ${ }^{1,4,7}$ VEGFR-2 mediates crucial functions of endothelial cells such as proliferation, migration, NO synthase upregulation, NO-release and survival. ${ }^{8-10}$ However, the role of VEGFR-1 in endothelial cells is less clear, although it can cross-talk with VEGFR-2, which is required for maximal activation of VEGFR-2. ${ }^{11,12}$ The proven function of VEGFR-1 in adult life is its chemotactic action on monocytes and macrophages. ${ }^{13-15}$ Likewise, cytokine (TNF- $\alpha$ and IL-1 $\beta$ ) and chemokine (MCP-1, IL-8 and MIP-1 $\beta$ ) gene expression as well as chemotaxis are VEGFR-1-dependent in the monocytic cell line THP-1. ${ }^{16}$

Among cardiovascular risk factors, diabetes mellitus (DM) is the most important one that negatively affects vascular cell function, the integrity of the arterial wall as well as the growth of new vessels. ${ }^{17}$ The development and function of coronary collateral vessels is significantly reduced in patients with DM. ${ }^{18}$ The reduced collateral growth in diabetic individuals corresponds with a significantly altered chemotactic response of monocytes to VEGF-A ex vivo (VEGF resistance) ${ }^{19}$ which is associated with impaired arteriogenesis. An intracellular signal transduction defect downstream from VEGFR-1 was suggested as the cause of the impaired monocytic response, although the tyrosine kinase function of VEGFR-1 remained intact in monocytes derived from diabetic individuals. ${ }^{19}$

DM-associated hyperglycemia is a risk factor for both micro- and macrovascular complications. ${ }^{20}$ Persisting hyperglycemia can cause long-term alterations in cellular biochemistry by inducing production of reactive oxygen species (ROS) and excessive formation of advanced glycation end products (AGEs). ${ }^{17}$ These glucose-induced biochemical alterations adversely affect cellular function by altering various signal transduction pathways. The underlying molecular basis remains largely unclear, however they are likely to be the result of negative pathological alterations including oxidative stress $\left(\right.$ reviewed in ${ }^{17}$ ). 
Monocyte chemotaxis in response to ligand-induced VEGFR-1 activation is mediated by distinct signal transduction pathways ${ }^{15}$ involving PI3K/Akt or mitogen-activated protein kinases p38 and ERK1/2. The activation of these pathways is initiated by upstream kinases such as the VEGFR-1 tyrosine kinase, while their inactivation occurs as a result of functional counteraction by protein tyrosine phosphatases (PTPs). This reflects a balance between tyrosine kinases and PTPs. ${ }^{21,22}$

In the present study we show for the first time that monocytes from DM individuals display an increased baseline activation of VEGFR-1-related signal transduction pathways. As a consequence, VEGFR-1 ligands PlGF-1 and VEGF-A are unable to further stimulate both activation and migration of monocytes from DM subjects. Oxidative stress in vitro causes increased baseline tyrosine phosphorylation in monocytes. Furthermore, oxidative stress is capable of inducing oxidative modifications of PTPs in monocytes from DM individuals resulting in the inhibition of PTPs. These DM-related signaling defects represent a molecular basis for DM-related VEGF resistance of monocytes.

\section{Materials and Methods}

\section{Reagents}

Recombinant human VEGF-A ${ }_{165}$ was kindly provided by Denis Gospodarowicz (Chiron, Emeryville, CA, USA), PIGF-1 and VEGFR-1 antibody were obtained from RELIATech $\mathrm{GmbH}$ (Braunschweig; Germany) and formylMetLeuPhe (fMLP) was from Sigma-Aldrich (Saint Louis, Missouri; USA). Antibodies recognizing phosphorylated Akt (Ser473), ERK1/2 (Thr202/Tyr204) and p38 (Thr180/Tyr182) were from New England BioLabs/Cell Signaling (Beverly, MA; USA) and an anti-p38 kinase antibody was from BD Biosciences Pharmingen (Franklin Lakes, NJ, USA). Anti-RAGE antibody was from Chemicon (Temecula, CA, USA). Secondary horseradish peroxidaseconjugated goat anti-mouse, goat anti-rabbit and donkey anti-goat antibodies were from Santa Cruz Biotechnology Inc. (Santa Cruz, CA, USA). RPMI 1640 medium was purchased from Invitrogen (Karlsruhe; Germany). Fetal calf serum (FCS) was from Biochrom AG (Berlin, Germany). Western blot stripping buffer was from Pierce (Rochford, IL, USA). S100b and $\mathrm{bpV}(\mathrm{phen})$ were from Calbiochem (San Diego, CA, USA). Protein assay was from Bio-Rad Laboratories $\mathrm{GmbH}$ (Munich, Germany) and Phosphatase Assay System and Cell Titer 96 Non-Radiactive Cell Proliferation Assay from Promega (Madison, WI, USA). Percoll separation solution was from Sigma-Aldrich (Saint Louis, 
MO, USA). Primers for RAGE were purchased from Eurogentec S.A. (Seraing, Belgium).

\section{Characterization of patient groups}

The present study conforms to the principles of the Declaration of Helsinki. The study protocol was approved by the Ethical Committee of the University Hospital of Maastricht (The Netherlands). Patients with DM type 2 (DM group) and matched non-diabetic individuals (non-DM group) were studied (Table 1). Patients with underlying inflammatory or malignant disease were excluded from the study. The two study groups showed similar characteristics and significantly differed only with regard to the use of calcium antagonists and statins and history of myocardial infarction. Informed consent was obtained according to the requirements of the local ethical committee.

Table 1. Characteristics of the study population

\begin{tabular}{|l|c|c|c|}
\hline & non-DM & DM & $\mathrm{p}$ \\
\hline $\mathrm{n}$ & 17 & 17 & $\mathrm{n} . \mathrm{s}$. \\
\hline Age (years) & $65.0(56.0-73.0)^{*}$ & $74.0(61.0-77.5)$ & 0.270 \\
\hline Sex (male/female) & $9 / 8$ & $10 / 7$ & 0.734 \\
\hline BMI $\left(\mathrm{kg} / \mathrm{m}^{2}\right)$ & $26.5(24.0-30.75)$ & $27.0(25.0-29.0)$ & 0.911 \\
\hline HbA1c (\%) & n.d. & $6.2(6.9-8.1)$ & - \\
\hline Glucose (mmol/L) (\#) & $5.4(4.7-5.7)$ & $8.6(7.7-11.1)$ & 0.001 \\
\hline Insulin (mU/L) (\#) & $6.7(6.0-16.5)$ & $28.2(10.5-49.8)$ & 0.006 \\
\hline C-peptide (nmol/L) (\#) & $0.94(0.74-1.36)$ & $1.22(0.95-1.65)$ & 0.218 \\
\hline Medications: & & & \\
\hline ACE inhibitors & 6 & 5 & 0.718 \\
\hline AT-II receptor antagonists & 3 & 1 & 0.294 \\
\hline Diuretics & 3 & 5 & 0.426 \\
\hline$\beta$-blockers & 16 & 13 & 0.152 \\
\hline Ca-channel blockers & 3 & 10 & 0.015 \\
\hline Glycosides & 2 & 0 & 0.151 \\
\hline Statins & 8 & 16 & 0.003 \\
\hline Nitrates (long-acting) & 5 & $11 / 6$ & $0.307 / 0.037$ \\
\hline Smoking (present/history) & $2 / 8$ & & 0.297 \\
\hline $\begin{array}{l}\text { Coronary artery disease (stable/ } \\
\text { history of myocardial infarction) }\end{array}$ & $8 / 1$ & & $0.551 / 0.735$ \\
\hline
\end{tabular}

*- Data are presented as median $\left(25^{\text {th }}-75^{\text {th }}\right.$ percentiles $)$ where applicable;

\# - Parameters measured at the time of blood sampling 
Patient enrolment into the study was performed in pairs, i.e. on each occasion an individual from non-DM group was recruited together with an individual from DM group. The subsequent handling of samples was performed in parallel.

\section{Isolation of monocytes from peripheral venous blood}

Monocytes were isolated from $100 \mathrm{~mL}$ of heparinized venous blood samples as described. ${ }^{19}$ The purity of the extracted monocytes was determined by analysis with a fluorescence-activated cell sorter using an antibody recognizing CD14. The vitality of the isolated monocytes was assessed by trypan blue exclusion and was generally above $95 \%$.

\section{Isolation of monocytes from buffy coats}

For the experiments with $\mathrm{H}_{2} \mathrm{O}_{2}, \mathrm{~S} 100 \mathrm{~b}$, and $\mathrm{bpV}$ (phen) monocytes were isolated from buffy coats. The isolation was performed as described above.

\section{Analysis of reversible PTP oxidation with 'modified in-gel assay'}

The protocol was adopted from Markova et al. ${ }^{23}$ In brief, monocytes $\left(5 \times 10^{6}\right.$ cells/assay) were isolated either from blood of DM and non-DM individuals or from buffy coats (as indicated). In the experiments with $\mathrm{H}_{2} \mathrm{O}_{2}$, monocytes were incubated with appropriate concentrations of $\mathrm{H}_{2} \mathrm{O}_{2}$ and for indicated time periods. Moncytes were first washed two times with overnight degassed icecold PBS and then lysed in ice-cold buffer (degassed overnight) containing 50 $\mathrm{mmol} / \mathrm{L}$ Hepes, $\mathrm{pH} 7.4,150 \mathrm{mmol} / \mathrm{L} \mathrm{NaCl}, 0.5 \%$ Nonidet P40, $1 \mathrm{mmol} / \mathrm{L}$ EDTA, $2 \mathrm{mM}$ EGTA, $20 \mu \mathrm{g} / \mathrm{mL}$ leupeptin, $1 \mu \mathrm{g} / \mathrm{mL}$ pepstatin, $200 \mathrm{KIE} / \mathrm{mL}$ aprotinin, and $1 \mathrm{mmol} / \mathrm{L}$ PMSF (protease inhibitors are added freshly). To detect reversibly oxidized PTPs, lysis was performed in the presence of 150 $\mathrm{mmol} / \mathrm{L}$ sodium iodoacetate ('modified in-gel assay'), similarly as described by Meng et al. ${ }^{24}$ Cell lysates were centrifuged at $13000 \mathrm{rpm}$ for 15 minutes and aliquots of supernatant containing equal amount of protein were resolved on $10 \%$ SDS-PAGE containing ${ }^{32} \mathrm{P}-$-labeled poly(Glu4Tyr) $2 \times 10^{5} \mathrm{CPM} / \mathrm{mL}$ gel. Gels were treated as described ${ }^{2}$ and imaging was performed by exposure to high sensitivity films using an intensifying screen at $-80^{\circ} \mathrm{C}$. Images were scanned and analyzed using LAS-3000 software (Fuji Photo Film Co).

\section{Analysis of PTP activity}

PTP activity was evaluated using Tyrosine Phosphatase Assay System (Promega). Monocytes were lysed using ice-cold buffer (degassed overnight) as above. After removal of insoluble debris, lysates were eluted through Sephadex G-25 to remove free phosphate. $2 \mu \mathrm{g}$ of total protein from each sample was used 
to measure overall PTP activity following the manufacturer's instructions. Measured absorbance was converted into amount of free phosphate after subtraction of corresponding control (lysate without addition of labeled substrate).

$300 \mu \mathrm{g}$ of total protein from each sample was used for PTP1B immunoprecipitation. First, lysates were pre-cleared with $25 \%$ anti-mouse IgGAgarose. Subsequently, lysates were incubated with PTP1B antibody overnight followed by 2 hour incubation with 25\% anti-mouse IgG-Agarose. Assay was performed with the imuunoprecipitates. Measured absorbance was converted into amount of free phosphate after subtraction of corresponding control (lysate after immunoprecipitation with omitted primary antibody without addition of labeled substrate).

\section{Monocyte chemotaxis}

Chemotaxis of freshly isolated monocytes was performed as described. ${ }^{15}$

\section{Flow cytometry analysis}

The analysis was accomplished on a FACSCalibur flow-cytometer using the CellQuest software (Becton Dickinson). $100 \mu \mathrm{L}$ of heparinized was used for staining. Staining with peridinin-chlorophyll-protein (PerCp)-conjugated antiCD14 antibodies was used to define monocyte population. Staining for RAGE was performed subsequently following cell permeabilization with Triton X-100. Specific fluorescein isothiocyanate (FITC)-conjugated secondary antibodies were subsequently applied.

For VEGFR-1 expression, isolated CD14+ monocytes were stained with VEGFR-1 antibody. Specific fluorescein isothiocyanate (FITC)-conjugated secondary antibodies were subsequently applied.

\section{RT-PCR analysis of RAGE mRNA splice variants}

Total RNA was isolated with the RNeasy Mini Kit (Qiagen). First strand cDNA synthesis was performed with Omniscript reverse transcriptase (Qiagen). As a control the enzyme was omitted from the reaction. The presence of full length (F-RAGE), C-truncated (C-RAGE) and N-truncated (N-RAGE) RAGE splice variants was detected using the primers and PCR conditions as reported. ${ }^{25}$

\section{Western blot analysis of RAGE protein expression}

Isolated monocytes $\left(5 \times 10^{6}\right.$ cells/assay) were centrifuged $\left(5000 \mathrm{rpm}, 4^{\circ} \mathrm{C}\right)$, washed with ice-cold PBS, pH 7.4 and subsequently solubilized in ice-cold lysis buffer $(20 \mathrm{mmol} / \mathrm{L}$ Tris-HCl, $\mathrm{pH} 7.4 ; 150 \mathrm{mmol} / \mathrm{L} \mathrm{NaCl} ; 10$ mmol/L EDTA, 
$10 \%$ glycerol, $1 \%$ Trasylol (Bayer AG), $1 \mathrm{mmol} / \mathrm{L}$ phenylmethylsulfonyl fluorid; $1 \%$ Triton X-100. Cell lysates were centrifuged at $13000 \mathrm{rpm}$ for 15 minutes and the protein concentration was estimated in the supernatant using the Bio-Rad protein assay.

Supernatants containing equal amounts of protein were heated in $\beta$ mercaptoethanol-containing sample buffer at $96^{\circ} \mathrm{C}$ for 5 minutes, and resolved using 7.5\% sodium dodecylsulphate polyacrylamide gel electrophoresis (SDSPAGE) followed by a transfer onto nitrocellulose membranes (Amersham). Membranes were blocked with 5\% semi-dry milk solution and incubated with specific primary antibodies. Antibodies recognizing human RAGE were used at a dilution of 1:8000. Horseradish peroxidase-conjugated secondary antibodies were added, and the specific proteins were detected using Supersignal chemiluminescence substrate (Thermo Fischer). The intensity of bands was quantified by scanning with a LAS documentation system (Fuji Photo Film).

\section{Western blot analysis and immunostaining for Akt, p38 and ERK1/2}

Western blot analysis was performed as previously described. ${ }^{15}$

\section{Statistical analysis}

Statistical analysis was performed using SPSS 12.0.1 software. The probability of differences between samples was evaluated using Kruskal-Wallis test. Wilcoxon signed-rank test was used for intragroup analysis, and the MannWitney test was used for intergroup analysis. Differences with $p<0.05$ are considered significant.

\section{Results}

\section{Elevated baseline phosphorylation of signalling molecules in DM}

We compared the activation and phosphorylation of distinct VEGFR-1-related signalling pathways in monocytes from diabetic and non-diabetic individuals (Table 1). Stimulation of monocytes from non-DM individuals with either PIGF-1 or VEGF-A resulted in a significant increase in phosphorylation of Akt (1.53-fold and 2.54-fold, respectively; Fig. 1A, C), ERK1 (2.13-fold and 2.26fold, respectively; Fig. 1A, E), and p38 (1.51-fold and 1.8-fold, respectively; Fig. 1A, D) as compared to baseline control values. Rather unexpectedly, DM monocytes did not respond to the stimulation with PlGF-1 or VEGF-A, as these ligands could not stimulate phosphorylation of Akt, ERK1 or p38; their phosphorylation level remained at the level of the baseline controls in DM monocytes (Fig. 1A). 


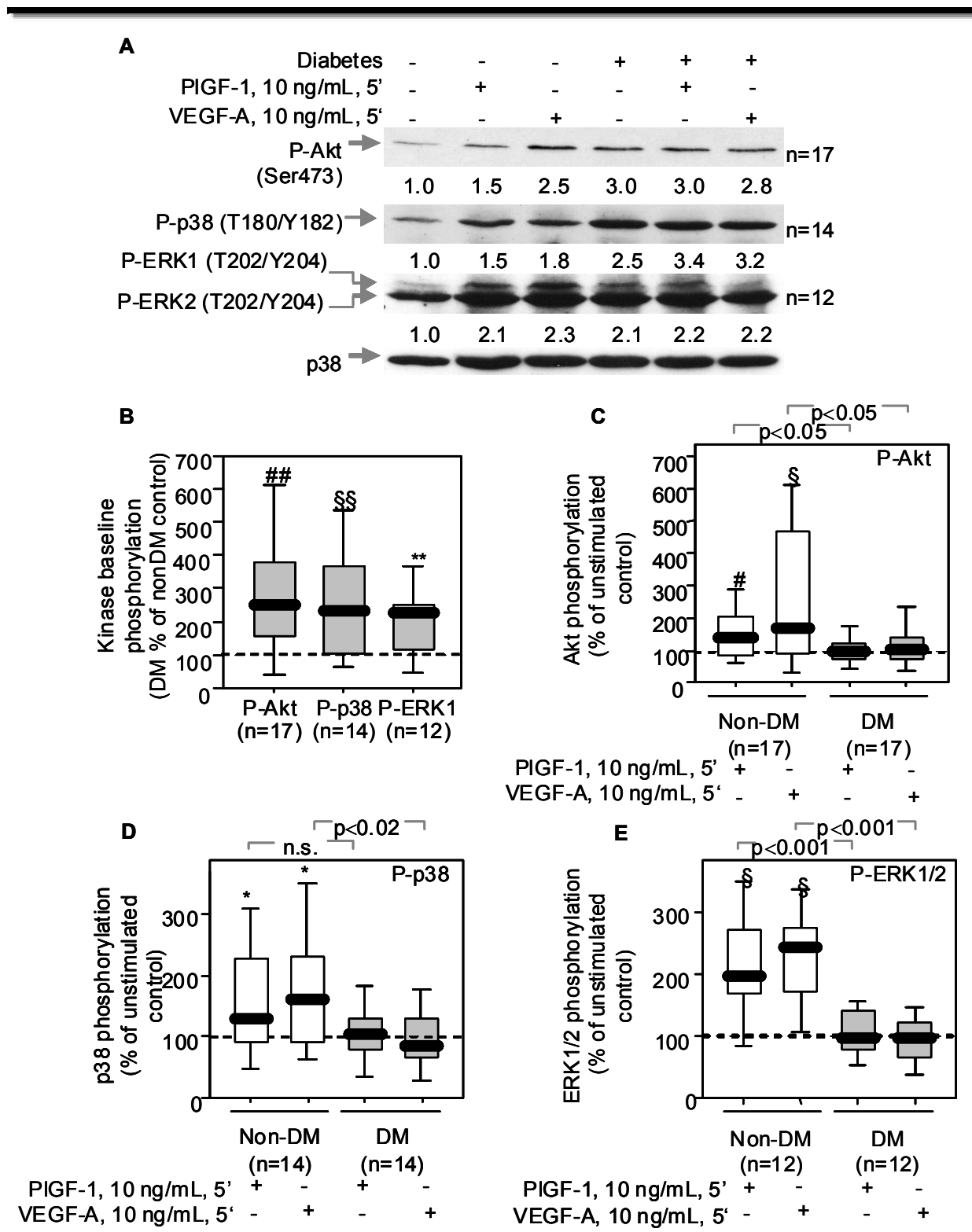

Figure 1. Baseline and PlGF-1- and VEGF-A-induced kinase phosphorylation in non-diabetic and diabetic. A-E, Enzyme phosphorylation in monocytes after stimulation with P1GF-1 or VEGF-A. A, Representative blots. Numbers below the corresponding blots represent the mean. B, Kinase baseline phosphorylation in diabetic monocytes as compared to corresponding baseline phosphorylation in non-diabetic monocytes (refered as 100\%-dashed line); Mann-Withney test was used for intergroup comparison $(* *-p<0.02, \S \S-\mathrm{p}<0.01$, \#\#-p<0.001 as compared to nondiabetic baseline). C-E, P1GF-1- and VEGF-A-induced phosphorylation of Akt (C), p38 (D) and ERK1/2 (E). Data presented as percentage of stimulation as compared to corresponding unstimulated control (refered as $100 \%$-dashed line). Mann-Withney test was used for intergroup comparison (ligand-induced kinase phosphorylation, diabetic vs. non-diabetic); Wilcoxon test for intragroup comparison $(*-p<0.05, \#-p<0.02, \S-p<0.01$ as compared to non-diabetic baseline). 
However, baseline values of Akt, ERK1 and p38 phosphorylation were significantly higher in the DM group compared to the non-DM group (Fig. 1A, B): Akt baseline phosphorylation in DM was 2.95-fold higher than Akt baseline (referred to as $100 \%$ ) phosphorylation in non-DM, while ERK1 showed a 2.06fold and p38 a 2.51-fold increase in DM. Of note, these elevated baseline phosphorylation levels in DM monocytes were at, or even above, the levels reached for P1GF-1- or VEGF-A-induced phosphorylation of Akt, ERK1 or p38 in non-DM monocytes.

PlGF-1 stimulated chemotaxis of monocytes from non-DM, but not from DM individuals (Fig. 2A) while fMLP led to a comparable stimulation of chemotaxis from both non-DM and DM individuals (Fig. 2B). VEGFR-1 expression on monocytes did not differ between non-DM and DM individuals (Fig. 2C).
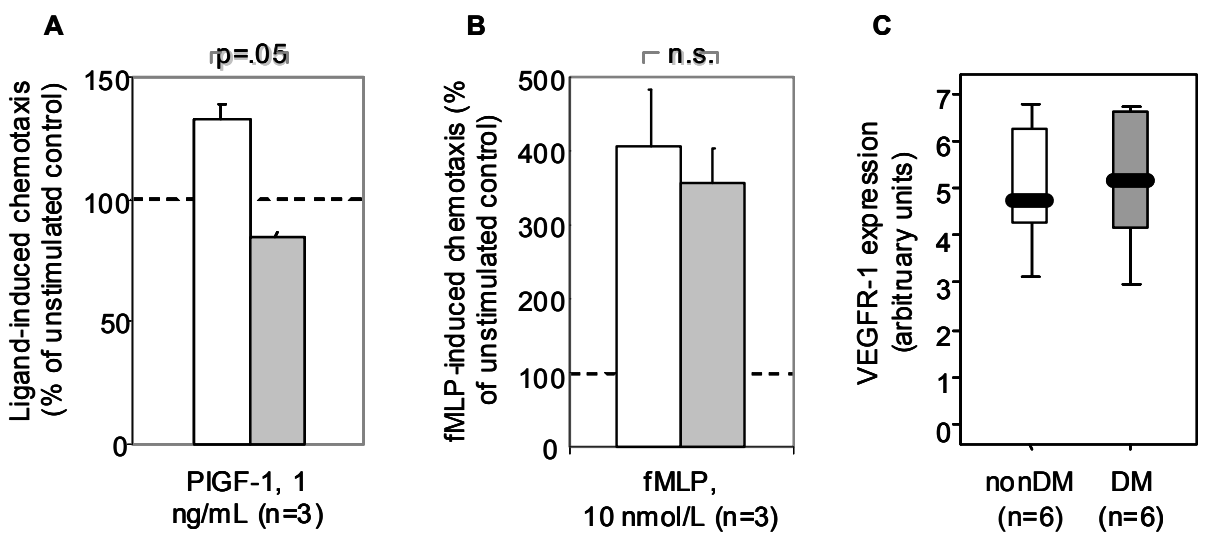

Figure 2. Chemotaxis and VEGFR-1 expression of diabetic and non-diabetic monocytes. A, B monocyte chemotaxis; open bar - non-diabetic monocytes, grey bar - diabetic monocytes, data presented as percentage of ligand-induced chemotaxis as compared to corresponding unstimulated control (chemokinesis, referred to as 100\%-dashed line). B. VEGFR-1 expression given as ratio (arbitruary units) between mean fluorescence of specific detection (open curve) and staining with the secondary antibody only (filled curve) calculated for each individual (for details: Supplement Fig. 1).

The level of baseline activation/phosphorylation in DM individuals correlated with the HbAlc level. When DM individuals were split into 2 groups, i.e. with $\mathrm{HbA} 1 \mathrm{c}$ levels above and below the median value (6.9\%), ERK1/2 baseline phosphorylation was significantly higher in the subgroup with $\mathrm{HbA1c}$ levels above the median $(p<0.05$, Fig. 3C). Baseline phosphorylation of neither Akt ( $\mathrm{p}=0.165$, Fig. $3 \mathrm{~A})$ nor $\mathrm{p} 38$ ( $\mathrm{p}=0.465$, Fig. 3B) showed any significant differences between the 2 subgroups. 
A

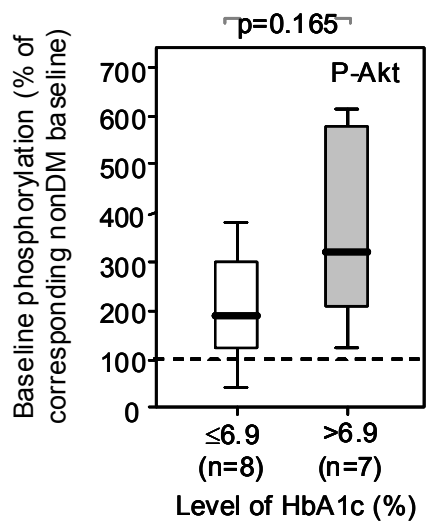

C

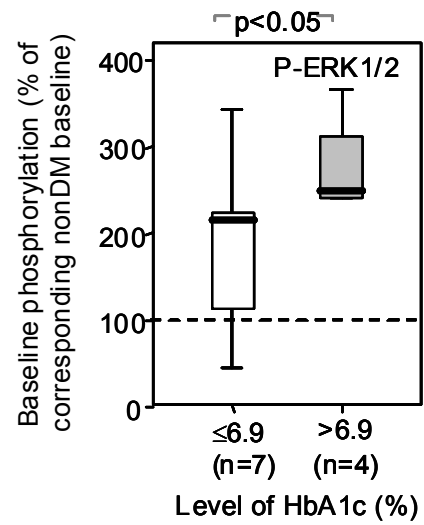

B

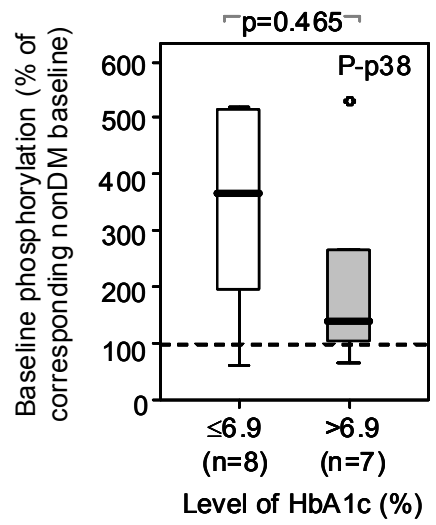

Figure 3. Baseline Akt (A), $p 38$ (B) and ERK1/2 (C) phosphorylation in primary human monocytes from diabetic individuals: relation to HbAlc plasma level. Baseline phosphorylation of Akt, p38, and ERK1/2 in monocytes from diabetic individuals is presented as percentage of a corresponding baseline phosphorylation in monocytes from non-diabetic individuals $(100 \%$ baseline level, dashed line).

Is this DM-related defect specific for VEGFR-1-mediated signals? This seems to be the case - at least to some extent. fMLP, which induces monocyte migration in both non-DM as well as DM monocytes (Fig. 1B and ${ }^{19}$ ), was capable of inducing significant activation of several signalling molecules in cells from both non-DM and DM individuals. fMLP stimulation increased Akt phosphorylation 6.97-fold in non-DM and 7.27-fold in DM (Fig. 4A, B), p38 phosphorylation increased to 4.72-fold in non-DM and to 2.58-fold in DM (Fig. 4A, C), while ERK1 phosphorylation increased 7.72-fold in non-DM and 3.04fold in DM monocytes (Fig. 4A, D). The magnitude of fMLP-induced phosphorylation was not significantly different between non-DM and DM monocytes (Fig. 4B-D). fMLP was readily able to induce phosphorylation of Akt, ERK1 and p38 in DM monocytes despite the elevated baseline phosphorylation (Fig. 4A). 
A

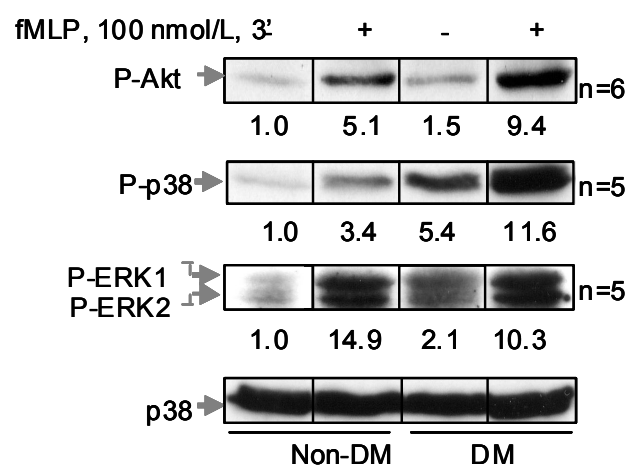

B

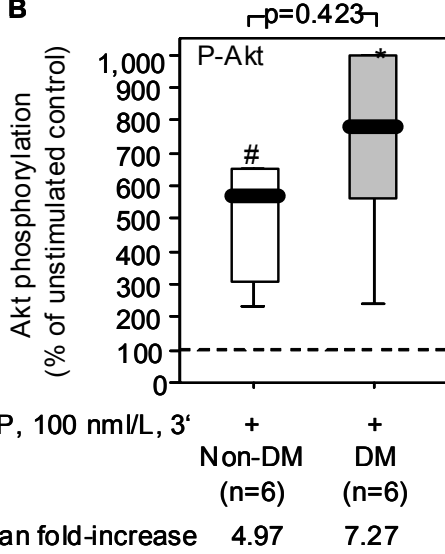

D


$\begin{array}{ccc}\mathrm{fMLP}, 100 \mathrm{nmol} / \mathrm{L}, 3^{\prime} & + & + \\ & \begin{array}{c}\text { Non-DM } \\ (\mathrm{n}=5)\end{array} & \begin{array}{c}\mathrm{DM} \\ (\mathrm{n}=5)\end{array} \\ \text { Mean fold-increase } & 7.72 & 3.04\end{array}$

Figure 4. $f M L P$-induced phosphorylation of Akt (A), p38 (B) and ERK1/2 (C) in primary human monocytes from non-diabetic and diabetic individuals. A-D, Enzyme phosphorylation in monocytes after stimulation with fMLP. A, Representative blots. Numbers below the corresponding blots represent the mean. B-D, fMLP-induced phosphorylation of Akt (B), p38 (C) and ERK1/2 (D) in monocytes from non-diabetic and diabetic individuals. Data presented as percentage of stimulation as compared to corresponding unstimulated control (referred as $100 \%$ dashed line). Mann-Withney test was used for intergroup comparison; Wilcoxon test was used for intragroup comparison (\#-p $<0.05$ as compared to unstimulated non-diabetic control, ${ }^{*}$-p $<0.05$ as compared to unstimulated diabetic control).

\section{Increased oxidation of PTPs in monocytes from DM individuals in vivo and under oxidative stress in vitro}

Monocytes from DM individuals showed increased levels of reversible PTP oxidation, when compared to non-DM monocytes in the 'modified in-gel assay' (Fig. 5A). This is reflected by a higher PTP activity of certain PTP species (indicated in Fig. 5A) in DM monocytes recovered in the presence of sodium iodoacetate (IAA). The identity of these PTPs remains to be established. These data clearly indicate a DM-related deregulation and oxidation of PTPs. 
Incubation of non-DM monocytes with $\mathrm{H}_{2} \mathrm{O}_{2}$ caused oxidative stress in vitro. Increasing $\mathrm{H}_{2} \mathrm{O}_{2}$ concentrations augmented reversible oxidative modifications of PTPs (Fig. 5B).

A



$\begin{array}{lllll}1.0 & 1.7 & 1.0 & 1.4 \quad \text { 4,Overall activity" }\end{array}$

C

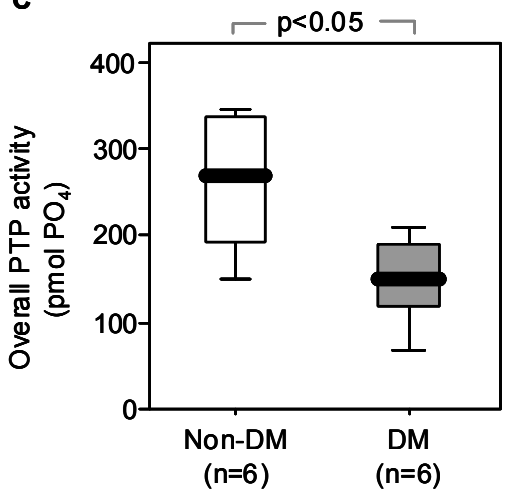

\section{B}

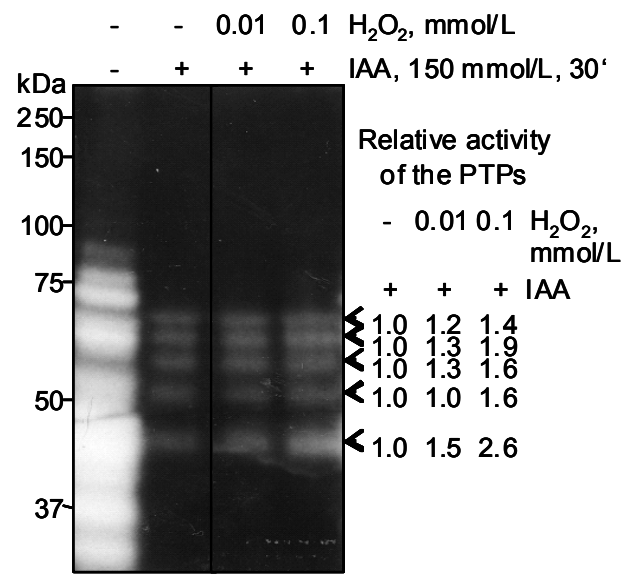

D

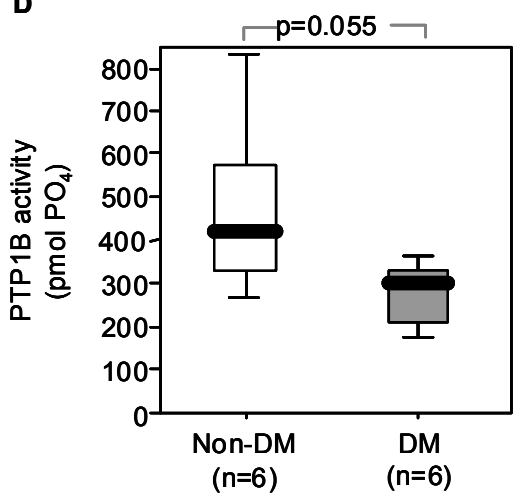

Figure 5. Effect of DM and oxidative stress in vitro on PTP oxidation and activity in monocytes. A, 'Modified in-gel assay' with monocyte lysates from non-diabetic (C1, C2) and diabetic (D1, D2) individuals. PTPs were visualized as activity (white) bands after renaturation. Quantification of signals is shown on the right of the autoradiogram. B, 'Modified in-gel assay' with lysates of monocytes exposed to $\mathrm{H}_{2} \mathrm{O}_{2}$ in vitro. C. Overall activity of PTPs in monocytes from non-diabetic and diabetic individuals. Samples measured in duplicates. PTP activity is shown as amount of free phosphate generated. D. Activity of PTP1B in monocytes from non-diabetic and diabetic individuals. PTP1B immunoprecipitation was followed by the PTP activity assay as in panel A.

\section{PTP activity is reduced in DM monocytes}

Monocytes from DM individuals showed a significantly decreased overall PTP activity as compared to non-DM monocytes. This was measured by the release 
of free phosphate from a pre-labelled substrate (Fig. 5C). Likewise, the specific PTP1B activity tended to be reduced in DM monocytes (Fig. 5D) compared to their non-DM counterparts.

\section{PTP inhibition in monocytes in vitro results in activation of kinases and inhibition of motility}

Incubation of monocytes from non-DM individuals with the PTP inhibitor $\mathrm{bpV}$ (phen) led to a strong activation of ERK1/2 (Fig. 6A) in a time- and dosedependent manner. P38 activation appeared in a somewhat delayed fashion. Increased Akt phosphorylation was only observed at higher PTP inhibitor concentration.

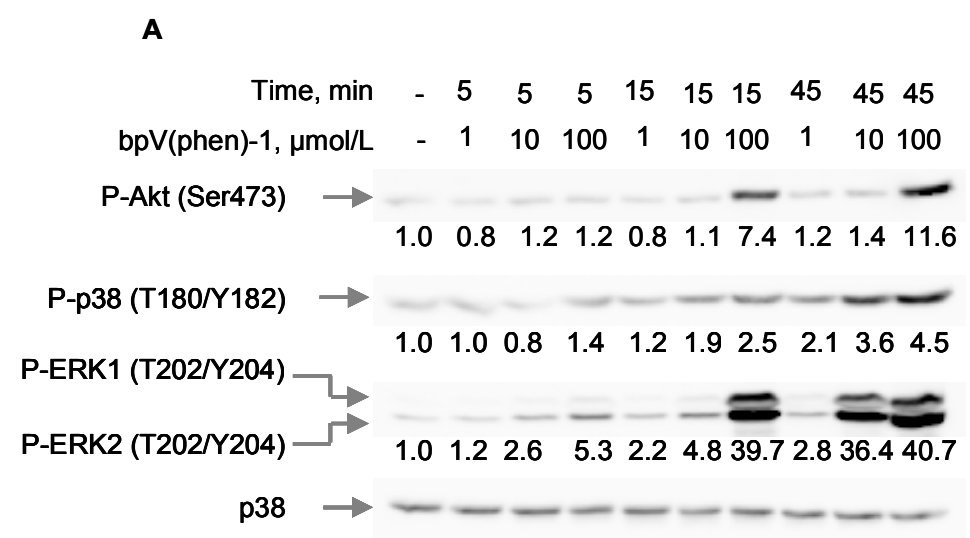

B

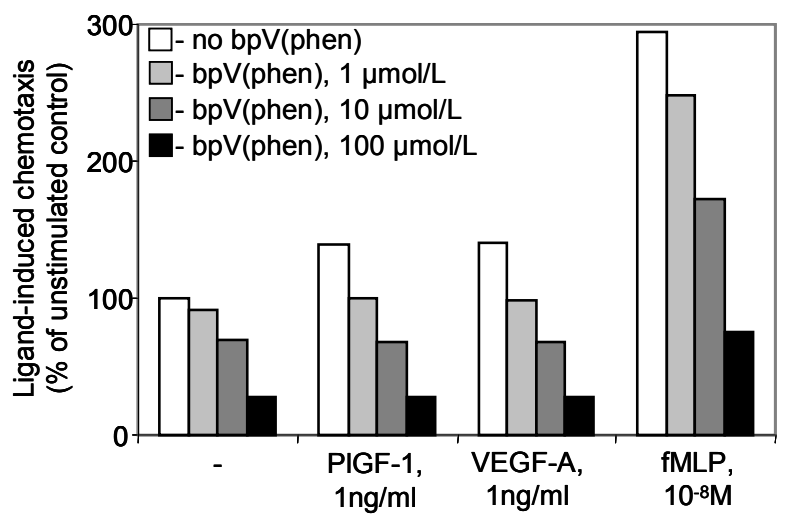

Figure 6. Effect of PTP inhibition on kinase phosphorylation in monocytes and on monocyte motility. A, Phosphorylation of Akt, ERK1/2 and p38 were assessed following monocyte incubation with $\mathrm{bpV}(\mathrm{phen})$ as indicated. $\mathrm{B}$, Monocytes were pre-incubated with $\mathrm{bpV}(\mathrm{phen})$ at 1 $\mu \mathrm{mol} / \mathrm{L}$ (light grey bars), $10 \mu \mathrm{mol} / \mathrm{L}$ (dark grey bars), or $100 \mu \mathrm{mol} / \mathrm{L}$ (black bars) or left untreated (open bars). Monocyte chemotaxis assay was performed thereafter. Results of 2 independent experiments. 
We preincubated monocytes from non-DM individuals with different concentrations of $\mathrm{bpV}(\mathrm{phen})$ and analyzed their chemotactic responses to PlGF1, VEGF-A or fMLP (Fig. 6B). The PTP inhibitor caused a dose-dependent decrease in chemokinesis and chemotaxis towards PIGF-1 and VEGF-A. Therefore, the biochemical and functional consequences of $\mathrm{bpV}$ (phen) pretreatment are similar to the ones detected in DM monocytes.

\section{Oxidative stress activates monocyte signalling}

Incubation of non-DM monocytes with $\mathrm{H}_{2} \mathrm{O}_{2}$ in vitro resulted in a strong, although distinct, increase in phosphorylation of Akt, p38 and ERK1/2 (Fig. 7).

Both $0.1 \mathrm{mmol} / \mathrm{L}$ and $1 \mathrm{mmol} / \mathrm{L}$ of $\mathrm{H}_{2} \mathrm{O}_{2}$ caused phosphorylation of Akt, p38 and ERK1/2 after already $1 \mathrm{~min}$ of incubation (Fig. 7A). The level of ERK1/2 phosphorylation further tremendously increased after 5 and $25 \mathrm{~min}$, whereas Akt phosphorylation reached a maximum following 5 min incubation with $\mathrm{H}_{2} \mathrm{O}_{2}$. Prolonged 25 min incubation resulted in an additional increase of ERK1/2 phosphorylation. The $\mathrm{H}_{2} \mathrm{O}_{2}$-induced phosphorylation of $\mathrm{p} 38$ reached its maximum level earlier, i.e. after $1 \mathrm{~min}$ of incubation (Fig. 7A).

To directly compare the effect of different concentrations of $\mathrm{H}_{2} \mathrm{O}_{2}$ on enzyme phosphorylation, a 5 min incubation period was used (Fig. 7B). Akt phosphorylation was already increased at $0.001 \mathrm{mmol} / \mathrm{L}$ of $\mathrm{H}_{2} \mathrm{O}_{2}$, reaching its maximum at $1 \mathrm{mmol} / \mathrm{L}$. Phosphorylation of ERK2 greatly increased at 0.1-1 $\mathrm{mmol} / \mathrm{L}$ of $\mathrm{H}_{2} \mathrm{O}_{2}$. A similar pattern was observed for ERK1 with a slight initial increase at $0.01 \mathrm{mmol} / \mathrm{L}$ of $\mathrm{H}_{2} \mathrm{O}_{2}$. Phosphorylation of $\mathrm{p} 38$ rose drastically over the unstimulated level at a concentration of $0.1 \mathrm{mmol} / \mathrm{L}$ of $\mathrm{H}_{2} \mathrm{O}_{2}$, with further increase at $1 \mathrm{mmol} / \mathrm{L}$.

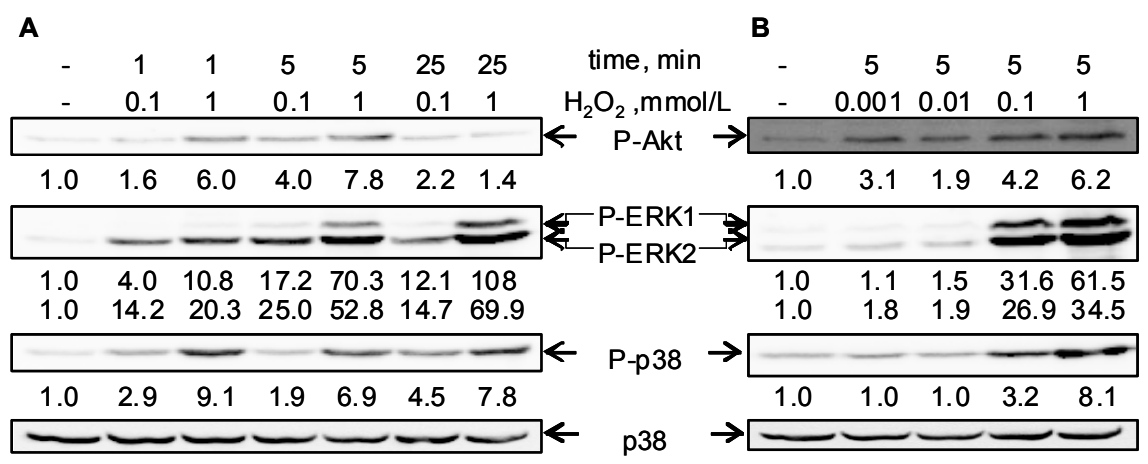

Figure 7. Effect of oxidative stress in vitro $\left(\mathrm{H}_{2} \mathrm{O}_{2}\right.$ treatment) on activation of signal transduction molecules in primary human monocytes. Monocytes were isolated from buffy coat. Monocytes were treated with 2 different concentrations of $\mathrm{H}_{2} \mathrm{O}_{2}$ for different time periods (time course, A) or for 5 minutes with different concentrations of $\mathrm{H}_{2} \mathrm{O}_{2}$ (dose response, B). Data shown are representative of two independent experiments. 


\section{RAGE is expressed in monocytes and mediates monocyte activation}

Do primary monocytes express RAGE, the functional receptor for different $\mathrm{AGEs}^{26}$ ? We addressed this important question. Monocytes from non-DM individuals expressed full RAGE as well as both C-truncated and N-truncated RAGE splice variants (Fig. 8A). Furthermore, primer sets designed to specifically amplify multiple splice variants (full length and N-truncated or full length and $\mathrm{N}$ - and C-truncated) generated the expected amplicons (Fig. 8A).

A

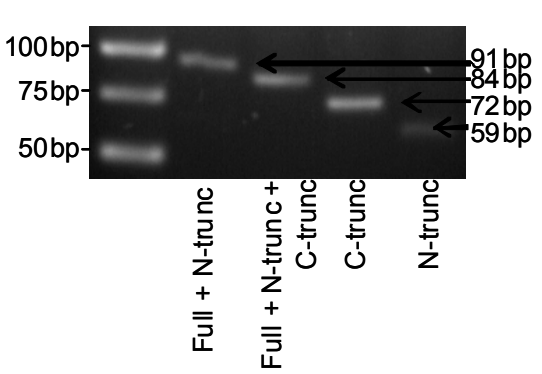

C

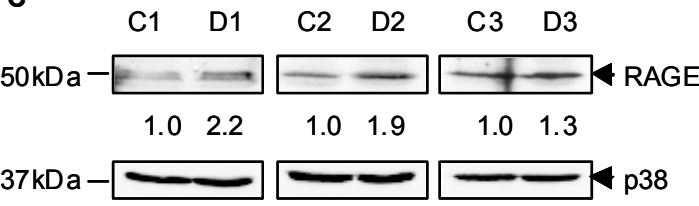

B
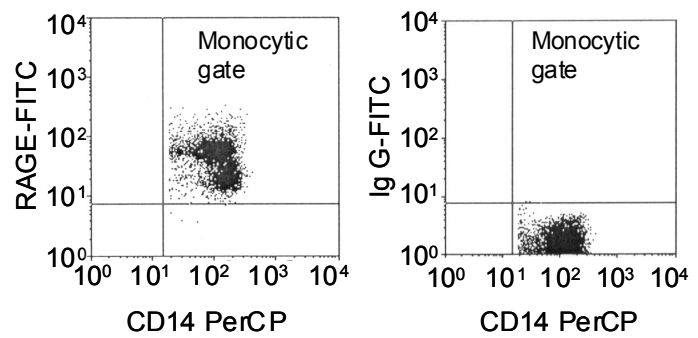

Figure 8. RAGE expression in monocytes. A, Different RAGE mRNA splice-variants in primary human monocytes. B, RAGE expression in CD14+ primary human monocytes. C, RAGE expression in non-DM (C) and DM (D) monocytes.

The presence of RAGE protein in primary human monocytes from nonDM individuals was confirmed by FACS analysis using an antibody against the C-terminus of RAGE therefore recognizing only full length and N-truncated RAGE. CD14+ monocytes expressed RAGE. Critically, two subpopulations of CD14+ monocytes could be distinguished with different levels of RAGE expression (Fig. 8B). Of note and in line with our signalling data (above), monocytes from DM individuals expressed higher levels of RAGE protein (range from 1.31- to 2.17-fold) as compared to non-DM monocytes (Fig. 8C, upper panel). Full length RAGE appeared as a $50 \mathrm{kDa}$ band (Fig. 8C) similar to the observations in primary endothelial cells and pericytes. ${ }^{27}$

Can RAGE stimulate the activation of primary monocytes? RAGE ligation with its ligand $\mathrm{S} 100 \mathrm{~b}$ at $1 \mu \mathrm{g} / \mathrm{mL}$ and $10 \mu \mathrm{g} / \mathrm{mL}$ led to the phosphorylation of Akt and ERK1/2 (Fig. 9A). Akt phosphorylation (Fig. 9A, top) was maximal at 5-15 min following RAGE stimulation, whereas ERK1/2 phosphorylation (Fig. 9A, middle) peaked after $45 \mathrm{~min}$. Phosphorylation of p38 (Fig. 9A, bottom) remained unaffected by RAGE-stimulation. 
We investigated whether RAGE activation in non-DM monocytes affects their chemotactic response. S100b $(10 \mu \mathrm{mol} / \mathrm{L})$ leads to Akt and ERK1/2 phosphorylation (Fig. 9A). Preincubation of monocytes with S100b $(10 \mu \mathrm{g} / \mathrm{mL}$, 1 hour) inhibited monocyte chemotaxis to PlGF-1 and VEGF-A, but not to fMLP (Fig. 9B). These data support the contribution of RAGE ligation in monocyte activation in DM.

A

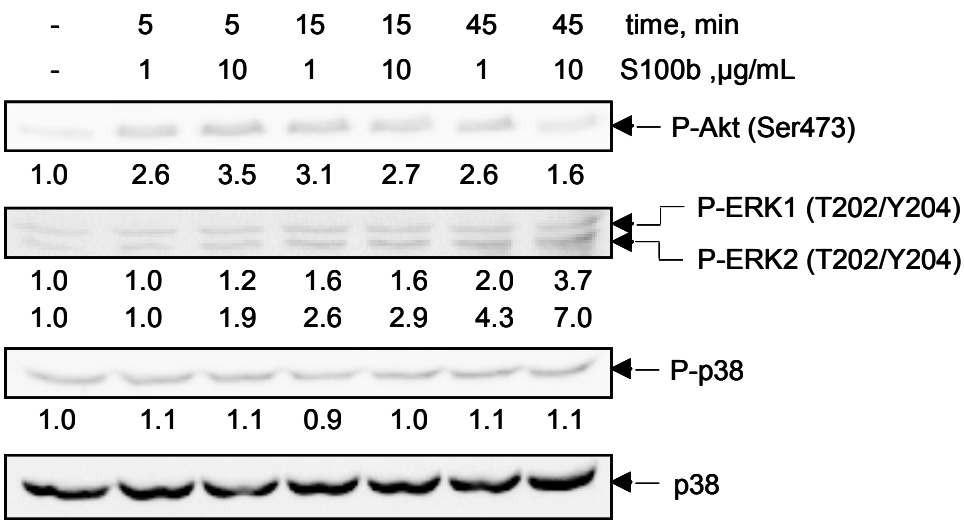

B

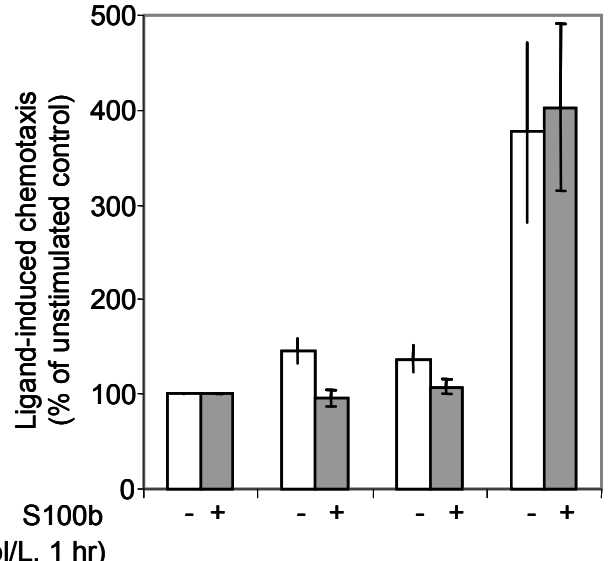

$(10 \mu \mathrm{mol} / \mathrm{L}, 1 \mathrm{hr})$

PIGF-1 VEGF-A fMLP

$1 \mathrm{ng} / \mathrm{ml} 1 \mathrm{ng} / \mathrm{ml} 10 \mathrm{nmol} / \mathrm{L}$

Figure 9. Effect of RAGE ligation on kinase activation in monocytes and monocyte chemotaxis. A, Monocytes (non-DM, buffy coat) were incubated with RAGE ligand S100b as indicated. Kinase phosphorylation was studied with Western blotting. B, Monocytes were pre-incubated with $\mathrm{S} 100 \mathrm{~b}(10 \mu \mathrm{mol} / \mathrm{L}$, 1hour; grey bars) or left untreated (open bars). Monocyte chemotaxis assay was performed thereafter. Results of 3 independent experiments, each performed in triplicate. 


\section{Discussion}

This is the first report on molecular mechanisms of growth factor signal transduction defects in primary human monocytes. This aspect is of major pathophysiological importance as monocytes have recently been established as important cellular mediators of vascular growth including arteriogenesis ${ }^{4,5}$ and wound healing. ${ }^{6}$ Moreover, monocyte dysfunction has been described in the context of DM. ${ }^{19}$ We now report that type 2 DM-related alterations of the activation of cellular signalling pathways - including Akt, p38 and ERK1/2 contribute to the observed VEGF resistance, namely the blunted monocyte responsiveness to VEGFR-1-mediated growth factor stimulation. The elevated baseline activity of these pathways in DM results in monocyte activation and refractoriness to further specific stimulation. It may be caused by $i$.) the increased production of ROS (oxidative stress), which inhibits PTPs, and/or by ii.) increased signalling via the AGE/RAGE axis. It remains to be clarified whether the two pathways operate independently or cooperate (Fig. 10).
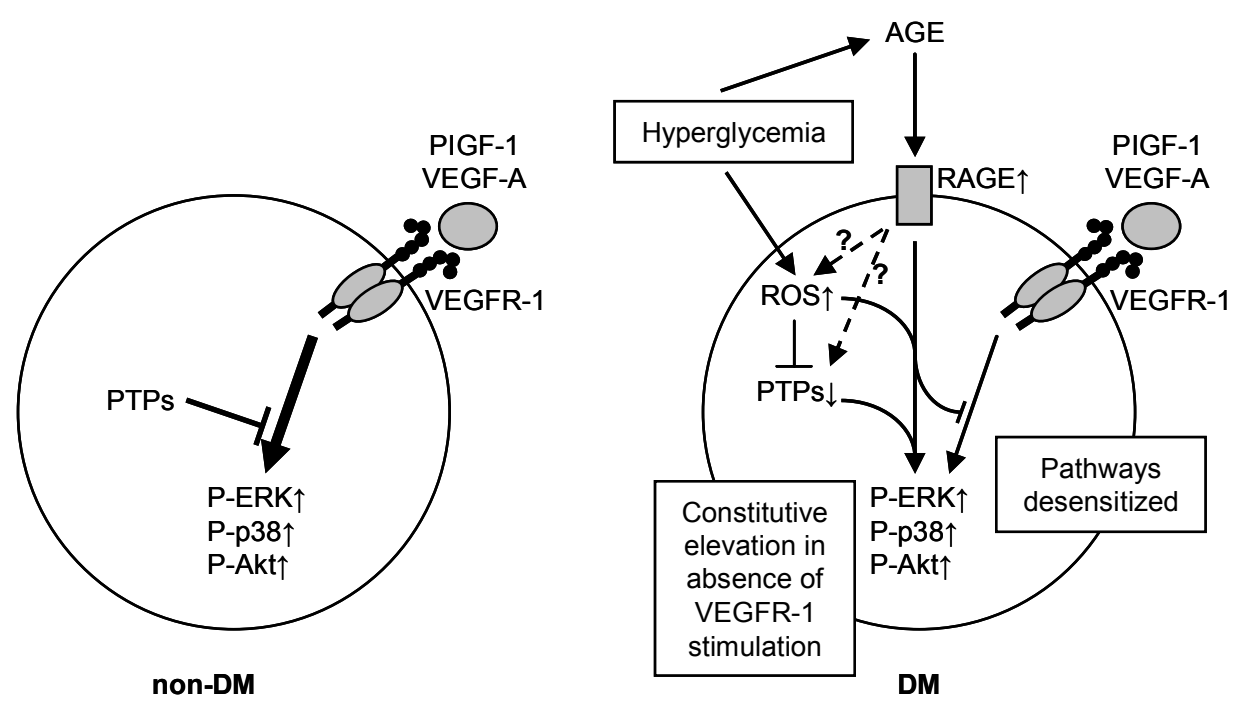

Figure 10. Mechanisms of DM-related molecular alterations in monocytes. In the absence of DM (i.e. non-DM) ligand binding of VEGFR-1 leads to the activation of distinct signaling pathways, balanced by PTPs, mediating monocyte migration (non-DM, thick black arrow). In DM, elevated RAGE expression and signaling in Mo lead to increased baseline signaling activity. Furthermore, oxidative stress (ROS) may either directly contribute to the increase in baseline signaling activity or indirectly via inhibition of PTPs. Increase in ROS is mostly attributable to hyperglycemia (solid arrow). It is possible that RAGE activation also contributes to ROS production and PTP inactivation, however, such links have yet to be established (dashed arrows). The increased baseline signaling activity results in desensitization of VEGFR1 responses (DM, thin black arrow). 
An important physiological function of monocytes is chemotaxis, i.e. their ability to migrate along gradients of growth factors and cytokines. Monocyte migration to sites of vascular growth is VEGFR-1-dependent. ${ }^{5}$ Recent evidence suggests that DM and its underlying pathophysiological mechanisms affect the function of circulating cells with angiogenic or arteriogenic potential. ${ }^{19,28,29}$ The chemotactic response of monocytes to VEGF-A ${ }^{19}$ or PlGF-1, ligands of VEGFR-1 (Fig. 2A), was completely blunted in DM monocytes, but remained intact towards the (strong) inflammatory mediator fMLP (Fig. 2B and ${ }^{19}$ ). This functional defect of DM monocytes occurs despite unaffected expression (Fig. 2C) and preserved function ${ }^{19}$ of VEGFR-1. Likewise, CD34+ cells from DM patients do not migrate in response to VEGF. ${ }^{29} \mathrm{CD} 34+$ cells derived from diabetic subjects also showed a functional migratory defect in response to stromal cell-derived factor-1 (SDF-1). Similarly, transendothelial migration of DM monocytes towards the proinflammatory chemokines CCL2 and CCL3 was decreased. ${ }^{30}$

The adverse effect of acute hyperglycemia on the activation of particular signalling pathways in circulating cells has recently been established. In monocytes, type $2 \mathrm{DM}$ was associated with increased expression of the glucosesensitive isoform of PKC, which was activated. ${ }^{31,32}$ Likewise, MEK/ERK1/2 pathway activation was demonstrated in monocytes of healthy volunteers subjected to acute hyperglycemia. ${ }^{33}$ Similarly, CD14+ monocytes from DM individuals were found in an activated state ${ }^{34}$ with increased expression of several pro-inflammatory genes. Mononuclear cells, when cultured under hyperglycemic conditions, revealed notable increase in the expression of several transcription factors. ${ }^{28}$ The impaired cellular physiology was due to activation of the p38 signaling pathway as specific blockade of this signaling pathway reversed the hyperglycemia-related impairment of cell function. ${ }^{28}$

As recently shown, distinct signal transduction pathways including $\mathrm{p} 38$, ERK1/2 and Akt, mediate monocyte migration in response to VEGFR-1 activation. ${ }^{15}$ Our current data demonstrate that these signalling pathways cannot be further activated in DM monocytes upon stimulation with VEGFR-1 ligands. Therefore, DM-related pre-activation of monocyte signalling pathways represents the molecular basis for the refractoriness of diabetic monocytes to this specific, VEGFR-1-mediated chemotactic stimulus reflecting VEGF resistance.

Several studies have reported increased levels of AGEs in DM populations. ${ }^{26}$ Repeatedly elevated glucose plasma levels result in the glycation of proteins and the formation of AGEs including HbAlc. ${ }^{26}$ RAGE, the receptor for AGEs, is a functional receptor and AGE-RAGE interaction leads to the 
activation of distinct signalling pathways p 38 and ERK $1 / 2$ in the monocytic cell line THP- $1{ }^{35}$ This is associated with a proinflammatory cellular activation with increased COX-2 mRNA and prostaglandin E2 expression. ${ }^{35}$ The existence of different splice variants of RAGE in endothelial cells has recently been reported. ${ }^{25}$ We now for the first time report the presence of all three splice variants of RAGE, i.e. C-truncated, N-truncated and full-lengh variants, in primary human monocytes. Their individual contribution to cardiovascular pathology and DM remains to be clarified. ${ }^{36,37}$

We report an increased expression of full-length RAGE (protein) in DM monocytes (Fig. 8C). This observation may have critical implications for the pathophysiology of DM considering that RAGE ligands up-regulate RAGE expression. ${ }^{26}$ Furthermore, ligation of RAGE with S100b, an established ligand of RAGE, ${ }^{35}$ caused an increase in Akt and ERK1/2 phosphorylation in monocytes from non-DM subjects (Fig. 9A). This observation is in line with the significantly elevated baseline phosphorylation level of ERK $1 / 2$ in the subgroup of DM individuals with high HbAlc values (Fig. 3C). Baseline phosphorylation of Akt also showed a trend to be increased in the subgroup with high HbAlc levels (Fig. 3A) without notable changes for p38. HbA1c is primarily used to identify the average plasma glucose concentration over prolonged time periods. We therefore propose that baseline ERK $1 / 2$ phosphorylation in monocytes may serve as a marker for DM-related cellular dysfunction and may prospectively be used to monitor cellular (dys)function in DM. Moreover, we studied the effect of S100b on monocyte motility in vitro to model elevated AGE levels in DM. Pre-activation of non-diabetic monocytes with S100b inhibits VEGFR-1mediated chemotaxis (Fig. 9B) resembling the diabetic phenotype. Altogether, these findings highlight the functional role of RAGE in DM-induced monocyte activation.

Oxidative stress has been implicated in the pathophysiology of diabetic complications. ${ }^{17}$ Monocytes from DM individuals produce significantly more superoxide $\mathrm{O}_{2}(-) .{ }^{38}$ This observation was causally linked to RAGE ligation on THP-1 cells. We now show that oxidative stress in vitro leads to the activation of Akt, p38 and ERK1/2 in non-DM monocytes in a dose- and time-dependent manner (Fig. 7).

The activation of kinases occurs via phosphorylation of target proteins, ${ }^{21}$ whereas inactivation and termination of signal transduction involves protein dephosphorylation by PTPs. The proper function of phosphatases is dependent on the reduced status of a cysteine sulfhydril group in the active site. ${ }^{23,24}$ Reversible oxidation of PTPs, involving targeted oxidation of catalytic cysteine, is an established physiological mechanism negatively regulating PTP activity. ${ }^{39}$ 
In contrast, prolonged oxidative stress under pathological conditions such as DM may even result in an irreversible oxidation of PTP. Such a modification of PTPs resulting in their functional knock-down was reported under hyperglycemic conditions in vitro. ${ }^{40}$ Oxidized cysteine cannot function as a phosphate acceptor, a crucial step in PTP function. ${ }^{39}$ We now report that particular PTPs in DM monocytes have increased reversible oxidative modifications. This deregulation can potentially explain their malfunction. We observed similar effects on PTPs in monocytes under conditions of oxidative stress in vitro. In addition, we now report for the first time that overall PTP activity is decreased in DM monocytes as is the activity of the phosphatase PTP1B. These findings provide initial evidence that increased generation of ROS in DM may lead to functional down-regulation of PTPs and thereby contribute to kinase activation. Moreover, we demonstrated for the first time that the inhibition of PTP - using bpV(phen) - not only activated some intracellular signalling cascades (including of Akt, ERK1/2 and p38), but also inhibited chemokinesis and VEGFR-1-mediated chemotaxis. These consequences of PTP inhibition are essentially similar to the biochemical and functional consequences observed in diabetic monocytes, and thereby strongly implementing oxidation-related impairment of PTP function as a mechanism contributing to the signal transduction defect in DM individuals.

There is accumulating evidence that circulating cells with angiogenic potential, namely monocytes and progenitor cells, are adversely affected under diabetic conditions. This results in an aberrant ability of these cells to adhere or to migrate towards specific stimuli such as VEGF-A. The same is true for cellular homing to sites of angiogenesis. Our data suggest that the DMassociated impairment of VEGFR-1 mediated monocyte chemotaxis is caused by the pre-activation of critical signal transduction pathways. This activation disables monocytes to respond to further stimulation with (amongst others) VEGFR-1 ligands. The reported monocyte pre-activation appears to involve signaling through RAGE as well as increased production of ROS, both wellestablished pathophysiological mechanisms of DM. ${ }^{17}$ Increased levels of ROS are likely to be the result of hyperglycemia. It remains to be established, whether the RAGE-mediated augmentation of ROS production (as demonstrated in THP-1 cells ${ }^{38}$ ) has implications for monocyte dysfunction in DM (Figure 10, dashed line). Increased levels of ROS may lead to the direct activation of signaling molecules/kinases in monocytes. Simultaneously, increased levels of ROS may indirectly lead to kinase activation (or decreased inactivation) by inhibiting PTP activity by means of oxidation. We identified PTP1B as a candidate PTP, which is inhibited in DM monocytes. Our 
observations provide a novel molecular basis to explain the DM-related signal transduction defect resulting in monocyte dysfunction.

Our data describe a novel pattern of DM-related molecular alterations in monocytes. These include oxidative stress and RAGE signaling all leading to unspecific monocyte activation with a functional negative impact on consecutive monocyte activation via VEGFR-1 (Fig. 10), resulting in VEGF resistance. Selective alteration of VEGFR-1 signaling (in contrast to fMLPinduced signaling) in DM indicates a higher sensitivity, i.e. vulnerability of the VEGFR-1 system. The described alterations related to DM-induced monocyte dysfunction may represent a basis for the therapeutic correction of DM-related cellular dysfunction by interfering on the level of molecular oxidation and/or glycation. Furthermore, these data demonstrate that circulating cells may function as "biosensors", translating metabolic aberrations into altered cellular function.

\section{Acknowledgments}

We are grateful to Mr. D.M. Johnson (B. Sc.) for carefully reading the manuscript.

\section{Funding Sources}

This study was supported in part by the Deutsche Forschungsgemeinschaft (Priority Research Program 1069; Wa734/6-3 to J.W. and grant DFG Bo1043/71 to F.B.), by the EU Marie-Curie Network MRTN-CT-2006-035830 (to F.B.), by the Cardiovascular Research Institute Maastricht (CARIM) and by the University Hospital Maastricht (azM) (all to J.W).

\section{Conflict of Interest Disclosures}

All four authors: None.

\section{References}

1. Carmeliet P. Mechanisms of angiogenesis and arteriogenesis. Nat Med. 2000;6:389-395.

2. Waltenberger J. Modulation of growth factor action: implications for the treatment of cardiovascular diseases. Circulation. 1997;96:4083-4094.

3. Arras M, et al. Monocyte activation in angiogenesis and collateral growth in the rabbit hindlimb. J Clin Invest. 1998;101:40-50.

4. Babiak A, et al. Coordinated activation of VEGFR-1 and VEGFR-2 is a potent arteriogenic stimulus leading to enhancement of regional perfusion. Cardiovasc Res. 2004;61:789-795.

5. Pipp F, et al. VEGFR-1-selective VEGF homologue PIGF is arteriogenic: evidence for a monocyte-mediated mechanism. Circ Res. 2003;92:378-385.

6. Crowther M, et al. Microenvironmental influence on macrophage regulation of angiogenesis in wounds and malignant tumors. J Leukoc Biol. 2001;70:478-490. 
7. Ferrara N, et al. The biology of VEGF and its receptors. Nat Med. 2003;9:669-676.

8. Kroll J, et al. VEGF-A induces expression of eNOS and iNOS in endothelial cells via VEGF receptor-2 (KDR). Biochem Biophys Res Commun. 1998;252:743-746.

9. Waltenberger J, et al. Different signal transduction properties of KDR and Flt1, two receptors for vascular endothelial growth factor. J Biol Chem. 1994;269:26988-26995.

10. Yilmaz A, et al. p38 MAPK inhibition is critically involved in VEGFR-2-mediated endothelial cell survival. Biochem Biophys Res Commun. 2003;306:730-736.

11. Autiero M, et al. Role of PlGF in the intra- and intermolecular cross talk between the VEGF receptors Flt1 and Flk1. Nat Med. 2003;9:936-943.

12. Carmeliet $\mathrm{P}$, et al. Synergism between vascular endothelial growth factor and placental growth factor contributes to angiogenesis and plasma extravasation in pathological conditions. Nat Med. 2001;7:575-583.

13. Clauss $\mathrm{M}$, et al. The vascular endothelial growth factor receptor Flt-1 mediates biological activities. Implications for a functional role of placenta growth factor in monocyte activation and chemotaxis. J Biol Chem. 1996;271:17629-17634.

14. Hiratsuka S, et al. Flt-1 lacking the tyrosine kinase domain is sufficient for normal development and angiogenesis in mice. Proc Natl Acad Sci U S A. 1998;95:9349-9354.

15. Tchaikovski V, et al. The molecular basis of VEGFR-1 signal transduction pathways in primary human monocytes. Arterioscler Thromb Vasc Biol. 2008;28:322-328.

16. Selvaraj SK, et al. Mechanism of monocyte activation and expression of proinflammatory cytochemokines by placenta growth factor. Blood. 2003;102:1515-1524.

17. Tchaikovski V, et al. Angiogenesis and Arteriogenesis in Diabetes Mellitus: Signal Transduction Defects as The Molecular Basis of Vascular Cell Dysfunction Therapeutic Neovascularization: Quo Vadis? : E. Deindl and C. Kupatt, editors. Springer. Munich, Germany; 2007.

18. Werner GS, et al. Impaired acute collateral recruitment as a possible mechanism for increased cardiac adverse events in patients with diabetes mellitus. Eur Heart J. 2003;24:1134-1142.

19. Waltenberger J, et al. Vascular endothelial growth factor-A-induced chemotaxis of monocytes is attenuated in patients with diabetes mellitus: A potential predictor for the individual capacity to develop collaterals. Circulation. 2000;102:185-190.

20. Stevens RJ, et al. Risk factors for myocardial infarction case fatality and stroke case fatality in type 2 diabetes: UKPDS 66. Diabetes Care. 2004;27:201-207.

21. Kyriakis JM, et al. Mammalian mitogen-activated protein kinase signal transduction pathways activated by stress and inflammation. Physiol Rev. 2001;81:807-869.

22. Tonks NK. Protein tyrosine phosphatases: from genes, to function, to disease. Nat Rev Mol Cell Biol. 2006; 7:833-846.

23. Markova B, et al. Investigation of protein-tyrosine phosphatases by in-gel assays. Methods. 2005;35:22-27.

24. Meng TC, et al. Development of a modified in-gel assay to identify protein tyrosine phosphatases that are oxidized and inactivated in vivo. Methods. 2005;35:28-36.

25. Lieuw-a-Fa ML, et al. Interaction of Nepsilon(carboxymethyl)lysine- and methylglyoxalmodified albumin with endothelial cells and macrophages. Splice variants of RAGE may limit the responsiveness of human endothelial cells to AGEs. Thromb Haemost. 2006;95:320-328.

26. Goldin A, et al. Advanced glycation end products: sparking the development of diabetic vascular injury. Circulation. 2006;114:597-605.

27. Yonekura $\mathrm{H}$, et al. Novel splice variants of the receptor for advanced glycation end-products expressed in human vascular endothelial cells and pericytes, and their putative roles in diabetes-induced vascular injury. Biochem J. 2003;370:1097-1109.

28. Seeger FH, et al. p38 mitogen-activated protein kinase downregulates endothelial progenitor cells. Circulation. 2005;111:1184-1191.

29. Segal MS, et al. Nitric oxide cytoskeletal-induced alterations reverse the endothelial progenitor cell migratory defect associated with diabetes. Diabetes. 2006;55:102-109. 
30. Bouma G, et al. An increased MRP8/14 expression and adhesion, but a decreased migration towards proinflammatory chemokines of type 1 diabetes monocytes. Clin Exp Immunol. 2005;141:509-517.

31. Ceolotto G, et al. Protein kinase $\mathrm{C}$ activity is acutely regulated by plasma glucose concentration in human monocytes in vivo. Diabetes. 1999;48:1316-1322.

32. Ding Y, et al. Phosphorylation of pleckstrin increases proinflammatory cytokine secretion by mononuclear phagocytes in diabetes mellitus. J Immunol. 2007;179:647-654.

33. Ceolotto G, et al. Hyperglycemia acutely increases monocyte extracellular signal-regulated kinase activity in vivo in humans. $J$ Clin Endocrinol Metab. 2001;86:1301-1305.

34. Cipolletta C, et al. Activation of peripheral blood CD14+ monocytes occurs in diabetes. Diabetes. 2005;54:2779-2786.

35. Shanmugam N, et al. Regulation of cyclooxygenase-2 expression in monocytes by ligation of the receptor for advanced glycation end products. J Biol Chem. 2003;278:34834-34844.

36. Basta G, et al. Circulating soluble receptor for advanced glycation end products is inversely associated with glycemic control and S100A12 protein. $J$ Clin Endocrinol Metab. 2006;91:4628-4634.

37. Yamagishi S, et al. Positive association between serum levels of advanced glycation end products and the soluble form of receptor for advanced glycation end products in nondiabetic subjects. Metabolism. 2006;55:1227-1231.

38. Ding Y, et al. Activation of RAGE induces elevated O2- generation by mononuclear phagocytes in diabetes. J Leukoc Biol. 2007;81:520-527.

39. Meng TC, et al. Reversible oxidation and inactivation of protein tyrosine phosphatases in vivo. Mol Cell. 2002;9:387-399.

40. $\mathrm{Wu} \mathrm{XF}$, et al. The role of microglia in paraquat-induced dopaminergic neurotoxicity. Antioxid Redox Signal. 2005;7:654-661.

\section{Supplement Figures}
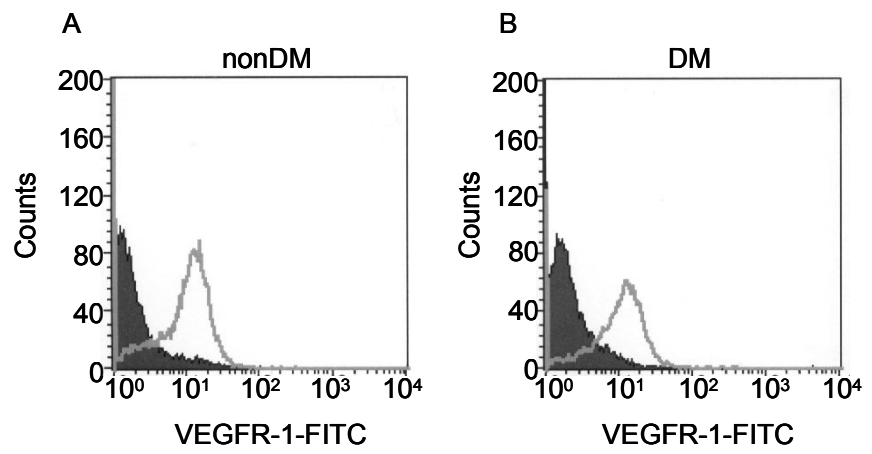

Supplement Figure 1. Expression of VEGFR-1 on primary human monocytes from non-diabetic and diabetic individuals. Representative FACS histogram plots of VEGFR-1 expression in nondiabetic (A) and diabetic (B) monocytes. Filled curve - staining with secondary antibody only, open curve - staining with primary antibody recognizing VEGFR-1 and secondary antibody. Expression of VEGFR-1 in non-diabetic and diabetic monocytes. 


\section{Chapter 4}

\section{Monocyte dysfunction as a previously}

unrecognized pathophysiological mechanism

in ApoE-/- mice contributing to impaired

arteriogenesis

Based on:

1. Kerber M, Reiss Y, Wickersheim A, Jugold M, Kiessling F, Heil M, Tchaikovski V, Waltenberger J, Shibuya M, Plate KH, Machein MR. Flt-1 signaling in macrophages promotes glioma growth in vivo. Cancer Res. 2008;68(18):7342-51.

2. Tchaikovski V, Tchaikovski S, Olieslagers S, Waltenberger J. Monocyte dysfunction as a previously unrecognized pathophysiological mechanism in ApoE-/- mice contributing to impaired arteriogenesis. Submitted for publication. 


\section{Abstract}

Objective Monocytes participate in wound repair, arteriogenesis and atherogenesis. Chemoattractants including vascular endothelial growth factor (VEGF) and monocyte chemoattractant protein-1 (MCP-1) mediate monocyte recruitment from the blood. Data from human studies indicate that hyperlipidemia/hypercholesterolemia adversely affect monocyte chemotactic responses to VEGF-A or MCP-1. In this study we aimed to establish 1) monocyte isolation from mice and 2) analyze monocyte chemotaxis in i) ApoE/- mice (an established mouse model of hyperlipidemia) and ii) Flt TK-/- mice (to investigate the importance of TK domain of VEGFR-1 for migratory response of monocytes).

Methods and Results CD11b+ monocytes were isolated from blood of C57B16 (wild type, WT), ApoE-/- or Flt TK-/- mice. Monocyte chemotaxis to P1GF-1, VEGF-A or MCP-1 was quantitatively assessed using modified Boyden chamber. Both VEGF-A (1 ng/mL) and MCP-1 (10 ng/mL) significantly induced chemotaxis of monocytes from WT mice. In contrast, monocytes from ApoE-/- mice had a significantly attenuated chemotaxis to VEGF-A $(p=0.021)$ that was not distinguishable from baseline migration (chemokinesis). The chemotactic response of monocytes from ApoE-/- mice to MCP-1 was reduced as well $(\mathrm{p}=0.076)$. Of note, monocytes from ApoE-/- mice had a significantly increased baseline migration (chemokinesis) as compared to WT mice $(\mathrm{p}=0.03)$. Monocytes from Flt TK-/- failed to migrate towards VEGFR-1 ligands (P1GF-1 and VEGF-A) while the migratory response to MCP-1 was fully preserved.

Conclusions TK domain of VEGFR-1 plays a crucial role for the induction of monocyte migration in response to PlGF or VEGF-A. Monocytes from ApoE-/mice show an impaired chemotactic response to VEGF-A and MCP-1, while these cells are activated as reflected by enhanced chemokinesis. Impaired monocyte chemotaxis is a novel, pathophysiologially relevant component in ApoE-/- mice that may be contributing to a hampered arteriogenesis in hyperlipidemia. 


\section{Introduction}

Hyperlipidemia (HL) is one of the major atherosclerotic risk factors promoting coronary and peripheral artery disease. Concomitantly, collateral vessel development, a crucial compensatory mechanism in occlusive arterial disease, is negatively influenced by HL. ${ }^{1,2}$

Monocytes and tissue-resident macrophages, supplying growth factors, cytokines and proteolytic enzymes, accelerate the arteriogenic response. ${ }^{3} \mathrm{~A}$ decreased monocyte/macrophage accumulation around a growing collateral vessel is associated with a jeopardized arteriogenesis in HL. ${ }^{4}$

Monocyte extravasation to sites of collateral growth is a crucial step. Several factors are known to facilitate monocyte chemotaxis in arteriogenesis. Monocyte chemoattractant protein-1 (MCP-1), one of the most potent arteriogenic factors, ${ }^{3}$ strongly stimulates monocytes migration. Also vascular endothelial growth factor-A (VEGF-A) and placenta growth factor-1 (PlGF-1) are established chemoattractants for monocytes. ${ }^{5,6}$

Previous studies in humans by our group indicated that cardiovascular risk factors such as HL severely hamper ex vivo monocyte chemotaxis to VEGF-A and MCP-1. ${ }^{7}$ Based on these findings, we proposed that monocytes can be used as circulating "biosensors" to detect metabolic dysregulation and elevated cardiovascular risk. ${ }^{7}$ However, HL often co-exists with other cardiovascular risk factors such as diabetes mellitus (DM) and/or smoking, all known to negatively affect monocyte chemotaxis. ${ }^{7,8}$

With this study we could establish monocyte isolation from mice and analyze their migration ex vivo. In wild type (WT) mice VEGFR-1 ligands (P1GF-1 and VEGF-A) as well as MCP-1 significantly stimulated monocyte migration. Monocyte chemotaxis ex vivo is impaired in ApoE-/- mice. ${ }^{9}$ We can document that ApoE-/- monocytes show completely abrogated chemotaxis in response to VEGF-A and decreased motility toward MCP-1. Monocytes from Flt TK-/- failed to migrate towards VEGFR-1 ligands (PlGF-1 and VEGF-A) while the migratory response to $\mathrm{MCP}-1$ was fully preserved.

\section{Methods}

\section{Reagents}

MCP-1 was provided by Boehringer Ingelheim (Biberach, Germany). PlGF-1 was purchased from ReliaTech (Braunschweig; Germany). Recombinant human VEGF-A $A_{165}$ was kindly provided by Denis Gospodarowicz (Chiron, Emeryville, CA, USA). RPMI 1640 medium was from Invitrogen (Karlsruhe, Germany). 
Hystopaque-1077 was from Sigma (St. Louis, USA). Mouse CD11b MicroBeads were from Miltenyi Biotec (Bergisch Gladbach, Germany).

\section{Mice}

C57Bl/6, Flt TK-/- and ApoE-/- mice were housed in the animal facility of Maastricht University. Experiments were approved by the local animal ethical committee and performed according to the institutional guidelines. All efforts were made to minimize the number of animals used and their suffering.

\section{Blood sampling and plasma levels of lipids}

Mice of the same sex and comparable age were used for each set of experiments. The blood was sampled as previously described ${ }^{10}$ and analysis of general hematological parameters was carried out using Coulter AcT Diff Hematology Analyzer (Fullerton, CA, USA). $100 \mu \mathrm{L}$ of blood from each mouse was used to measure triglycerides, total cholesterol and HDL cholesterol in plasma enzymatically. LDL cholesterol was calculated using the Friedwald formula $(\mathrm{LDL}=$ Total cholesterol $-\mathrm{HDL}$ cholesterol - Triglycerides/5), using corresponding measured values.

\section{Monocyte isolation and chemotaxis}

Blood from mice of the same genetic background was pooled and diluted 1:2 PBS/EDTA and subjected to density-gradient centrifugation using Hystopaque1077 (Sigma, St. Louis, USA). Monocytes were further enriched using antimouse CD11b magnetic microbeads (Miltenyi Biotechnologies, Bergisch Gladbach, Germany). Chemotaxis was studied using modified Boyden chamber (Nucleopore, Pleasanton, CA). Isolated monocytes were resuspended in RPMI1640. Chemoattractants were loaded in the lower chamber, and cell suspension was loaded in the upper chamber. Cells migrated across membrane with $5 \mu \mathrm{m}$ pore size (Nucleopore, Pleasanton, CA). Chemotaxis was allowed to proceed for 3 hours, at $37^{\circ} \mathrm{C}$. Membranes were fixed in $100 \%$ ethanol and stained with Giemsa's azur eosin methylene blue solution (Merck, Darmstadt, Germany). Cells adherent to the upper surface of the membrane were carefully scraped. The membrane was mounted onto microscopic slide with superimposed cover slide. Cells adherent to the lower surface of the membrane were referred as migrated. Migrated cells were counted in 5 power fields by an investigator blinded to the conditions of the experiment, at magnification 20X. In each experiment experimental condition was done in duplicate. 


\section{Statistical analysis}

Data are presented as Statistical analysis was performed using SPSS 12.0.1 software. The probability of difference between the groups was evaluated using Kruskal-Wallis test. Subsequently, Mann-Whitney test was performed to estimate the level of significance. Values of $p<0.05$ were considered statistically significant.

\section{Results}

\section{Plasma lipid levels monocyte numbers}

Plasma lipid levels are significantly elevated in ApoE-/- mice with total cholesterol measuring 8-fold of the WT level; LDL-cholesterol plasma levels were even $\sim 50$ times higher in ApoE-/- mice (Table 1). ApoE-/- mice had significantly elevated levels of CD11b+ monocytes $(p<0.01)$.

Table 1. Characteristics of mice, plasma lipid levels and monocyte numbers

\begin{tabular}{|l|c|c|c|}
\hline & WT $(\mathrm{n}=5)$ & ApoE-/- $(\mathrm{n}=5)$ & $\mathrm{p}$-value \\
\hline Age of mice (weeks) & $35.6 \pm 10.7$ & $33.6 \pm 13.7$ & n.s. \\
\hline Total cholesterol (mg/dL) & $56.03 \pm 16.82$ & $402.90 \pm 58.29$ & $\mathrm{p}<0.001$ \\
\hline LDL cholesterol (mg/dL) & $5.63 \pm 3.13$ & $266.33 \pm 63.74$ & $\mathrm{p}<0.001$ \\
\hline HDL cholesterol (mg/dL) & $44.65 \pm 14.06$ & $97.66 \pm 18.29$ & $\mathrm{p}<0.001$ \\
\hline Triglicerides (mg/dL) & $32.59 \pm 7.02$ & $55.61 \pm 14.05$ & $\mathrm{p}<0.05$ \\
\hline Mononuclear cells $\left(\mathrm{MNC}, \times 10^{6} / \mathrm{mL}\right)$ & $1.40 \pm 0.29$ & $1.53 \pm 0.37$ & $\mathrm{n} . \mathrm{s}$. \\
\hline CD11b+ monocytes $(\%$ of $\mathrm{MNC})$ & $6.42 \pm 0.88$ & $11.67 \pm 2.17 *$ & $\mathrm{p}<0.01$ \\
\hline
\end{tabular}

\section{Monocytes from ApoE-/- mice show impaired chemotactic responses to VEGF-A and MCP-1}

When assessing monocytes from ApoE-/- mice, we could detect a functionally impaired phenotype. VEGF-A $(1 \mathrm{ng} / \mathrm{mL})$ and MCP-1 $(10 \mathrm{ng} / \mathrm{mL})$ significantly increased chemotaxis of monocytes from WT mice (Figure 1A, B). In contrast to WT, monocytes from ApoE-/- mice had a significantly decreased chemotaxis to VEGF-A $(\mathrm{p}=0.021)$ and tended to have a decreased response to MCP-1 $(\mathrm{p}=0.076)$. Chemotaxis of monocytes from ApoE-/- mice to VEGF-A was fully abrogated and was not distinguishable from baseline migration (chemokinesis). 
In ApoE-/- monocytes, the chemotactic response to both VEGF-A and MCP-1 was decreased in a dose-dependent manner (Fig. 1A, B). Furthermore, monocytes from ApoE-/- mice had a significantly elevated baseline migration (chemokinesis, Figure 1C) as compared to WT mice $(\mathrm{p}=0.03)$.

A

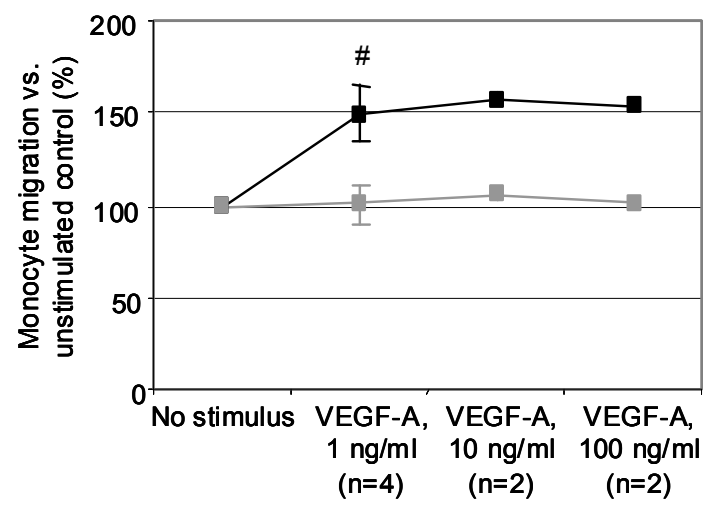

B

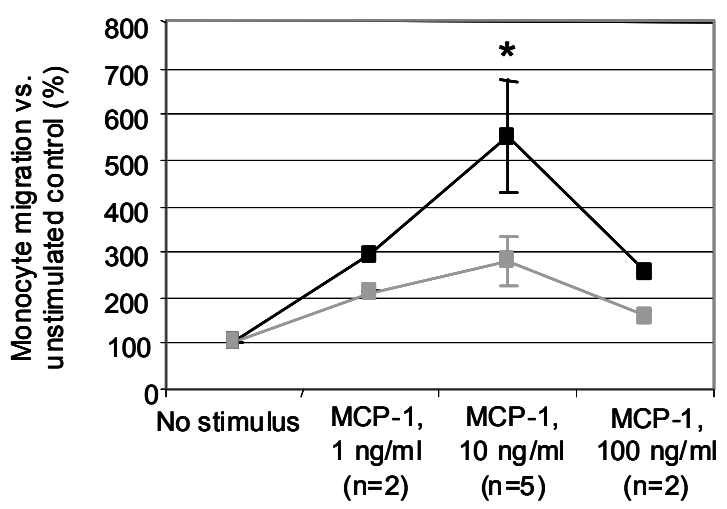

C

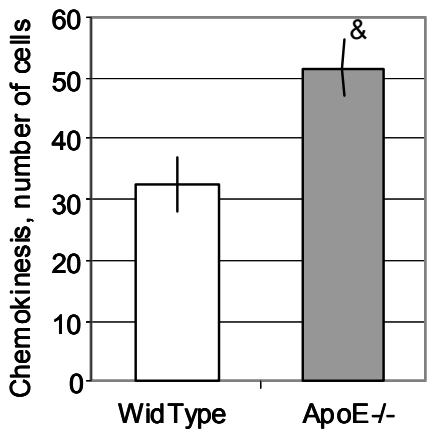

Figure 1. Chemotactic response of monocytes from WT and ApoE-/- mice to VEGF-A and MCP1. Monocytes $\left(5^{*} 10^{5} / \mathrm{mL}\right)$ were subjected to chemotaxis assay in modified Boyden chamber. Migrated cells ( 3 hours) were counted by an investigator blinded to the assay conditions, namely in 15 medium-power fields (20x magnification) of 3 wells. Chemotaxis data are presented as mean value ( \pm standard error of mean) of migrated cells. Chemotactic response to VEGF-A (A) and MCP-1 (B) presented as percentage of unstimulated control; $\mathrm{C}$, baseline migration (chemokinesis) presented as cell number/power field (mean \pm standard error of mean). \# - p = 0.021 , * $-\mathrm{p}=0.076, \&-\mathrm{p}=0.032$, comparing corresponding conditions of two mouse phenotypes. 


\section{Assessment of monocyte chemotaxis in Flt TK-/- mice}

We examined whether or not the tyrosine kinase (TK) of Flt-1 is crucial for VEGFR1-mediated monocyte migration. Primary monocytes from both WT and Flt $\mathrm{TK}^{-/}$mice were used for the cell migration assay. As shown in Fig. 2, monocytes from WT mice displayed a significant increase in PlGF-1- and VEGF-A-induced monocyte migration $(\mathrm{p}<0.02)$. In contrast, PlGF-1- and VEGF-A-induced monocyte migration was abrogated for monocytes isolated from Flt TK-/- mice. This was significantly lower than the effect of respective ligands in WT mice ( $<<0.01$ and $p<0.05$, correspondingly). However, these monocytes (Flt TK-/-) did properly respond to MCP-1 similar to monocytes isolated from WT mice ( $<<0.02$ for both as compared to unstimulated control). These observations indicate that the Flt- 1 TK domain is required for the induction of monocyte migration in response to PIGF or VEGF-A.

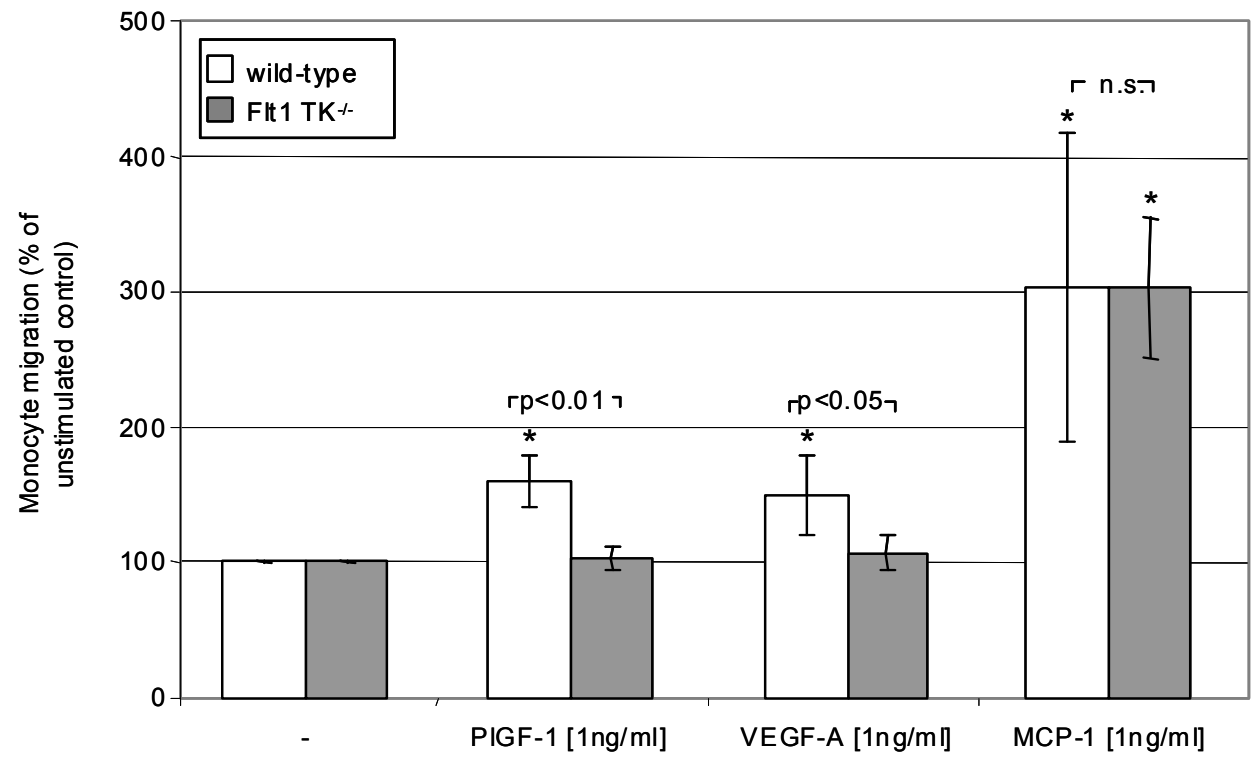

Fig. 2. Assessment of mouse monocyte chemotaxis in Flt-TK ${ }^{--}$mice. Monocytes were isolated from heparinized mouse venous blood, taken from the right ventricle of the beating heart. Chemotaxis was assessed in the modified Boyden chamber at $37^{\circ} \mathrm{C}$ for 3 hours. Chemoattractants (PIGF-1, VEGF-A and MCP-1) were loaded in the lower compartments, while cell suspensions were loaded in the upper compartments. Cells migrated across the membrane with $5 \mu \mathrm{m}$ pore size. Migrated cells were counted using light microscope, magnification $40 \times$. Data shown are derived from three independent experiments each performed in duplicate. Chemokinesis is referred as $100 \%$. Open bars refer to wild-type mice, grey bars refer to Flt $\mathrm{TK}^{-/-}$mice. Data are presented as mean \pm SD. Statistical analysis was performed using Wilcoxon test for comparison of ligandinduced chemotaxis with chemokinesis within one mouse background $(*-p<0.02)$; MannWithney $U$ test was used to compare respective ligand-induced chemotaxis between mice of two different backgrounds. 


\section{Discussion}

In the present study, we show for the first time that monocytes from ApoE-/mice are dysfunctional, as chemotaxis towards both the growth factor VEGF-A and the chemokine MCP-1 are severely impaired. These data imply that i.) monocytes show a functional defect in the presence of HL, and that ii.) monocyte dysfunction is likely to contribute to pathological changes observed in ApoE-/- mice. ${ }^{9}$

Besides its stimulatory role for atherogenesis, ${ }^{9}$ chronic hypercholesterolemia leads to the impairment of angiogenesis and arteriogenesis. ${ }^{1}$, 2, 4, 11 Monocytes contribute to collateral growth, i.e. arteriogenesis by their recruitment to the growing vessel. ${ }^{3}$ Monocyte migration as one component of monocyte recruitment from the blood stream to sites of vascular growth is mediated by VEGF via VEGFR $-1{ }^{6}$ and by MCP-1 via CCR$2{ }^{3}$ Several studies suggested that impaired arteriogenesis in HL may be due to an impaired expression of arteriogenic factors. Indeed, a decreased expression of VEGF-A was reported in ischemic hind-limbs of ApoE-/- mice ${ }^{2}$ and HIF- $\alpha$ expression was also decreased in LDLR -/-/ApoB-48-/- mice. ${ }^{4}$ The transcription factor HIF- $\alpha$ is a crucial regulator of the expression of the several angiogenic factors indeed. ${ }^{12}$ However, attempts to rescue impaired arteriogenesis in HL models largely failed: the arteriogenic response remained delayed in HL mice treated with PR39, a potent stimulator of angiogenic factor expression. ${ }^{4}$ Likewise, the therapeutic induction of arteriogenesis in HL rabbits with hindlimb-ischemia using the potent arteriogenic stimulus MCP-1 could not compensate for the negative impact of HL, and led to a limited initial "catchup" in hindlimb perfusion only at high dose. ${ }^{11}$ Impaired arteriogenesis in HL mice was accompanied by a decreased appearance of F4/80 macrophages in ischemic hindlimbs of LDLR-//ApoB-48-/- mice both under the native (HL) conditions as well as following the attempted angiogenic stimulation. ${ }^{4}$ This previous finding implies - in the light of our novel data - that both the native as well as the growth factor-stimulated arteriogenesis are reduced in $\mathrm{HL}$ due to a reduced accumulation of dysfunctional blood-derived monocytes at sites of vascular repair. ${ }^{4}$

Our previous work on human monocytes documented an impaired chemotactic response of circulating monocytes to arteriogenic ligands of VEGFR-1 and CCR-2 including VEGF-A and MCP- $1^{7}$ in the presence of HL and had predicted our novel findings in ApoE-/- mice.

Already a decade ago, impaired monocyte chemotaxis to VEGF-A was suggested to be potentially contributing to impaired arteriogenesis in the context 
of DM. ${ }^{7}$ In the meanwhile, it has been confirmed that DM is associated with impaired or delayed arteriogenesis. ${ }^{13}$ Both situations are associated with impaired monocyte chemotaxis towards VEGF-A. Recently, the biochemical mechanisms underlying DM-induced monocyte dysfunction have been unraveled. ${ }^{8}$ In fact, DM was shown to induce unspecific monocyte activation secondary to increased oxidative stress and advanced glycation of functionally relevant molecules.

It has been suggested that HL may have an even more detrimental effect on arteriogenesis than DM. ${ }^{1}$ Therefore, it will be of utmost importance to identify and dissect the mechanisms hampering monocyte chemotaxis in HL. Their elucidation will provide important insight into the pathophysiology of HL and will lay the basis for the therapeutic correction of monocyte function and potential improvement of arteriogenesis in HL. We can already speculate that the HL-related monocyte defect is different from the DM-related phenotype as monocyte chemokinesis is significantly elevated in HL.

Taken together, this is the first description of monocyte dysfunction in ApoE-/- mice, namely an impaired chemotactic response. This impaired monocyte chemotactic phenotype is likely to explain some of the pathogenetic consequences of HL including the activated atherogenesis as well as the hampered angiogenesis/arteriogenesis.

\section{References}

1. van Weel V, et al. Hypercholesterolemia reduces collateral artery growth more dominantly than hyperglycemia or insulin resistance in mice. Arterioscler Thromb Vasc Biol. 2006;26:1383-1390.

2. Couffinhal $\mathrm{T}$, et al. Impaired collateral vessel development associated with reduced expression of vascular endothelial growth factor in ApoE-/- mice. Circulation. 1999;99:31883198.

3. Schaper W. Collateral circulation: past and present. Basic Res Cardiol. 2009;104:5-21.

4. Tirziu D, et al. Delayed arteriogenesis in hypercholesterolemic mice. Circulation. 2005;112:2501-2509.

5. Babiak A, et al. Coordinated activation of VEGFR-1 and VEGFR-2 is a potent arteriogenic stimulus leading to enhancement of regional perfusion. Cardiovasc Res. 2004;61:789-795.

6. Tchaikovski $\mathrm{V}$, et al. The molecular basis of VEGFR-1 signal transduction pathways in primary human monocytes. Arterioscler Thromb Vasc Biol. 2008;28:322-328.

7. Waltenberger J. Stress testing at the cellular and molecular level to unravel cellular dysfunction and growth factor signal transduction defects: what Molecular Cell Biology can learn from Cardiology. Thromb Haemost. 2007;98:975-979.

8. Tchaikovski $\mathrm{V}$, et al. Diabetes mellitus activates signal transduction pathways resulting in VEGF resistance of human monocytes. Circulation. 2009;120:151-159.

9. Plump AS, et al. Severe hypercholesterolemia and atherosclerosis in apolipoprotein Edeficient mice created by homologous recombination in ES cells. Cell. 1992;71:343-353.

10. Tchaikovski SN, et al. Development of a calibrated automated thrombography based thrombin generation test in mouse plasma. J Thromb Haemost. 2007;5:2079-2086. 


\section{Chapter 4}

11. van Royen N, et al. Effects of local MCP-1 protein therapy on the development of the collateral circulation and atherosclerosis in Watanabe hyperlipidemic rabbits. Cardiovasc Res. 2003;57:178-185.

12. Pugh CW, et al. Regulation of angiogenesis by hypoxia: role of the HIF system. Nat Med. 2003;9:677-684.

13. Werner GS, et al. Impaired acute collateral recruitment as a possible mechanism for increased cardiac adverse events in patients with diabetes mellitus. Eur Heart J. 2003;24:1134-1142. 


\section{Chapter 5}

General Discussion 


\section{Biochemical mechanisms of vascular cell dysfunction in DM}

Diabetes mellitus (DM) leads to multiple alterations in nearly any organ and nearly any cell type. The most dramatic effects occur in the vascular tissue leading to the development of the diabetic macroangiopathy and microangiopathy. The negative influences of DM leading to the angiopathy are largely based on the mechanisms that negatively affect the compensatory processes of the vessel growth, with arteriogenesis among others, resulting in a reduced or impaired development of the collateral circulation. This in turn is associated with a negative clinical outcome and prognosis in patients with advanced coronary artery disease (CAD) and peripheral artery disease (PAD). The DM-associated molecular changes include alterations in the extracellular milieu, dysbalance between the proangiogenic and antiangiogenic growth factors and their receptors affecting the angiogenic stimulus and resulting in the cellular and vascular dysfunction.

Diabetes is a complex metabolic state with hyperglycemia considered to be a key causal factor in the development of diabetic vascular complications by causing divergent cellular dysfunction. ${ }^{1}$ Hyperglycemia occurs as a result of an impaired glucose utilization by tissues due to either whole-body insulin resistance in DM type 2 or lack of sufficient availability of insulin in DM type $1 .^{2}$ Generally, the hyperglycemia-induced cellular biochemical alterations are the major factors that result in the cellular dysfunction in DM. Elevated glucose levels can lead to the cellular dysfunction through the following biochemical pathways:

- increased polyol and hexosamine pathway flux;

- increased advanced glycation end-product (AGE) formation;

- activation of protein kinase $\mathrm{C}$ (PKC) isoforms;

- increased formation of reactive oxygen species (ROS) and other products of abundant oxidative stress, e.g. LPO. ${ }^{3}$

The hyperglycemia-induced cellular dysfunction leads to an attenuation of the angiogenic stimulus and impairs/delays in the angiogenic process.

Our recent study ${ }^{4}$ provided a molecular explanation, why diabetes mellitus is associated with defective repair processes (Chapter 3). Previously, we reported a diabetes-related monocyte defect detected as an attenuated VEGFR-1-mediated chemotactic response. ${ }^{5}$ In Chapter 3 we demonstrate that primary human monocytes from individuals with type 2 diabetes have an increased baseline phosphorylation of the VEGFR-1-related downstream signal transduction molecules. This diabetes-related baseline activation makes cells 
unresponsive to the further VEGFR-1 stimulation. Increased oxidative stress in diabetes contributes to the baseline activation of the monocyte signaling by either direct activation of the signaling molecules, or by inactivation of protein tyrosine phosphatases via oxidative modification (Chapter 3). Likewise, increased signaling via RAGE in diabetic monocytes can also lead to unspecific activation of the signaling pathways (Chapter 3 ).

\section{Advanced glycation end-products in DM-related cellular dysfuction}

Advanced glycation endproducts (AGEs) are a heterogeneous class of modified proteins and lipids that are formed in multiple pathological settings including hyperglycemia. ${ }^{6}$ Initially, the formation of AGEs was believed to occur extracellularly as a result of a non-enzymatic reaction between glucose and extracellular proteins. This possibility remains, but the rates of AGE formation from glucose in the extracellular space are significantly lower than the intracellular formation of AGEs involving glucose derivates. ${ }^{6}$ Realization of the importance of the AGE formation in vivo began in the mid-1970s with studies on hemoglobin A1c (HbAlc), ${ }^{7}$ a naturally occurring minor human hemoglobin that is elevated in diabetic patients. HbAlc is a posttranslational product of the reaction of glucose with the $\mathrm{N}$-terminal valine amino group of the beta-chain of hemoglobin. HbAlc is used as a marker for assessing the metabolic control in diabetic patients and provides an average of the integrated blood glucose concentration for approximately a period of 60-120 days. ${ }^{8}$

A key focus of the efforts in recent years has been on the identification and characterization of specific AGE structures. Specifically, carboxymethyllysine (CML)-modified adducts of proteins accumulate to accelerated degrees in vivo, and have been identified as the most prevalent AGEs that is found in tissues. ${ }^{9}, 10$ Other AGEs include structures such as carboxyethyllysine adducts (CEL) and pentosidine. ${ }^{11,12}$

The enhanced formation of AGEs has been associated with disruption of the homeostatic mechanisms in the settings of diabetes. Excessive cross-linking of matrix molecules may cause alterations in the matrix-matrix and the matrixcell interactions. ${ }^{13}$ AGE-modification of intracellular molecules may lead to impaired function of growth factors. ${ }^{14}$ Furthermore, AGEs can affect intrinsic signaling mechanisms, e.g. enhance quenching of NO. ${ }^{15}$ On type I collagen, intermolecular crosslinking by AGEs induces an expansion of the molecular packing. These AGE-induced crosslinks alter the function of the intact vessels. AGEs decrease the elasticity of large vessels in diabetic rats and increase fluid filtration across the vessel wall. ${ }^{16}$ AGE formation on type IV collagen and laminin inhibits the polymer self-assembly of these molecules into a normal 
network-like structure. ${ }^{17-19}$ The AGE formation in the extracellular matrix not only interferes with the matrix-matrix interactions, but also with the matrix-cell interactions. The AGE modification of the cell-binding domains of type IV collagen decreases EC adhesion. ${ }^{13,20}$

Largely, the aforementioned alterations do not require an interaction with distinct receptors. A number of the cell-surface AGE-binding proteins have been identified. Of these AGE-binding proteins, the receptor for AGE (RAGE) has clearly been demonstrated to function as a signal transduction receptor. ${ }^{21}$

\section{Receptor for AGE in the DM-related cellular dysfuction}

RAGE was identified as a cellular interaction site for AGEs in a range of cultured vascular cells. ${ }^{21}$ Furthermore, RAGE is present on blood cells. Namely, AGEs, either those prepared in vitro such as AGE-modified bovine serum albumin, or those retrieved/purified directly from diabetic subjects, were found to interact with EC, peripheral blood-derived monocytes/macrophages and VSMC. This interaction was dose-dependent and saturable and could be inhibited by a blocking antibody to the receptor or to the soluble RAGE, the extracellular ligand-binding domain of RAGE. ${ }^{22-26}$

Multiple studies have shown that RAGE is expressed at low levels in the adult tissues in different cell types including EC, macrophages, lymphocytes, VSMC, glomerular epithelial cells, podocytes, and neurons. ${ }^{27-29}$ Diabetes leads to a striking upregulation of the RAGE expression, ${ }^{29,}{ }^{30}$ and increases the ligand levels in blood ${ }^{31}$ and in tissues. ${ }^{32,33}$ RAGE consists of an extracelluar ligandbinding domain, a transmembrane part and an intracellular domain, which is critical for the RAGE-mediated intracellular signaling events. ${ }^{34}$ The cellular expression of RAGE is controlled by the nuclear factor (NF)- $\mathrm{kB}$ sites, by the interferon- $\gamma$ responsive element, and by the interleukin-6 (IL-6) DNA binding motif, all located on the RAGE promoter. ${ }^{35}$ Such control of the RAGE expression implies its involvement in the propagation of the activated status of several cell types in DM and hyperglycemia. We could clearly demonstrate (Chapter 3) that primary human monocytes express all three splice variants of RAGE. ${ }^{4}$ Our results demonstrate that RAGE ligation on monocytes using an established RAGE ligand S100b leads to the activation of multiple signaling pathways interfering with the signaling via VEGFR-1 (Chapter 3). ${ }^{4}$

Binding of multiple AGE ligands to RAGE on the acceptor cell types results in a modulation of cellular function. RAGE engagement leads to the activation of:

- several signaling cascades, in physiologic conditions involved in propagating basic cellular processes (proliferation, migration etc.), 
- production of ROS,

- activation of the cellular transcriptional machinery.

In EC, SMC and monocytes, the ligation of RAGE leads to the activation of the ras21, MAPK signaling cascades and GTPases. ${ }^{36,} 37$ RAGE-induced oxidative stress in EC s predominantly caused by the upregulation of NADPH oxidase ${ }^{38,39}$ Production of ROS can, in turn, lead to further activation of multiple signaling cascades. ${ }^{40}$ The upregulated status of the signaling machinery, especially MAPKs and oxidative stress result in the transcriptional activation by NF- $\mathrm{KB}$ and other factors. RAGE ligation leads to increased expression of proinflammatory cytokines IL-1, IL- 6 , tumor necrosis factor- $\alpha,{ }^{41}$, ${ }^{42}$ some of which in turn are known to induce the RAGE transcription. ${ }^{35}$

The increased signaling through AGE/RAGE results in a constant activation of the enzymes, which are critical for the directed migratory response of the angiogenic cells during the process of new vessel growth. Therefore, in parallel with an increased cellular adhesiveness in DM and hyperglycemia, ${ }^{43}$ the cells loose their physiologic ability to migrate along the gradient of angiogenic stimuli such as VEGF-A. ${ }^{5}$ Indeed, the impaired migratory response of monocytes to the ligands of VEGFR-1 is caused by the baseline activation of the VEGFR-1-related signaling pathways (Chapter 3). ${ }^{4}$

\section{Reactive oxygen species (ROS) in DM-related cellular dysfuction}

The hyperglycemia-dependent biochemical pathways are intimately linked with each other displaying multiple points of cross-talk. ${ }^{3}$ The existence of a plethora of cross-talk points between the DM-related alterations in cellular physiology may allow the self-supporting multiplication of adverse influences of hyperglycemia, creating a kind of a vicious circle.

The increased production of ROS has been put forward as a downstream mechanism linking the major hyperglycemia-induced biochemical pathways. ${ }^{4-}$ ${ }^{46}$ Indeed, an overproduction of ROS, or so-called oxidative or reductive stress, can be seen as a result of the activation of the PKC pathway, of the increased production of AGE and, subsequently, of the RAGE ligation as well as of the increased auto-oxidation of glucose. ${ }^{46}$ Monocytes from DM individuals were shown to produce significantly more superoxide $\mathrm{O}_{2}(-) .{ }^{47}$ This observation was causally linked to the RAGE ligation on THP-1 cells.

On the other hand, a direct production of ROS occurs as a result of the increased glucose utilization through the sorbitol pathway and parallel, as well as subsequent, due to the misbalance in NAD+/NADH, NADP+/NADPH, FAD+/FADH, GAPD+/GAPDH and GSSG/GSH ratios etc. The latter, with different contribution, results either in an increased mitochondrial production of 
ROS or in depression of the defensive antioxidant mechanisms. This dysbalance is referred to as oxidative stress.

ROS and the ROS-producing enzymes, $\mathrm{NAD}(\mathrm{P}) \mathrm{H}$ oxidases to be the most abundant, play an important role in angiogenesis being produced by either migrating blood cells or resident vascular cells. ${ }^{48}$ ROS has functional impacts on the vascular cells, i.e. EC, $\mathrm{VSMC}^{48}$ and fibroblasts. ${ }^{49}$ This includes effects on apoptosis/survival, proliferation, migration, gene expression and the regulation of ECM turnover by these cells. In contrast, in the settings of hyperglycemia and DM the leakage of ROS from the mitochondrial respiratory chain and oxidase activation occurs. This leads, for example, to uncoupling of eNOS in vasculature of diabetic individuals in vivo ${ }^{50}$ or direct scavenging of ROS on $\mathrm{NO}^{48}$ and thereby impaired endothelium-dependent vasorelaxation. ${ }^{51,52}$

\section{Protein tyrosine phosphatases}

Early studies implicated protein tyrosine phosphatases (PTPs) into the development of insulin resistance and subsequently diabetes. ${ }^{53,54}$ PTP1B is one of the PTPs, which is widely expressed. It has been established that PTP1B can promote insulin receptor dephosphorylation and down-regulate postreceptor signaling; and conversely, experimental approaches targeting insulin receptorPTP1B interaction have generally shown an enhancement of the insulin signaling. ${ }^{55}$ Therefore, PTP1B was selected as a target to achieve the improvement in the insulin receptor signaling. ${ }^{56,57}$ However, in the recent years it became evident that in contrast to the insulin-resistant state, where different PTPs were found both to be up-regulated and activated, individuals with DM type 2 appear to have decreased both expression and activity of PTPs. ${ }^{58-60}$ The decreased PTP activity was linked to the oxidative stress in the overt DM via the mechanisms of (reversible and irreversible) PTP oxidation. ${ }^{61}$

In monocytes increased production of ROS occurs in the presence DM. ${ }^{47}$ This process can be mediated by increased signaling via RAGE. ${ }^{39,47}$ We show that indeed an increase in ROS levels in the circulating monocytes results in the inhibition of PTP activity (Chapter 3), ${ }^{4}$ which contributes to the activation of these cells.

\section{Summary}

Our data on the VEGFR-1 function (Chapter 2) and dysfunction (Chapters 3 and 4) are of special clinical importance as monocytes have been identified as the key players in the wound healing and arteriogenesis. Both processes are impaired in diabetes mellitus. The novel signal transduction defects that we could identify provide a molecular explanation for diabetes-related VEGF 
resistance in monocytes (Chapter 3), which is responsible for the cell dysfunction. We propose that monocyte chemotaxis ex vivo may serve as a functional test to assess the VEGF responsiveness. This also implies that monocytes may be used for diagnostic purposes and may be regarded as "living biosensors" that translate metabolic aberrations into altered cellular function. ${ }^{62}$ In addition, our novel data may provide a metabolism-related explanation for the interindividual differences in arteriogenesis (poor and good collateralizers) and may be of a great value for the development of the strategies to stimulate therapeutic arteriogenesis. Furthermore, the findings that the functional downregulation of PTPs occurs in DM should be beard in mind while developing and applying strategies aiming to inhibit the PTP function.

\section{References}

1. Sheetz MJ, et al. Molecular understanding of hyperglycemia's adverse effects for diabetic complications. Jama. 2002;288:2579-2588.

2. DeFronzo RA. Lilly lecture 1987. The triumvirate: beta-cell, muscle, liver. A collusion responsible for NIDDM. Diabetes. 1988;37:667-687.

3. Tchaikovski V, et al. Angiogenesis and Arteriogenesis in Diabetes Mellitus: Signal Transduction Defects as The Molecular Basis of Vascular Cell Dysfunction Therapeutic Neovascularization: Quo Vadis? : E. Deindl and C. Kupatt, editors. Springer. Munich, Germany; 2007.

4. Tchaikovski $\mathrm{V}$, et al. Diabetes mellitus activates signal transduction pathways resulting in VEGF resistance of human monocytes. Circulation. 2009;120:151-159.

5. Waltenberger J, et al. Vascular endothelial growth factor-A-induced chemotaxis of monocytes is attenuated in patients with diabetes mellitus: A potential predictor for the individual capacity to develop collaterals. Circulation. 2000;102:185-190.

6. Yan SF, et al. Glycation, inflammation, and RAGE: a scaffold for the macrovascular complications of diabetes and beyond. Circ Res. 2003;93:1159-1169.

7. Wautier JL, et al. Advanced glycation end products, their receptors and diabetic angiopathy. Diabetes Metab. 2001;27:535-542.

8. Sacks DB, et al. Guidelines and recommendations for laboratory analysis in the diagnosis and management of diabetes mellitus. Clin Chem. 2002;48:436-472.

9. Ikeda $\mathrm{K}$, et al. $\mathrm{N}$ (epsilon)-(carboxymethyl)lysine protein adduct is a major immunological epitope in proteins modified with advanced glycation end products of the Maillard reaction. Biochemistry. 1996;35:8075-8083.

10. Reddy S, et al. N epsilon-(carboxymethyl)lysine is a dominant advanced glycation end product (AGE) antigen in tissue proteins. Biochemistry. 1995;34:10872-10878.

11. Ahmed MU, et al. N-epsilon-(carboxyethyl)lysine, a product of the chemical modification of proteins by methylglyoxal, increases with age in human lens proteins. Biochem J. 1997;324 ( Pt 2):565-570.

12. Grandhee SK, et al. Mechanism of formation of the Maillard protein cross-link pentosidine. Glucose, fructose, and ascorbate as pentosidine precursors. J Biol Chem. 1991;266:1164911653.

13. Haitoglou CS, et al. Altered cellular interactions between endothelial cells and nonenzymatically glucosylated laminin/type IV collagen. J Biol Chem. 1992;267:1240412407. 
14. Giardino I, et al. Nonenzymatic glycosylation in vitro and in bovine endothelial cells alters basic fibroblast growth factor activity. A model for intracellular glycosylation in diabetes. $J$ Clin Invest. 1994;94:110-117.

15. Bucala $\mathrm{R}$, et al. Constitutive production of inflammatory and mitogenic cytokines by rheumatoid synovial fibroblasts. $J$ Exp Med. 1991;173:569-574.

16. Huijberts MS, et al. Aminoguanidine treatment increases elasticity and decreases fluid filtration of large arteries from diabetic rats. J Clin Invest. 1993;92:1407-1411.

17. Charonis AS, et al. A novel synthetic peptide from the B1 chain of laminin with heparinbinding and cell adhesion-promoting activities. J Cell Biol. 1988;107:1253-1260.

18. Monnier VM, et al. Cross-linking of the extracellular matrix by the maillard reaction in aging and diabetes: an update on "a puzzle nearing resolution". Ann N Y Acad Sci. 2005;1043:533544.

19. Tsilibary EC, et al. The effect of nonenzymatic glucosylation on the binding of the main noncollagenous NC1 domain to type IV collagen. J Biol Chem. 1988;263:4302-4308.

20. Paul RG, et al. The effect of advanced glycation end-product formation upon cell-matrix interactions. Int J Biochem Cell Biol. 1999;31:653-660.

21. Bierhaus A, et al. Understanding RAGE, the receptor for advanced glycation end products. $J$ Mol Med. 2005;83:876-886.

22. Kislinger $\mathrm{T}$, et al. $\mathrm{N}$ (epsilon)-(carboxymethyl)lysine adducts of proteins are ligands for receptor for advanced glycation end products that activate cell signaling pathways and modulate gene expression. J Biol Chem. 1999;274:31740-31749.

23. Miyata T, et al. The receptor for advanced glycation end products (RAGE) is a central mediator of the interaction of AGE-beta2microglobulin with human mononuclear phagocytes via an oxidant-sensitive pathway. Implications for the pathogenesis of dialysis-related amyloidosis. J Clin Invest. 1996;98:1088-1094.

24. Neeper M, et al. Cloning and expression of a cell surface receptor for advanced glycosylation end products of proteins. J Biol Chem. 1992;267:14998-15004.

25. Schmidt AM, et al. Isolation and characterization of two binding proteins for advanced glycosylation end products from bovine lung which are present on the endothelial cell surface. J Biol Chem. 1992;267:14987-14997.

26. Schmidt AM, et al. Regulation of human mononuclear phagocyte migration by cell surfacebinding proteins for advanced glycation end products. J Clin Invest. 1993;91:2155-2168.

27. Hori $\mathrm{O}$, et al. The receptor for advanced glycation end products (RAGE) is a cellular binding site for amphoterin. Mediation of neurite outgrowth and co-expression of rage and amphoterin in the developing nervous system. J Biol Chem. 1995;270:25752-25761.

28. Ritthaler U, et al. Expression of receptors for advanced glycation end products in peripheral occlusive vascular disease. Am J Pathol. 1995;146:688-694.

29. Tanji N, et al. Expression of advanced glycation end products and their cellular receptor RAGE in diabetic nephropathy and nondiabetic renal disease. $J$ Am Soc Nephrol. 2000;11:1656-1666.

30. Kislinger T, et al. Receptor for advanced glycation end products mediates inflammation and enhanced expression of tissue factor in vasculature of diabetic apolipoprotein E-null mice. Arterioscler Thromb Vasc Biol. 2001;21:905-910.

31. Kosaki A, et al. Increased plasma S100A12 (EN-RAGE) levels in patients with type 2 diabetes. J Clin Endocrinol Metab. 2004;89:5423-5428.

32. Hofmann MA, et al. RAGE mediates a novel proinflammatory axis: a central cell surface receptor for S100/calgranulin polypeptides. Cell. 1999;97:889-901.

33. Park L, et al. Suppression of accelerated diabetic atherosclerosis by the soluble receptor for advanced glycation endproducts. Nat Med. 1998;4:1025-1031.

34. Schmidt AM, et al. The multiligand receptor RAGE as a progression factor amplifying immune and inflammatory responses. J Clin Invest. 2001;108:949-955.

35. Li J, et al. Characterization and functional analysis of the promoter of RAGE, the receptor for advanced glycation end products. J Biol Chem. 1997;272:16498-16506. 
36. Lander HM, et al. Activation of the receptor for advanced glycation end products triggers a p21(ras)-dependent mitogen-activated protein kinase pathway regulated by oxidant stress. $J$ Biol Chem. 1997;272:17810-17814.

37. Schiekofer $\mathrm{S}$, et al. Impaired revascularization in a mouse model of type 2 diabetes is associated with dysregulation of a complex angiogenic-regulatory network. Arterioscler Thromb Vasc Biol. 2005;25:1603-1609.

38. Wautier MP, et al. Activation of NADPH oxidase by AGE links oxidant stress to altered gene expression via RAGE. Am J Physiol Endocrinol Metab. 2001;280:E685-694.

39. Yan SD, et al. Enhanced cellular oxidant stress by the interaction of advanced glycation end products with their receptors/binding proteins. J Biol Chem. 1994;269:9889-9897.

40. Obrosova IG. Increased sorbitol pathway activity generates oxidative stress in tissue sites for diabetic complications. Antioxid Redox Signal. 2005;7:1543-1552.

41. Basta G, et al. Advanced glycation end products and vascular inflammation: implications for accelerated atherosclerosis in diabetes. Cardiovasc Res. 2004;63:582-592.

42. Neumann A, et al. High molecular weight hyaluronic acid inhibits advanced glycation endproduct-induced NF-kappaB activation and cytokine expression. FEBS Lett. 1999;453:283-287.

43. Bouma G, et al. An increased MRP8/14 expression and adhesion, but a decreased migration towards proinflammatory chemokines of type 1 diabetes monocytes. Clin Exp Immunol. 2005;141:509-517.

44. Brownlee M. The pathobiology of diabetic complications: a unifying mechanism. Diabetes. 2005;54:1615-1625.

45. Hammes HP, et al. Benfotiamine blocks three major pathways of hyperglycemic damage and prevents experimental diabetic retinopathy. Nat Med. 2003;9:294-299.

46. Tilton RG. Diabetic vascular dysfunction: links to glucose-induced reductive stress and VEGF. Microsc Res Tech. 2002;57:390-407.

47. Ding Y, et al. Activation of RAGE induces elevated O2- generation by mononuclear phagocytes in diabetes. J Leukoc Biol. 2007;81:520-527.

48. Taniyama Y, et al. Reactive oxygen species in the vasculature: molecular and cellular mechanisms. Hypertension. 2003;42:1075-1081.

49. Rey FE, et al. The reactive adventitia: fibroblast oxidase in vascular function. Arterioscler Thromb Vasc Biol. 2002;22:1962-1971.

50. Evans JL, et al. Oxidative stress and stress-activated signaling pathways: a unifying hypothesis of type 2 diabetes. Endocr Rev. 2002;23:599-622.

51. Guzik TJ, et al. Mechanisms of increased vascular superoxide production in human diabetes mellitus: role of $\mathrm{NAD}(\mathrm{P}) \mathrm{H}$ oxidase and endothelial nitric oxide synthase. Circulation. 2002;105:1656-1662.

52. Hink U, et al. Mechanisms underlying endothelial dysfunction in diabetes mellitus. Circ Res. 2001;88:E14-22.

53. Goldstein BJ, et al. Tyrosine dephosphorylation and deactivation of insulin receptor substrate1 by protein-tyrosine phosphatase $1 \mathrm{~B}$. Possible facilitation by the formation of a ternary complex with the Grb2 adaptor protein. J Biol Chem. 2000;275:4283-4289.

54. Mooney RA, et al. Phosphorylation of the insulin receptor in permeabilized adipocytes is coupled to a rapid dephosphorylation reaction. J Biol Chem. 1989;264:6850-6857.

55. Goldstein BJ. Protein-tyrosine phosphatase 1B (PTP1B): a novel therapeutic target for type 2 diabetes mellitus, obesity and related states of insulin resistance. Curr Drug Targets Immune Endocr Metabol Disord. 2001;1:265-275.

56. Evans JL, et al. Protein tyrosine phosphatases: their role in insulin action and potential as drug targets. Expert Opin Investig Drugs. 1999;8:139-160.

57. Zhang ZY. Protein tyrosine phosphatases: prospects for therapeutics. Curr Opin Chem Biol. 2001;5:416-423.

58. Ahmad F, et al. Alterations in skeletal muscle protein-tyrosine phosphatase activity and expression in insulin-resistant human obesity and diabetes. J Clin Invest. 1997;100:449-458. 
59. Kusari J, et al. Skeletal muscle protein tyrosine phosphatase activity and tyrosine phosphatase 1B protein content are associated with insulin action and resistance. $J$ Clin Invest. 1994;93:1156-1162.

60. Worm D, et al. Altered basal and insulin-stimulated phosphotyrosine phosphatase (PTPase) activity in skeletal muscle from NIDDM patients compared with control subjects. Diabetologia. 1996;39:1208-1214.

61. Zhu L, et al. Use of an anaerobic environment to preserve the endogenous activity of proteintyrosine phosphatases isolated from intact cells. Faseb J. 2001;15:1637-1639.

62. Waltenberger J. Stress testing at the cellular and molecular level to unravel cellular dysfunction and growth factor signal transduction defects: what Molecular Cell Biology can learn from Cardiology. Thromb Haemost. 2007;98:975-979. 


\section{Summary}

Monocytes are cellular components of wound repair, arteriogenesis and atherogenesis. The growth factors VEGF-A and P1GF recruit monocytes to sites of arteriogenesis via stimulation of VEGF receptor-1 (VEGFR-1). The chemotactic response of monocytes to VEGF-A is attenuated in individuals with diabetes mellitus (DM). This VEGF resistance correlates with impaired collateral growth. The intrinsic mechanisms of VEGFR-1-dependent contribution of monocytes to arteriogenesis were not studied so far. Alike, the mechanisms of VEGFR-1 dysfunction in DM required to be investigated.

In Chapter 1 the mechanisms of arteriogenesis are described, and the role of monocytes in arteriogenesis is reviewed. Furthermore, the impact of VEGFR-1 and its ligands on promoting monocyte contribution into the process of arteriogenesis is highlighted. The studies describing the negative impact of DM on arteriogenesis are summarized.

In Chapter 2 monocytes isolated from peripheral venous blood of young healthy individuals were used to study about intracellular signaling pathways mediating the biological functions triggered by VEGFR-1 in primary monocytes. Stimulating monocytes with either VEGF-A or PlGF-1 led to VEGFR-1 autophosphorylation and phosphorylation of distinct downstream proteins: phosphatidylinositol-3 kinase (PI-3K), Akt, p38 and extracellular signal-regulated kinase-1/2 (ERK1/2). PI-3K appeared to be a central regulator in VEGFR-1 signaling in monocytes as the activation of Akt, p38 and ERK1/2 are PI-3-K-dependent. In addition, Akt was found to function downstream of p38 kinase. VEGFR-1-mediated chemotaxis of monocytes is dependent on the activation of PI-3K, p38 kinase, Akt and ERK1/2. The role of tyrosine kinase (TK) domain of VEGFR-1 in VEGFR-1-mediated monocytes chemotaxis was further supported by the findings in Chapter 4 showing that monocytes from mice deficient for TK of VEGFR-1 lack the migratory response to VEGFR-1 ligands.

Chapter 3 unravels the molecular basis of VEGF resistance and impaired monocyte response in DM. Baseline phosphorylation of Akt, p38 and ERK1/2 was significantly elevated in monocytes from DM as compared to non-DM subjects. Of note, $\mathrm{H}_{2} \mathrm{O}_{2}$ activated Akt, p38 and ERK1/2 in non-DM monocytes ex vivo. Protein Tyrosine Phosphatases (PTPs) had stronger oxidative modifications in monocytes from DM than from non-DM individuals, which reflects functional PTP inhibition, similarly as seen after $\mathrm{H}_{2} \mathrm{O}_{2}$ challenge. Overall PTP and PTP1B activity were reduced in DM monocytes. DM monocytes revealed higher expression of RAGE. Stimulation with RAGE 
ligands resulted in activation of non-DM monocytes and inhibition of VEGFR1-mediated chemotaxis. The elevated baseline phosphorylation/activation of Akt, p38 and ERK1/2 in DM monocytes is likely causing the resistance to further stimulation with specific stimuli, such as VEGF-A, revealing a molecular explanation of the DM-related signal transduction defect.

Chapter 4 focuses on the establishment of 1) monocyte isolation from mice and subsequent 2) analysis of monocyte chemotaxis. It also justifies the potential use of a mouse (and as an example a mouse model of isolated hyperlipidemia, ApoE-/- mice) to study the mechanisms of adverse effects of cardiovascular risk factors on monocyte function.

In conclusion, this thesis describes the mechanisms of VEGFR-1-dependent monocyte motogenicity. It also highlights that elevated RAGE expression and increased oxidative stress in diabetic Mo lead to activation of VEGFR-1-related signaling pathways and to desensitization of VEGFR-1 responses. These data establish VEGF resistance as a novel molecular concept for DM-related cellular dysfunction. 


\section{Samenvatting}

Monocyten fungeren als cellulaire componenten in wondheling, arteriogenese en atherogenese. De groeifactoren VEGF-A en PlGF-1 zijn in staat deze monocyten te recruteren naar locaties van arteriogenese via stimulatie van VEGF receptor-1 (VEGFR-1). De chemotactische respons van monocyten richting VEGF-A is verstoord in individuen met diabetes mellitus (DM). Deze VEGF-resistentie correleert met een verhinderde collaterale groei. De intrinsieke mechanismen voor VEGFR-1-afhankelijke contributie van monocyten aan arteriogenese waren voorheen nog niet bestudeerd, evenals de mechanismen die ten grondslag liggen aan de VEGFR-1-dysfunctie in DM.

In hoofdstuk 1 worden de mechanismen van arteriogenese beschreven, tezamen met de rol van monocyten in deze. Eveneens wordt het effect van VEGFR-1 en haar liganden onder de aandacht gebracht met betrekking tot hun bijdrage aan arteriogenese. Verder worden de studies die het negative effect van DM op arteriogenese beschrijven samengevat.

In hoofdstuk 2 worden primaire humane monocyten van jonge, gezonde individuen bestudeerd om de intra-cellulaire signaaltransductiecascades bloot te leggen die verantwoordelijk zijn voor de VEGFR-1-gemedieerde functies van monocyten. Stimulatie met VEGF-A of PlGF-1 resulteert in VEGFR-1autofosforylatie, gevolgd door de activatie van de specifieke secundaire enzymen phosphatidylinositol-3 kinase (PI-3K), Akt, p38 en extracellular signal-regulated kinase-1/2 (ERK1/2). PI-3K is het centraal regulerend element in de VEGFR-1-signalering in monocyten, omdat de activatie van Akt, p38 en ERK1/2 afhankelijk zijn van deze kinase. Daarnaast blijkt de funtie van Akt afhankelijk te zijn van de kinase p38. VEGFR-1-geïnduceerde chemotaxis van monocyten is afhankelijk van activatie van PI-3K, p38 kinase, Akt en ERK1/2. De rol van het tyrosine kinase (TK) domein van VEGFR-1 in de via deze receptor gekanaliseerde monocytmotiliteit wordt verder ondersteund door bevindingen beschreven in hoofdstuk 4, waarin wordt bewezen dat monocyten afkomstig van VEGFR-1 TK deficiënte muizen niet in staat zijn tot chemotaxis naar VEGFR-1 liganden.

Hoofdstuk 3 is toegewijd aan de oorsprong van de moleculaire basis voor VEGF resistentie en de door DM teweeggebrachte verstoorde monocytrespons. Basale fosforylatie van Akt, p38 en ERK1/2 is significant verhoogd in monocyten geïsoleerd uit DM-patienten in vergelijking met monocyten uit nonDM-individuen. Aanvullend, H2O2 activeert Akt, p38 en ERK1/2 in non-DMmonocyten ex vivo. Protein Tyrosine Phosphatases (PTPs) ondervinden sterkere oxidative modificaties in DM-monocyten, wat een functionele PTP inhibitie 
weerspiegelt, evenredig aan modificaties geobserveerd na behandeling met $\mathrm{H} 2 \mathrm{O} 2$. Absoluut gezien is de activiteit van PTP en PTP1B gereduceerd in DMmonocyten. DM-monocyten laten een verhoogde expressie van RAGE zien en stimultie met RAGE agonisten resulteert in activatie van non-DM-monocyten en remming van VEGFR-1-geïnduceerde chemotaxis in deze. De verhoogde basale fosforylatie van Akt, p38 en ERK1/2 in DM-monoycten is waarschijnlijk de oorzaak van de resistentie, waardoor stimulatie met specifeke liganden niet meer mogelijk is. Dit vormt een verklaring voor het DM-gerelateerde signaleringsdefect.

Hoofdstuk 4 richt zich 1) op monocytisolatie uit muizen en vervolgens 2) op de chemotactische analyse van deze monocyten. Dit hoofdstuk rechtvaardigt tevens de potentie van het gebruik van muismodellen voor het bestuderen van de negatieve effecten van cardiovasulaïre risicofactoren op monocytfuntie. Als voorbeeld wordt het geïsoleerde hyperlipidemie ApoE-/- muismodel aangedragen.

Dit proefschrift beschrijft de mechanismen van VEGFR-1-afhankelijke monocytmotogeneciteit. Het presenteert tevens hoe verhoogde RAGE expressie en toegenomen oxidatieve stress in de diabetische monocyt leiden tot activatie van VEGFR-1-gerelateerde signaaltransductiecascades en de desensitatie van VEGFR-1-responsen. Deze data gezamelijk profileren VEGF-resistentie als moleculair concept voor DM-gerelateerde cellulaire dysfunctie. 


\section{Book chapter}

Tchaikovski V, Waltenberger J. Angiogenesis and Arteriogenesis in Diabetes Mellitus: Signal Transduction Defects as The Molecular Basis of Vascular Cell Dysfunction. In: Deindl E, Kupatt C, eds. Therapeutic Neovascularization: Quo Vadis? Munich: Springer; 2007:33-74.

\section{Original articles}

1. Cohen-Sacks H, Najajreh Y, Tchaikovski V, Gao G, Elazer V, Dahan R, Gati I, Kanaan M, Waltenberger J, Golomb G. Novel PDGFbetaR antisense encapsulated in polymeric nanospheres for the treatment of restenosis. Gene Ther. 2002;9(23):1607-16.

2. Tchaikovski V, Fellbrich G, and Waltenberger J. The molecular basis of VEGFR-1 signal transduction pathways in primary human monocytes. Arterioscler Thromb Vasc Biol. 2008;28(2):322-8.

3. Cleutjens KB, Faber BC, Rousch M, van Doorn R, Hackeng TM, Vink C, Geusens P, ten Cate H, Waltenberger J, Tchaikovski V, Lobbes M, Somers V, Sijbers A, Black D, Kitslaar PJ, Daemen MJ. Noninvasive diagnosis of ruptured peripheral atherosclerotic lesions and myocardial infarction by antibody profiling. J Clin Invest. 2008;118(8):2979-85.

4. Kerber M, Reiss Y, Wickersheim A, Jugold M, Kiessling F, Heil M, Tchaikovski V, Waltenberger J, Shibuya M, Plate KH, Machein MR. Flt-1 signaling in macrophages promotes glioma growth in vivo. Cancer Res. 2008;68(18):7342-51.

5. Tchaikovski SN, BJM van Vlijmen BJM, Cleuren ACA, Thomassen MCLGD, Tchaikovski V, Tans G, and Rosing J. Pregnancy-associated changes in the haemostatic system in wild type and factor VLeiden mice. $J$ Thromb Haemost. 2009;7(2):312-8.

6. Tchaikovski V, Olieslagers S, Böhmer F-D, Waltenberger J, Diabetes mellitus activates signal transduction pathways resulting in VEGF resistance of human monocytes. Circulation, 2009;120(2): 150-9.

7. Tchaikovski V, Tchaikovski S, Olieslagers S, Waltenberger J. Monocyte dysfunction as a previously unrecognized pathophysiological mechanism in ApoE-/- mice contributing to impaired arteriogenesis. Submitted.

8. Donners MMPC, Wolfs IMJ, Olieslagers S, Mohammadi-Motahhari Z, Tchaikovski V, Heeneman S, van Buul JD, Caolo V, Molin DGM, Post MJ, and Johannes Waltenberger. ADAM10 is a novel mediator of VEGFinduced endothelial cell function in angiogenesis and associated with atherosclerosis. Submitted. 


\section{Accepted abstracts}

1. VEGF and Monocytes in Collateral Growth. "New Frontiers in Cardiology." Munich, May 2004. Plenary lecture.

2. Enhanced baseline activity of mitogen-activated protein kinases and protein kinase B/Akt in monocytes from patients with diabetes mellitus: relation with impaired responsiveness of the VEGFR-1 pathway. Annual meeting of European Society of Cardiology, Stockholm, September 2005.

3. Melatonin is an inhibitor of vascular cell proliferation in vitro. $3^{\text {rd }}$ European Meeting on Vascular Biology and Medicine. Hamburg, September 2005.

4. Collateral growth in patients with chronic total coronary occlusions: enhanced proliferative activity in the collateral circulation of diabetics. $3^{\text {rd }}$ European Meeting on Vascular Biology and Medicine. Hamburg, September 2005.

5. Influence of diabetes mellitus on cellular and humoral components of collateral growth. Belgian-Dutch Interventional Cardiology Meeting. Antwerpen, December 2005. Oral Presentation, Young Investigator Award Session.

6. The antiproliferative activity of neurohormone Melatonin on vascular smooth muscle cells in vitro. Annual meeting of German cardiac society, Mannheim, April 2006. Oral presentation.

7. VEGFR-1 signalling in primary human monocytes: physiological and pathophysiological implications. XIVth Internatinal Vascular Biology Meeting. Noordwijkerhout, June 2006

8. VEGFR-1 function in monocytes in physiology and diabetes mellitus. $4^{\text {th }}$ European Meeting on Vascular Biology and Medicine. Bristol, September 2007.

9. VEGFR-1 signal transduction defect as the molecular basis of monocyte dysfunction in diabetes mellitus. Annual meeting of European Society of Cardiology, Munich, September 2008.

10. VEGF-A is a multipotent chemoattractant in vivo: evidence from air pouch model in mice. Annual Meeting of the Society for Microcirculation and Vascular Biology (CfMVB). Aachen, September 2008. Oral Presentation Young Investigator Award Session.

11. Diabetes mellitus activates signal transduction pathways in multiple ways: basis for VEGF resistance of human monocytes. Annual meeting of European Society of Cardiology, Barcelona, September 2009. 


\section{Acknowledgments}

No thesis is a one-man-work. It is, therefore, my pleasure to express my gratitude to the people who have made my research years at the University of Maastricht a very enjoyable, remarkable and fruitful experience and who accompanied and supported me all these years. Without them it would have been so much more difficult to realize the ideas reflected in the thesis and put them together in the papers that can be found in this thesis.

First of all, I express my deep and sincere gratitude to my promoter Johannes Waltenberger. Well, Johannes, it has been a while since my last thesis under your supervision and now we come with the next one. I am grateful to you for an opportunity to work in your group, for your continuous interest in the progress of my work as well as non-scientific matters. Thank you very much for the discussions we had and which were, sometimes, very heated but nevertheless fruitful.

I am thankful to my colleagues from the Laboratory for Molecular and Vascular Cardiology. Stefan, with whom we moved all the way from sunny Ulm to a less sunny, to say the least, Maastricht and the first thing we were challenged with were Ikea's office furniture manuals. I am thankful to my roommates Marina, Sandra, Nynke for their help and warm atmosphere. Of course, Servé, "the chief lab manager"! Your connections inside and outside of the University and your practical expertise were indispensable.

I extend my gratitude to Professor Harry Crijns for an excellent chance to work at the Department of Cardiology which he heads, as well as to all the coworkers at the department for a professional climate.

For their support in the development of the papers that laid basis to this thesis I would like to acknowledge our collaborators, Esther Lutgens (Department of Pathology, University of Maastricht), Menno de Winther (Department of Genetics, University of Maastricht). I express my special gratitude to Professor Frank Böhmer (Institute of Molecular Cell Biology, University of Jena), whose broad expertise in the field of phosphatases allowed us to gain a more comprehensive insight in monocyte biology and whose informative comments and suggestions and readiness to discuss were a real pleasure.

I am grateful to the research nurses of Academisch Ziekenhuis Maastricht, Aimée and Moniek for encouraging the patients to take part in our studies, and to the patients for their willingness to contribute to scientific development. 
My animal experiments would not have been so smooth without help of the colleagues from Centrale Proefdier Voorzieningen, Paulien, Richard and Rik.

I am grateful to Julian for his friendship and help with the cover of the thesis.

Я благодарен моим родителям, сделавшим для меня так много. Я благодарен моим родителям за то, что они произвели меня на свет. Если бы не они, не было бы этой книги, по крайней мере в моем исполнении. Я благодарен им за то, что они научили меня трудиться и добиваться. Я преклоняюсь перед ними за их постоянную поддержку и особенно тогда, когда я перешагнул через языковые и географические барьеры и оказался далеко, а они помнят, переживают, ждут и радуются успехам.

Я благодарю свою жену. За что? Да за все! За твои терпение и преданность. Ты наполняешь мою жизнь смыслом и я люблю тебя всем сердцем, За тепло и уют в доме, за то, что хочется возвращаться домой, и я дорожу этим больше всего на свете.

Я могу еще очень долго перечислять людей, которым я благодарен в своей жизни, поэтому перечислю коротко: воспитателям в детсаде, учителям в школе, преподавателям в институте.

Я благодарен всем моим друзьям за то, что они меня терпят, вероятно любят, и по возможности помогают. Саша и Эдик, спасибо за лучшие 6 лет вместе и 10 лет спустя. Наташа и Сабина, спасибо за неиссякающее гостеприимство. Вера Васильевна и Олег Федорович, с вами хочется встречаться снова и снова. Саша, Оля, Дима и Серёжа: вам выпала трудная судьба идти первыми; я благодарен вам за вашу готовность делиться опытом и помогать. 


\section{Curriculum Vitae}

Vadim Tchaikovski was born on April $30^{\text {th }}$, 1976, in Baranovichi, Republic of Belarus (former USSR). He attended primary school and physico-mathematical gymnasium in Baranovichi. After obtaining his high school diploma (with distinction) in 1993, he enrolled to study medicine at Grodno State Medical University. He completed his MD study with cum laude in June 1999. He conducted his internship at Baranovichi City Hospital in 1999-2000.

In 2001-2003 he was a research fellow at Laboratory for Molecular Cardiology (Department of Internal Medicine II/Cardiology, University of Ulm) where on May $8^{\text {th }}, 2003$ he received his degree "Doktor Medizin" based on the thesis entitled "Inhibition of post-angioplasty restenosis using antisense approach".

Since June 2003 he was a post-doc at Laboratory for Molecular Cardiology (Department of Internal Medicine II/Cardiology, University of Ulm). In September 2003 he started as a post-doc at Laboratory for Vascular and Molecular Cardiology (Department of Cardiology and Cardiocascular Research Institute of Maastricht, University of Maastricht). There he pursued research to unravel ht efunction of VEGFR-1 in primary monocytes as well as mechanisms of monocyte dysfunction in diabetes mellitus. The results of these studies are presented in this thesis. 
